\title{
NRIC Integrated Energy Systems Demonstration Pre-Conceptual Designs
}

\section{APRIL 2021}

Report for Project RC-21IN020701

Andrew Foss

John Smart

Haydn Bryan

Chris Dieckmann

Brian Dold

Paul Plachinda 


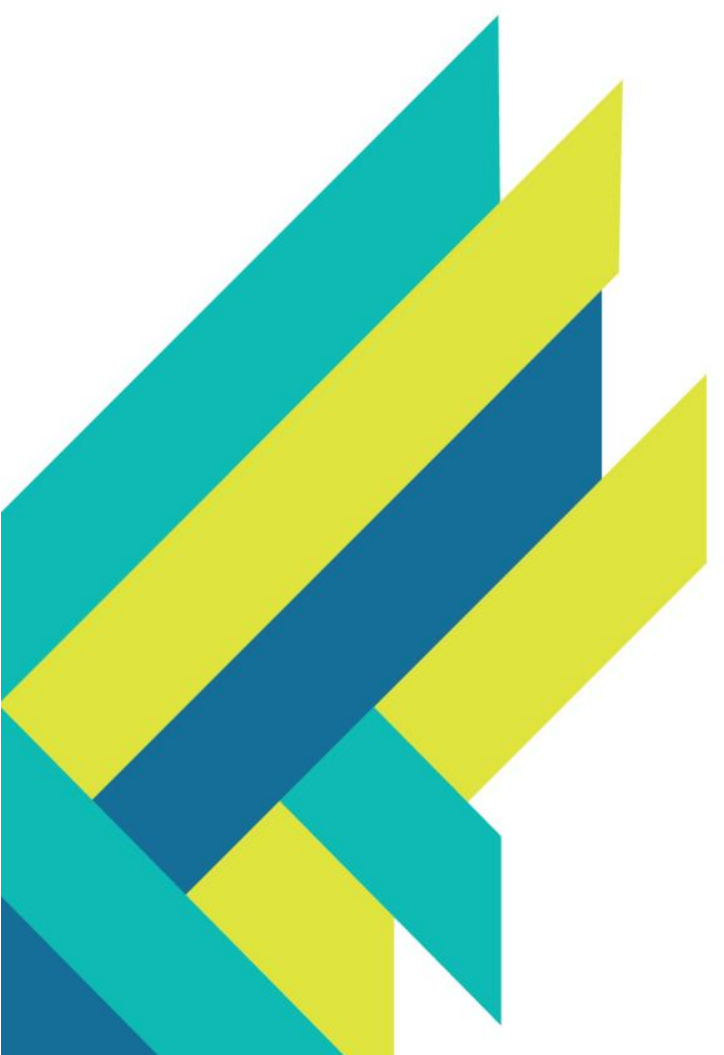

\section{DISCLAIMER}

This information was prepared as an account of work sponsored by an agency of the U.S.

Government. Neither the U.S. Government nor any agency thereof, nor any of their employees, makes any warranty, expressed or implied, or assumes any legal liability or responsibility for the accuracy, completeness, or usefulness, of any information, apparatus, product, or process disclosed, or represents that its use would not infringe privately owned rights. References herein to any specific commercial product, process, or service by trade name, trade mark, manufacturer, or otherwise, does not necessarily constitute or imply its endorsement, recommendation, or favoring by the U.S. Government or any agency thereof. The views and opinions of authors expressed herein do not necessarily state or reflect those of the U.S. Government or any agency thereof.

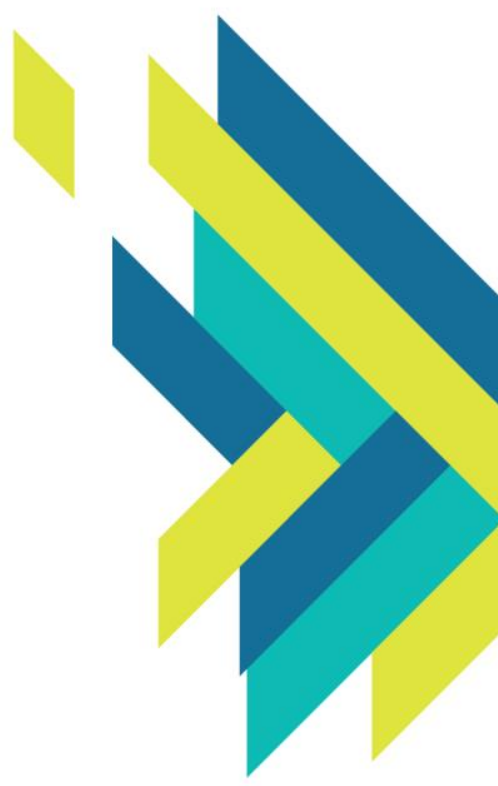




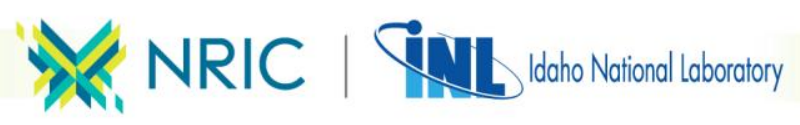

REVISION LOG

\begin{tabular}{|l|c|l|l|}
\hline $\begin{array}{c}\text { Revision } \\
\text { No. }\end{array}$ & Date & Affected Pages & \multicolumn{1}{c|}{ Description } \\
\hline 1 & $4 / 22 / 2021$ & All & Changes to overall document \\
\hline & & & \\
\hline & & & \\
\hline & & & \\
\hline & & & \\
\hline
\end{tabular}




\section{EXECUTIVE SUMMARY}

This report presents pre-conceptual design scenarios for a potential multiphase demonstration program for innovative uses of nuclear energy with the National Reactor Innovation Center (NRIC) and the Crosscutting Technology Development Integrated Energy Systems (CTD IES) program in the U.S. Department of Energy's Office of Nuclear Energy. The demonstration program would address the need for low-carbon energy sources among heavy industry, transportation, and other potential end users by identifying and implementing high-impact advanced nuclear projects within a holistic systems perspective, represented by the intersection of the three interlocking rings in Figure ES-1. Industry stakeholders can help shape and plan the demonstration program by submitting responses to the Expression of Interest (EOI) request available online. ${ }^{1}$

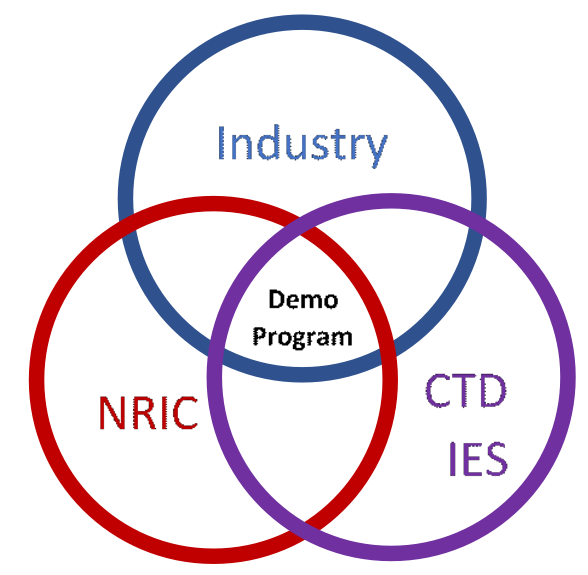

Figure ES-1. Demonstration program at the intersection of industry needs, NRIC, and CTD IES.

Concerns about climate change are driving significant changes in the nation's energy, transportation, and industrial sectors. Advances in nuclear energy technology create new opportunities for these sectors to produce and access reliable, low-cost, clean energy. Incorporating nuclear energy into novel applications further benefits U.S. industries by providing them versatile, flexible means of decarbonization and creating new economic value.

Congress created NRIC under the Nuclear Energy Innovation Capabilities Act of 2018 to strengthen and streamline U.S. efforts toward commercial deployment of advanced nuclear concepts. Led by INL, NRIC works closely with private companies, national laboratory researchers, and other collaborators to support, plan, and execute the work necessary to accelerate demonstration of advanced nuclear reactors. NRIC empowers innovators by enabling access to materials, facilities, sites, and expertise, supporting permitting and regulatory needs, facilitating contracting and engagement, and focusing on achievement of specific national goals. NRIC evaluates and fosters a wide range of advanced nuclear designs with various reactor systems, fuel cycles, coolant types, and safety profiles. By providing partners access to unique demonstration test beds and other resources, NRIC and CTD IES will empower private-sector innovators to advance innovative nuclear IES applications from pre-conceptual design to pilot-

1 https://sam.gov/opp/4f50f3f69e764lc3a4e223f0ab7f3529/view

The EOI request was issued on April 22, 2021, and the deadline for responses is June 4, 2021. The link may become inactive after the deadline. 
scale demonstration. For effective integration of equipment and concepts from multiple organizations, NRIC supports the use of digital engineering and model-based system engineering (MBSE) tools to design, build, and perform demonstrations. NRIC is preparing several test beds that could be used for the demonstration program with industry and the CTD IES program.

The CTD IES program incorporates multiple energy-generation resources and energy-use paths to provide affordable, reliable, and resilient energy, simultaneously reducing GHG emissions (McMillan et al. 2016; Bragg-Sitton, Rabiti, et al. 2020). Nuclear IES are already being demonstrated with existing light-water reactors. Advanced reactors currently under development will offer compelling features that enable new applications of nuclear IES. In addition to providing electricity for the grid, IES incorporating advanced nuclear technologies can provide heat, electricity, and other energy products, such as hydrogen and synthetic fuels, to microgrids, industrial complexes, military installations, remote industrial operations, commercial parks, and transportation hubs. Applications of IES may include thermal-, electrochemical-, or chemicalenergy storage to dynamically balance generation and load, such as balancing nuclear electricity generation with non-dispatchable renewable generation and cyclical electrical loads. Also, nuclear IES may include controllable thermal and electrical loads, such as water desalination, hydrogen electrolysis, and electric vehicle charging to balance loads with electricity and thermal generation resources.

This report identifies U.S. industries in which nuclear IES could be applied to benefit both the industries and the nation. These industries include the chemical, petrochemical and petroleum, nitrogenous fertilizer, plastics and resin, pulp and paper, and mineral mining industries. The temperature requirements for endothermic processes common in these industries are compatible with coolant temperatures of advanced reactors, indicating that nuclear IES has the potential to meet these industries' needs for low-carbon thermal energy. Additionally, nuclear IES can benefit the iron and steel manufacturing, hydrogen production, brackish and sea water desalination, and transportation industries. Finally, thermal energy storage as a technology and an industry plays a key role in the CTD IES program.

Figure ES-2 summarizes the potential uses for nuclear energy products as examples of industries and applications that could participate in the demonstration projects with advanced reactors. The colors of the arrows leading to the use cases correspond to the nuclear energy products in the center of the figure. The figure shows U.S. $\mathrm{CO}_{2}$ emissions for the various industries and applications in 2019 at the far right as proxy for fossil-fuel consumption and need for clean energy solutions. The seven use cases marked with asterisks have pre-conceptual design scenarios shown in this report. 

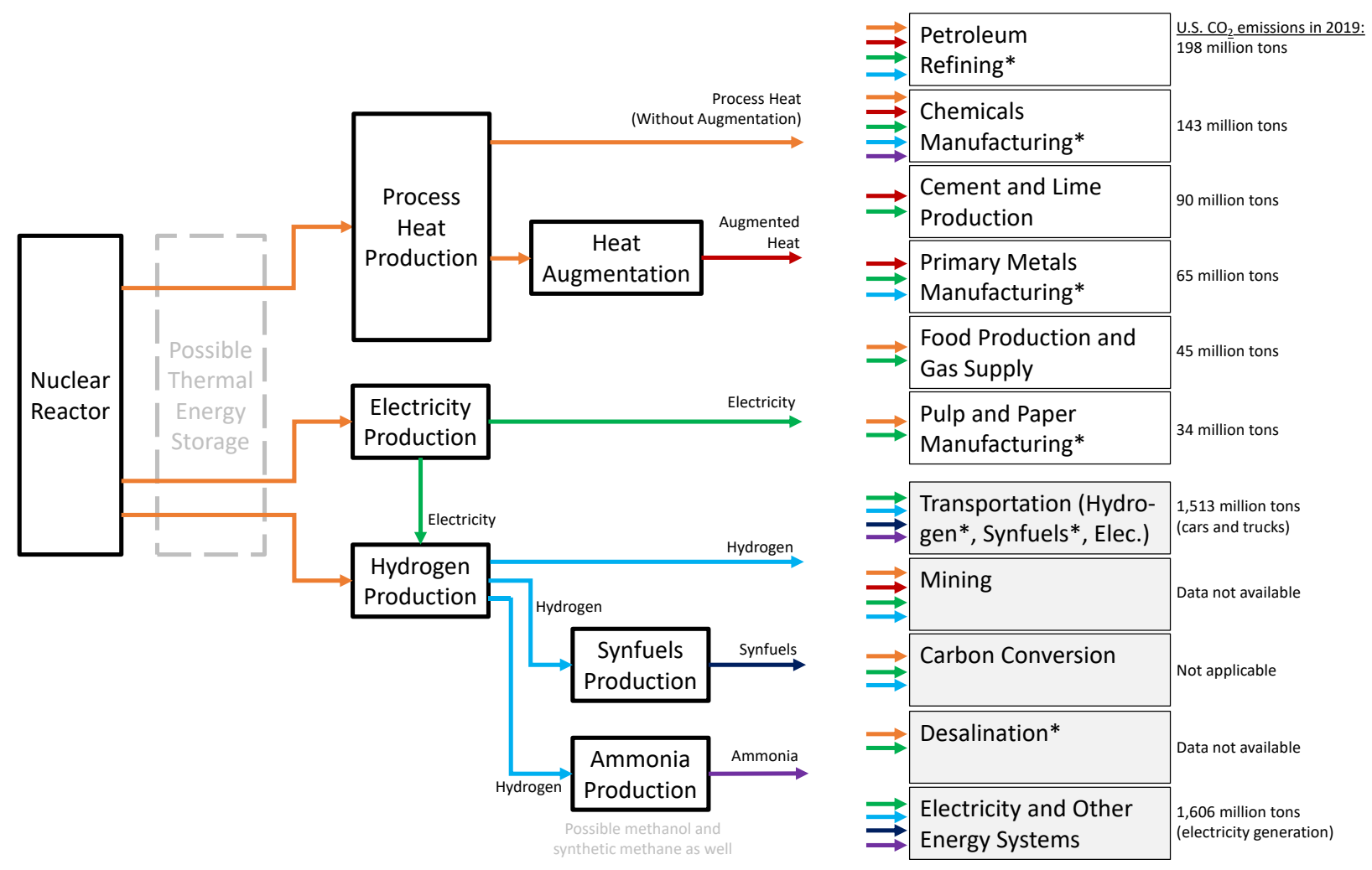

Figure ES-2. Linking advanced reactors and nuclear-generated products with use cases.

Down-selection of design scenarios for the demonstration program, with input from industry stakeholders who respond to the EOI, should reflect and advance NRIC's mission. To inspire the market, NRIC will favor applications and partnerships that demonstrate the versatility of advanced nuclear technologies and make a large economic and environmental impact. To empower innovators, NRIC aims to provide a first-of-a-kind demonstration platform capable of addressing multiple system integration issues, multiple energy resources, and multiple energy-use paths. Finally, to ensure successful outcomes, NRIC will favor applications that create synergy with NRIC advanced reactor demonstrations, leverage existing relationships with reactor developers and end users, and build on CTD IES research and development efforts.

In partnership with industry stakeholders, NRIC and CTD IES would seek to conduct pilot-scale demonstrations involving commercial hardware representative of the types that could be deployed in the selected applications, including a nuclear-fueled advanced reactor. Demonstration of these applications could include transport and storage of heat to industrial loads; emulation of plant thermal and electrical loads, based on data describing operation of the end user's plant; and time-varying dispatch of heat, electricity, and hydrogen production as plant energy demand changes and to provide grid services (e.g., renewables integration, demand response) where applicable. 
To facilitate this approach, NRIC plans to develop a CTD IES test bed platform that interfaces with NRIC's advanced reactor test beds to allow industry partners to integrate commercial components with an advanced reactor and system equipment. The platform could also be capable of hosting a pilot-scale representation of an end-use process that consumes heat and/or electricity, installed in partnership with an industrial end user. Alternatively, the platform could include surrogate thermal and electrical loads that can be controlled to represent one or more type of industrial unit operation, process, or facility. Functional requirements and additional technical details describing this platform will be developed in future work, in coordination with prospective industry partners. 


\section{CONTENTS}

EXECUTIVE SUMMARY

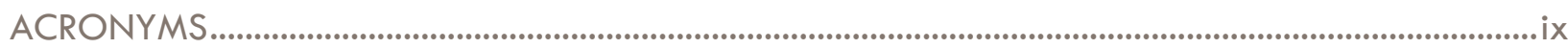

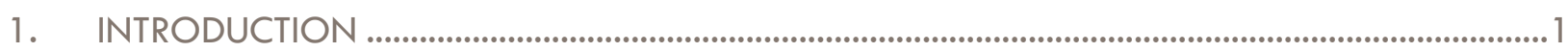

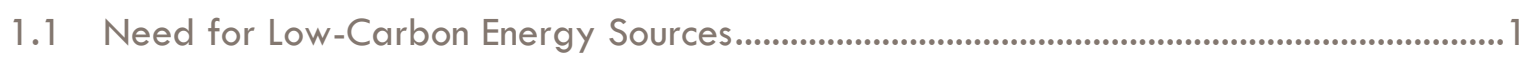

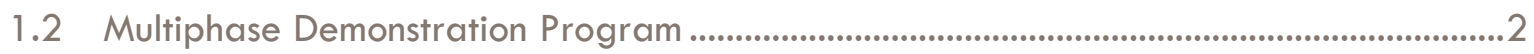

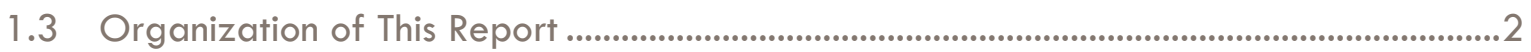

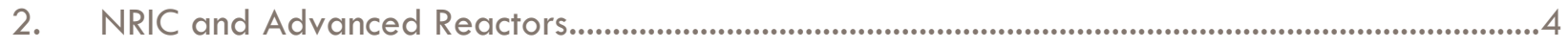

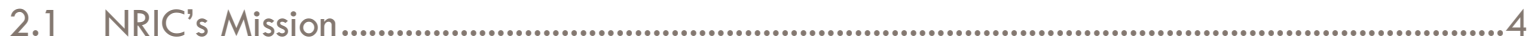

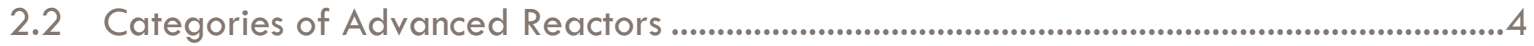

2.3 Government-Supported Advanced Reactor Projects ..........................................................5

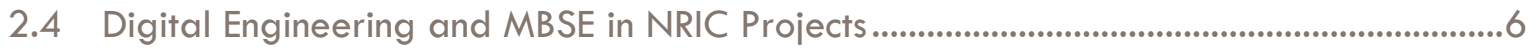

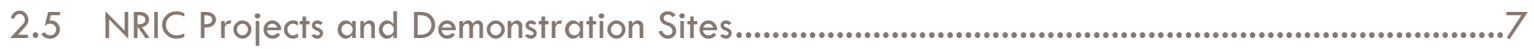

2.6 Cost-Reduction Strategies for Advanced Nuclear Plants ......................................................9

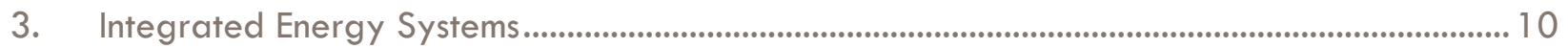

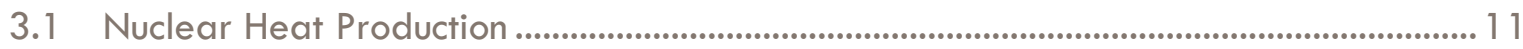

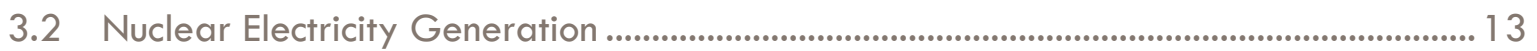

3.3 Nuclear Combined Heat and Power .................................................................................... 14

3.4 Nuclear Hydrogen Production and Derived Energy Carriers......................................... 14

3.5 Nuclear Thermal Energy Storage ................................................................................. 17

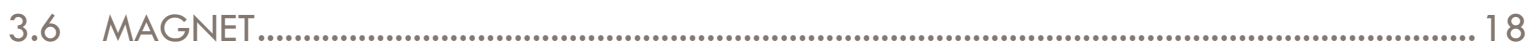

3.7 Analytical Methodologies and Tools .................................................................................. 19

4. Energy-Intensive Industries and Other End-Use Applications ........................................................ 20

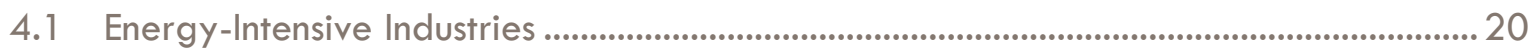

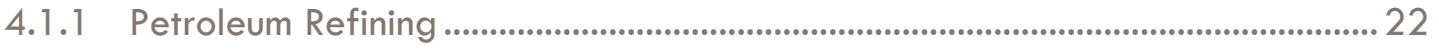

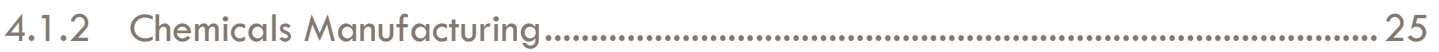

4.1.3 Cement and Lime Production......................................................................................... 27

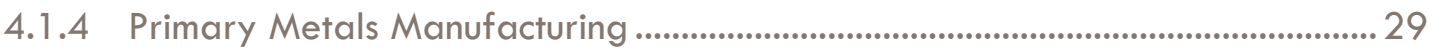

4.1.5 Food Production and Gas Supply ................................................................................. 31

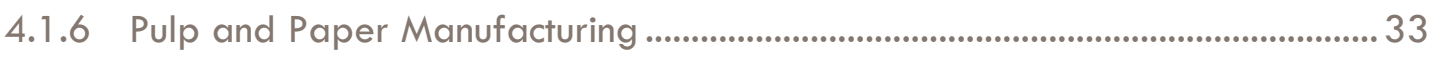

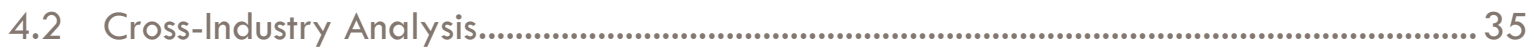

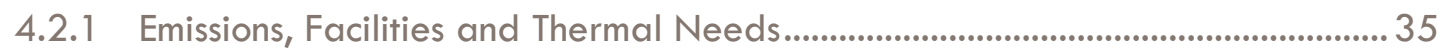

4.2.2 Industry Energy Histograms ........................................................................................... 35

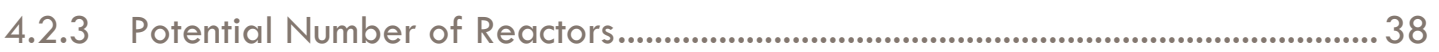

4.2.4 Alignment with Advanced Reactor Temperatures .....................................................38 
4.3 Potential Additional Applications for Advanced Reactors............................................39

4.3.1 Summary of Hydrogen Uses and Market.................................................................... 39

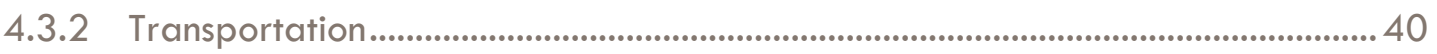

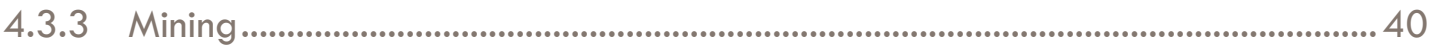

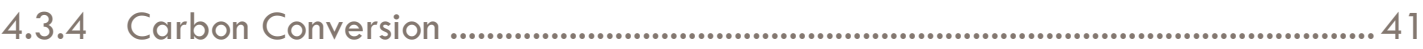

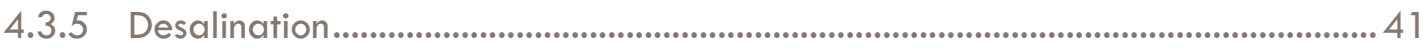

4.3.6 Electricity and Other Energy Systems.......................................................................... 42

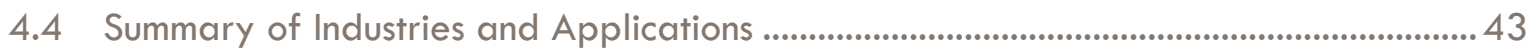

5. Multiphase Demonstration Program and Pre-conceptual Designs................................................ 44

5.1 Pre-Phase (Phase 0): Planning and Analysis...................................................................44

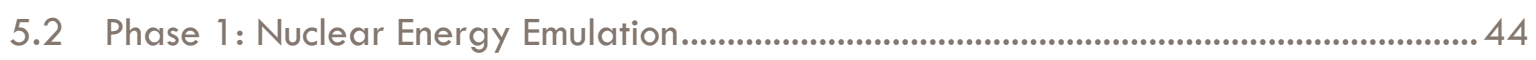

5.3 Phase 2: Microreactor Demonstrations ................................................................................44 44

5.4 Phase 3: Pilot-Scale Advanced Reactor Demonstrations .................................................. 44

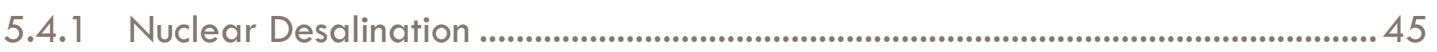

5.4.2 Nuclear Combined Heat and Power for Paper Facility ......................................... 46

5.4.3 Nuclear Hydrogen Production ......................................................................................... 46

5.4.4 Nuclear Oil Production and Refining .................................................................... 48

5.4.5 Nuclear Biomass Gasification ....................................................................................... 49

5.5 Further Considerations for Planning and Interfaces ..................................................50

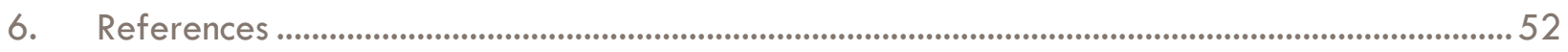

\section{FIGURES}

Figure ES-1. Demonstration program at the intersection of industry needs, NRIC, and CTD IES.

Figure ES-2. Linking advanced reactors and nuclear-generated products with use cases..................iii

Figure 1. Demonstration program at the intersection of industry needs, NRIC, and CTD IES. ........... 2

Figure 2. Projects supported by the DOE Advanced Reactor Demonstration Program (Finan 2021 with content from DOE). .......................................................................................................... 5

Figure 3. Completed data architecture of the MBSE process (Balsmeier and Core 2020). .............. 6

Figure 4. Illustrative Innoslate action diagram for NRIC and CTD IES demonstration projects.

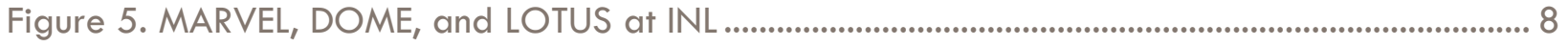

Figure 6. Innoslate diagram of primary test activities planned for DOME...................................... 9

Figure 7. Overview of nuclear heat and electricity pathways being evaluated by the CTD IES program for the production of multiple energy products (Bragg-Sitton 2020)......... 10

Figure 8. Summary of possible nuclear energy products........................................................................... 11 
Figure 9. Generic nuclear heat production diagram.

Figure 10. Estimated costs for delivered heat from clean energy sources (Friedmann, Fan, and Tang 2019). 13

Figure 11. Generic nuclear electricity generation diagram................................................................... 14

Figure 12. Generic nuclear heat and power diagram........................................................................ 14

Figure 13. Linkages between energy resources and hydrogen (U.S. Department of Energy

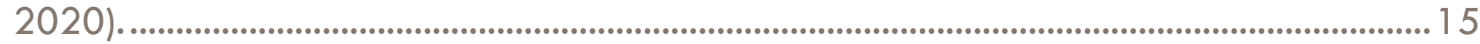

Figure 14. Generic nuclear hydrogen production diagram using LTE............................................... 16

Figure 15. Generic nuclear hydrogen production diagram using HTE............................................ 16

Figure 16. Generic thermal energy storage diagram. ................................................................... 17

Figure 17. TEDS at INL's Energy Systems Laboratory................................................................................ 18

Figure 18. Rendering of TEDS at INL's Energy Systems Laboratory...................................................... 18

Figure 19. MAGNET at INL's Energy Systems Laboratory. .................................................................19

Figure 20. Summary of supply and demand for hydrogen at U.S. petroleum refineries

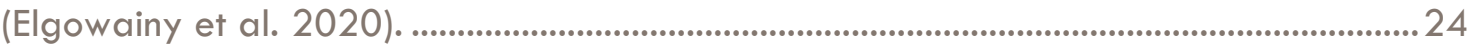

Figure 21. Emissions, energy, and facility data for subindustries ........................................................35

Figure 22. Potential addressable market by industry based on energy needs...................................38

Figure 23. Comparison of industrial process heat ranges to output temperature limits of nuclear reactors (McMillan et al. 2016) and (MIT 2018)......................................................39

Figure 24. Linking advanced reactors and nuclear-generated products with use cases..................45

Figure 25. Thermally driven nuclear desalination.................................................................................46

Figure 26. Nuclear CHP for a paper facility................................................................................................46

Figure 27. Nuclear hydrogen production using HTE. ...................................................................................4

Figure 28. Nuclear hydrogen production for steel manufacturing...........................................................48

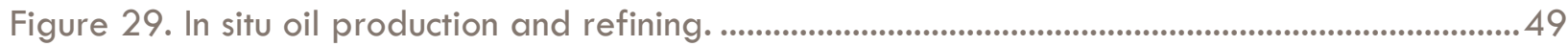

Figure 30. Integration of nuclear energy with chemical polymer production.....................................50

Figure 31. WGS reaction to capture $\mathrm{CO}_{2}$ and produce syngas. ....................................................50

Figure 32. ElA scenarios for natural gas price at Henry Hub (\$/MMBtu). Source: (U.S.

Energy Information Administration 2020a)......................................................................59

Figure 33. Natural gas spot-price differentials ( $\$ / M M B+u)$ at major regional hubs relative to Henry Hub. Source: (U.S. Energy Information Administration 2020b). ............................60

\section{TABLES}

Table 1. Energy-intensive industries and subindustries. 20 


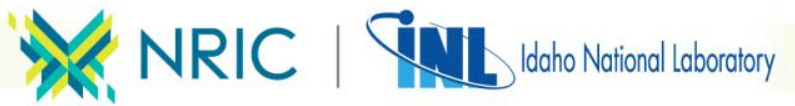

Table 2: $\mathrm{CO}_{2}$ emissions per cubic meter of produced water for different desalination technologies.....

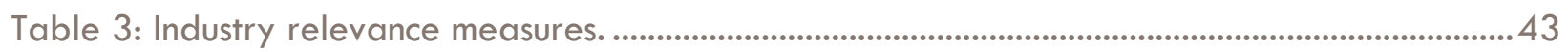




\section{ACRONYMS}

AMO Advanced Manufacturing Office of the U.S. Department of Energy

AR advanced reactors

CAGR compound annual growth rate

CHP combined heat and power

$\mathrm{CO}_{2}$ carbon dioxide

CTD IES Crosscutting Technology Development Integrated Energy Systems

DETAIL Dynamic Energy Transport and Integration Laboratory

DOE U.S. Department of Energy

DOME Demonstration of Operational Microreactor Experiments

EIA U.S. Energy Information Administration

EOI Expression of Interest

EPA U.S. Environmental Protection Agency

ESL Energy Systems Laboratory

EV electric vehicles

FCV fuel-cell vehicles

FHR fluoride-salt-cooled high-temperature reactors

FLIGHT Facility-Level Information on Greenhouse Gases Tool

GHG greenhouse gas

GHGRP Greenhouse Gas Reporting Program

HALEU high-assay, low-enriched uranium

HERON Holistic Economic Resource Optimization Network

HTE high-temperature electrolysis

HTGR high-temperature gas-cooled reactor

HVAC heating, venting, and air conditioning

IAEA International Atomic Energy Agency

INL Idaho National Laboratory

LFR lead-cooled fast reactor

LOTUS Laboratory for Operation and Testing in the United States

LTE low-temperature electrolysis 
LWR light-water reactor

MAGNET Microreactor Agile Non-Nuclear Experimental Test Bed

MARVEL Microreactor Applications Research, Validation, and Evaluation

MBSE model-based systems engineering

MED multi-effect distillation

MMT million metric tons

MSF multi-stage flash

MSR molten-salt reactors

NAICS North American Industry Classification System

NRIC National Reactor Innovation Center

$O \& M$ operating and maintenance

PV photovoltaic

R\&D research \& development

RAVEN Risk Analysis and Virtual Environment

RO reverse osmosis

SIPH solar industrial process heat

SFR sodium-cooled fast reactor

TEAL Tool for Economic Analysis

TEDS Thermal Energy Distribution System

TRISO tristructural-isotropic

VHTR very high-temperature reactor 


\section{INTRODUCTION}

This report presents pre-conceptual design scenarios for a potential multiphase demonstration program for innovative uses of nuclear energy with the National Reactor Innovation Center (NRIC) and the Crosscutting Technology Development Integrated Energy Systems (CTD IES) program in the U.S. Department of Energy's Office of Nuclear Energy. The demonstration program would address the need for low-carbon energy sources among industry stakeholders by identifying and implementing high-impact advanced nuclear projects within a holistic systems perspective.

Battelle Energy Alliance, LLC, the managing and operating contractor for the U.S. Department of Energy's Idaho National Laboratory (INL) in Idaho Falls, Idaho, is seeking Expressions of Interest (EOI) for industry stakeholder participation in the potential demonstration program. ${ }^{2}$ Funding sources have not yet been identified for the demonstration program. Responses to the EOI will shape the development and funding requirements for the potential program and inform the down-selection of project designs for further planning and analysis from the wide set of preconceptual design scenarios shown in this report.

This introductory section summarizes the need for low-carbon energy sources, describes the phases envisioned for the demonstration program, and outlines the organization of this report.

\subsection{Need for Low-Carbon Energy Sources}

Concerns about climate change currently drive significant changes in the U.S. energy, transportation, and industrial sectors. Motivated by a desire to mitigate climate change, the U.S. is now party to the Paris Climate Agreement, and several U.S. states have enacted legislation and imposed regulations to limit greenhouse gas (GHG) emissions beyond those established by the federal government (Bedsworth and Hanak 2013; The White House 2021). Likewise, numerous electric utilities and many other companies have voluntarily made commitments to reduce carbonbased emissions in their operations (Science Based Targets, n.d.). Renewable energy-generation technologies, such as wind power and solar photovoltaics (PV), proliferate in the bulk electric grid and local microgrids. Additionally, electrification of transportation, buildings, and industry is underway (Deloitte Insights 2020). Carbon-free production of hydrogen, so-called green hydrogen, is also receiving considerable attention and investment (Bloomberg NEF 2020). Governments, companies, and investors are also taking action to adapt to climate change. Scarcity of natural sources of fresh water is now considered a security issue (Stuckenberg and Contento 2018) and has motivated innovation in energy production to power water desalination plants (Lester 2015). Electric utilities are taking action to increase resiliency in the face of more frequent extreme weather events and natural disasters (Ward 2013). Industry leaders not voluntarily taking action to address the social cost of carbon may eventually need to comply with mandatory policies to reduce emissions, such as carbon taxes (Goulder and Schein 2013).

As the energy sector adapts to achieve decarbonization goals, nuclear energy should be included in the nation's energy portfolio to enable the production of accessible, low-cost energy and reduce energy sector GHG emissions (MIT 2018). However, the decreased cost of renewable energy generation and low cost and broad availability of natural gas have reduced the price of

2 https://sam.gov/opp/4f50f3f69e764lc3a4e223f0ab7f3529/view

The EOI request was issued on April 22, 2021, and the deadline for responses is June 4, 2021. The

link may become inactive after the deadline. 
electricity and put economic pressure on today's baseload nuclear energy providers (BraggSitton, Rabiti, et al. 2020). Incorporating nuclear energy into integrated energy systems that would produce both grid electricity and additional products (via electrical or thermal energy input to coupled processes) presents a solution to this problem by both creating new economic value for the nuclear industry and opening new opportunities for decarbonization.

\subsection{Multiphase Demonstration Program}

The demonstration program would aim to accelerate innovation and deployment of energy concepts at the intersection of industry needs, NRIC's mission, and the research and development (R\&D) portfolio of CTD IES, as shown in Figure 1.

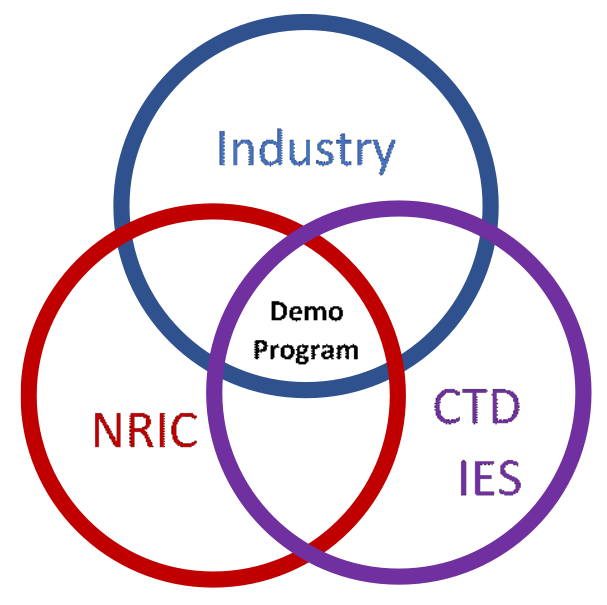

Figure 1. Demonstration program at the intersection of industry needs, NRIC, and CTD IES.

The potential demonstration program would begin in 2021 with a pre-phase (i.e., Phase 0) for planning and analysis. Phase 1 would then utilize existing test bed capabilities at INL's Energy Systems Laboratory to emulate integration of a nuclear reactor with thermal energy storage, high-temperature electrolysis for hydrogen production, or other novel applications. Phase 2 would leverage a microreactor test bed currently under development to demonstrate integrated energyuse concepts at a small scale. Phase 3 would integrate innovative systems with advanced nuclear reactors being planned for larger sites over the next several years.

The EOI request provides guidance for submitting responses and participating in the potential demonstration program. Subsequent section of this report, which describe ongoing NRIC and CTD IES activities, explain the rationale for undertaking the demonstration program as multiple phases based on the availability of sites and resources. As noted above, responses to the EOI will enable industry stakeholders to collaborate closely with NRIC and CTD IES managers to plan and execute the demonstration program, building upon the background information and pre-conceptual design scenarios included in this report.

\subsection{Organization of This Report}

The remainder of this report is organized as follows.

- Section 2 describes NRIC's mission, categories of advanced nuclear designs (with particular focus on temperatures and sizes for matching with industry needs), projects receiving financial support from the U.S. Department of Energy, and NRIC's role in preparing possible sites for advanced nuclear demonstration. This section also notes NRIC's use of model-based system engineering (MBSE) tools, especially Innoslate, to 
organize information and functional requirements from the very beginning of advanced nuclear demonstration projects to ensure effective collaboration and successful outcomes. This section also summarizes efforts to reduce the costs of advanced nuclear plants for future deployments, and additional considerations on advanced nuclear cost competitiveness are collected in Appendix A.

- Section 3 presents the range of possible energy products from nuclear reactors in the CTD IES R\&D portfolio, including heat, electricity, hydrogen, synthetic hydrocarbon fuels (synfuels), ammonia, and carbon conversion to create products through innovative methods from coal and other feedstocks. The nuclear systems could also include thermal energy storage for later use when the value and price of the energy products are high due to high demand. As discussed in this section, nuclear production of synfuels or other products containing carbon would lead to lower $\mathrm{CO}_{2}$ emissions than conventional production and consumption of fossil fuels. This section also describes CTD IES test beds in place or under development at INL's Energy Systems Laboratory as sites for early phases of the demonstration program.

- Section 4 discusses the energy-intensive industries and potential end-use applications that could utilize advanced reactors and IES concepts to reduce their fossil-fuel reliance and carbon emissions. This section contains information on industrial processes, necessary temperatures, energy consumption, resulting emissions, financial metrics, and opportunities for hydrogen or other alternative energy carriers to identify the areas of overlap with NRIC and CTD IES capabilities.

- Section 5 combines material from the previous report sections to match capabilities with potential industry uses in pre-conceptual design scenarios for the demonstration program phases. NRIC and CTD IES managers will use industry input from the EOI process to down-select from this set of pre-conceptual design scenarios and develop more detailed plans for the envisioned program.

Additional background information on NRIC, CTD IES, test bed capabilities, and future roadmaps appears in Finan (2020a), Bragg-Sitton, Rabiti et al. (2020), Core (2020), and Smart and Finan (2020). 


\section{NRIC and Advanced Reactors}

\subsection{NRIC's Mission}

Congress created NRIC (https://nric.inl.gov) under the Nuclear Energy Innovation Capabilities Act of 2018 to strengthen and streamline U.S. efforts toward commercial deployment of advanced nuclear concepts. Led by INL, NRIC works closely with private companies, national laboratory researchers, and other collaborators to support, plan, and execute the work necessary to accelerate demonstration of advanced nuclear reactors. NRIC empowers innovators by enabling access to materials, facilities, sites, and expertise, supporting permitting and regulatory needs, facilitating contracting and engagement, and focusing on achievement of specific national goals. NRIC evaluates and fosters a wide range of advanced nuclear designs with various reactor systems, fuel cycles, coolant types, and safety profiles.

\subsection{Caltegories of Advanced Reactors}

Advanced reactors differ from existing light-water reactors (LWRs) with regard to one or more fundamental attributes, such as coolant, fuel, size, design simplifications, delivery method, and/or energy product. The advanced reactor designs have inherent safety features, produce high-quality heat (approximately 500 to $1000^{\circ} \mathrm{C}$ ), mitigate nuclear waste, and enable new applications for nuclear energy beyond gigawatt-scale grid-connected power plants. The main classifications of non-LWR designs on coolant are the following (MIT 2018):

- Liquid-metal cooled fast reactors, such as sodium-cooled fast reactors (SFRs) and leadcooled fast reactors (LFRs), have temperatures from approximately 500 to $700^{\circ} \mathrm{C}$. The advantages of these coolants include high thermal conductivity, avoidance of boiling risks, and low pressure in the primary loop. These reactors have no moderator and therefore operate in the fast range of the neutron spectrum, which increases the efficiency of fuel consumption for certain types of fission reactions. Some designs surround the reactor in a pool of liquid metal, while others flow the liquid metal through loops. Heat pipes have recently emerged as another possible heat transfer system. Designs with sodium must prevent contact with air to avoid combustion.

- Molten-salt reactors (MSRs), with temperatures from approximately 600 to $1000^{\circ} \mathrm{C}$, remove heat from the reactor by circulating a salt medium containing fluorine, chlorine, and possibly lithium and/or beryllium. The fuel could be chemically bound with these salt elements or it could be encapsulated separately as in fluoride-salt-cooled hightemperature reactors (FHRs) using tristructural-isotropic (TRISO) particles with layers of carbon materials to contain fission products. The salt coolant circulates at low pressure, and the characteristics of fuels and salts for these designs prevent run-away reactions, but corrosion and fuel transport within the medium are issues for this category.

- High-temperature gas reactors (HTGRs), with temperatures from approximately 700 to $1000^{\circ} \mathrm{C}$, use helium as coolant. Several designs use graphite as a moderator while some other designs have no moderator and operate in the fast range of the neutron spectrum. As an inert gas, helium does not pose corrosion problems for the reactor system, but the coolant system must be carefully sealed to prevent leakage of the gas. These reactors also use TRISO fuel particles.

Size definitions for advanced nuclear reactors are presented in U.S. Department of Energy Office of Nuclear Energy (2021). In addition to full-sized reactors with electric capacity greater than $300 \mathrm{MW}_{\mathrm{e}}$, advanced designs include small reactors with capacity between 20 and 300 
$\mathrm{MWe}$, and microreactors with capacity less than $20 \mathrm{MW}$. These various sizes for advanced reactor designs could serve a wide array of uses, as discussed in subsequent sections of this report. Modularity, design simplifications, factory manufacturing, transportation in standard-sized shipping containers by truck or rail, fast installation, and other innovations for advanced reactors can broaden markets for nuclear energy and enhance cost competitiveness relative to other energy sources.

\subsection{Government-Supported Advanced Reactor Projects}

The U.S. Department of Energy (DOE) has awarded funding to several advanced nuclear developers for various types of projects to be completed over the next few years. NuScale will demonstrate its Integrated Pressurized Water Reactor (iPWR) at the INL site and Oklo is progressing its Aurora microreactor. In 2020, DOE announced three categories of awards under the Advanced Reactor Demonstration Program (Finan 2021). The first category, with funding for demonstration pathways, supports TerraPower and GE-Hitachi for their Natrium SFR with moltensalt energy storage and X-energy for the Xe-100 HTGR. The second category, for risk reduction projects, supports Kairos Power for the KP-FHR, BWX Technologies for the BWXT Advanced Nuclear Reactor, Southern Company for the Molten Chloride Reactor Experiment, Holtec International for the SMR-160, and Westinghouse for the eVinci heat pipe microreactor. The third category, for concept development over the next 20 years, supports Advanced Reactor Concepts for the Advanced Sodium-Cooled Reactor Facility, General Atomics for the Fast Modular Reactor, and MIT for the Horizontal Compact Fast Modular Reactor. The projects supported by the DOE Advanced Reactor Demonstration Program are shown in Figure 2. Other advanced concepts are also being supported by the U.S. Department of Defense for mobile operations.

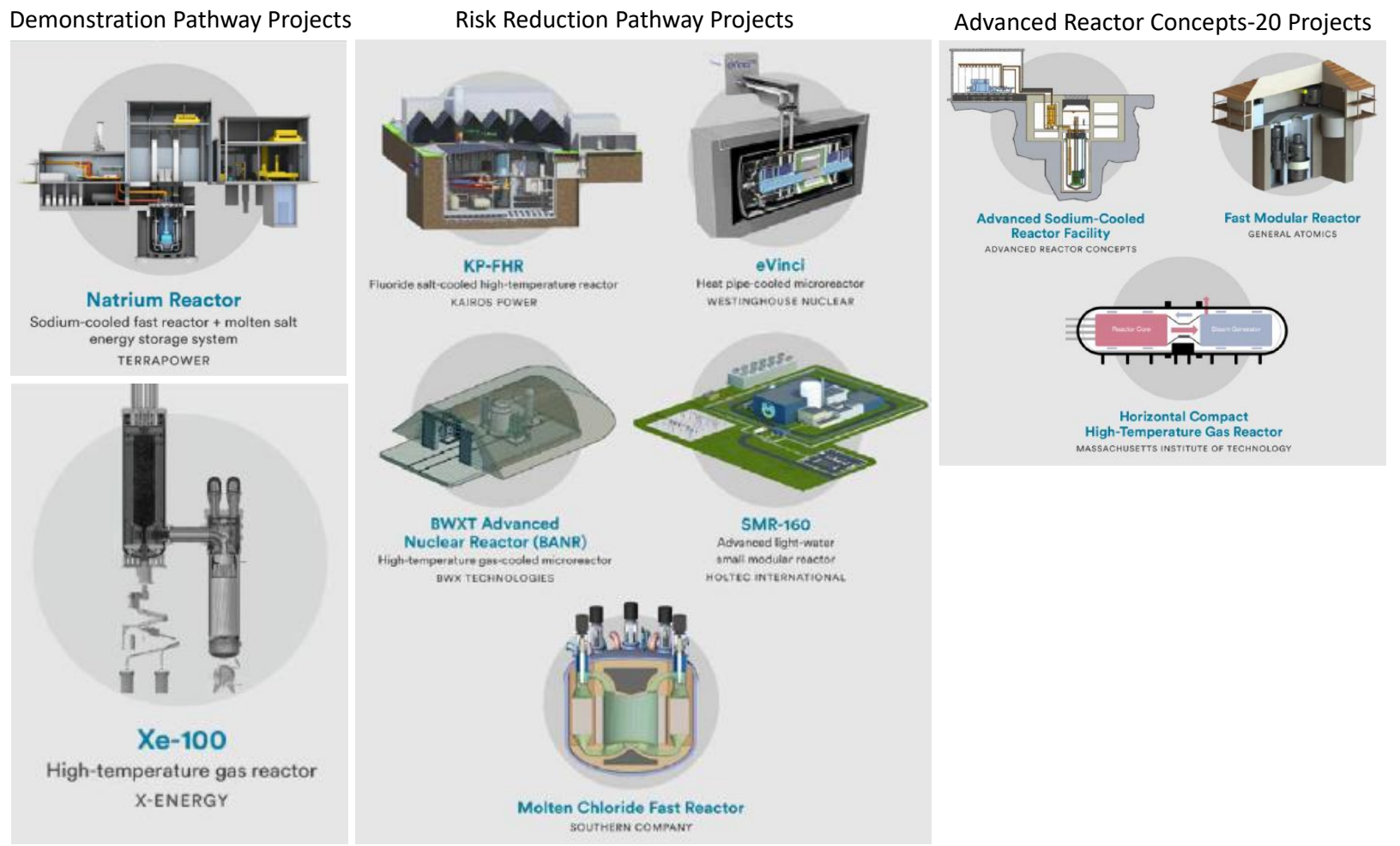

Figure 2. Projects supported by the DOE Advanced Reactor Demonstration Program (Finan 2021 with content from DOE). 
NRIC is coordinating with recipients of DOE funding by identifying infrastructure resources and needs across the national laboratory complex and partnering institutions. NRIC is also preparing demonstration sites for advanced reactor projects at INL and elsewhere, as described below.

\subsection{Digital Engineering and MBSE in NRIC Projects}

NRIC uses digital engineering and MBSE tools, including Innoslate (https://www.innoslate.com), to bring together multiple stages of projects and multiple sources of information in an integrated, comprehensive, and efficient manner. MBSE is used in modern engineering projects across many industries to serve as the "authoritative source of truth" for all information management. Figure 3, reproduced from (Balsmeier and Core 2020), illustrates the MBSE process.

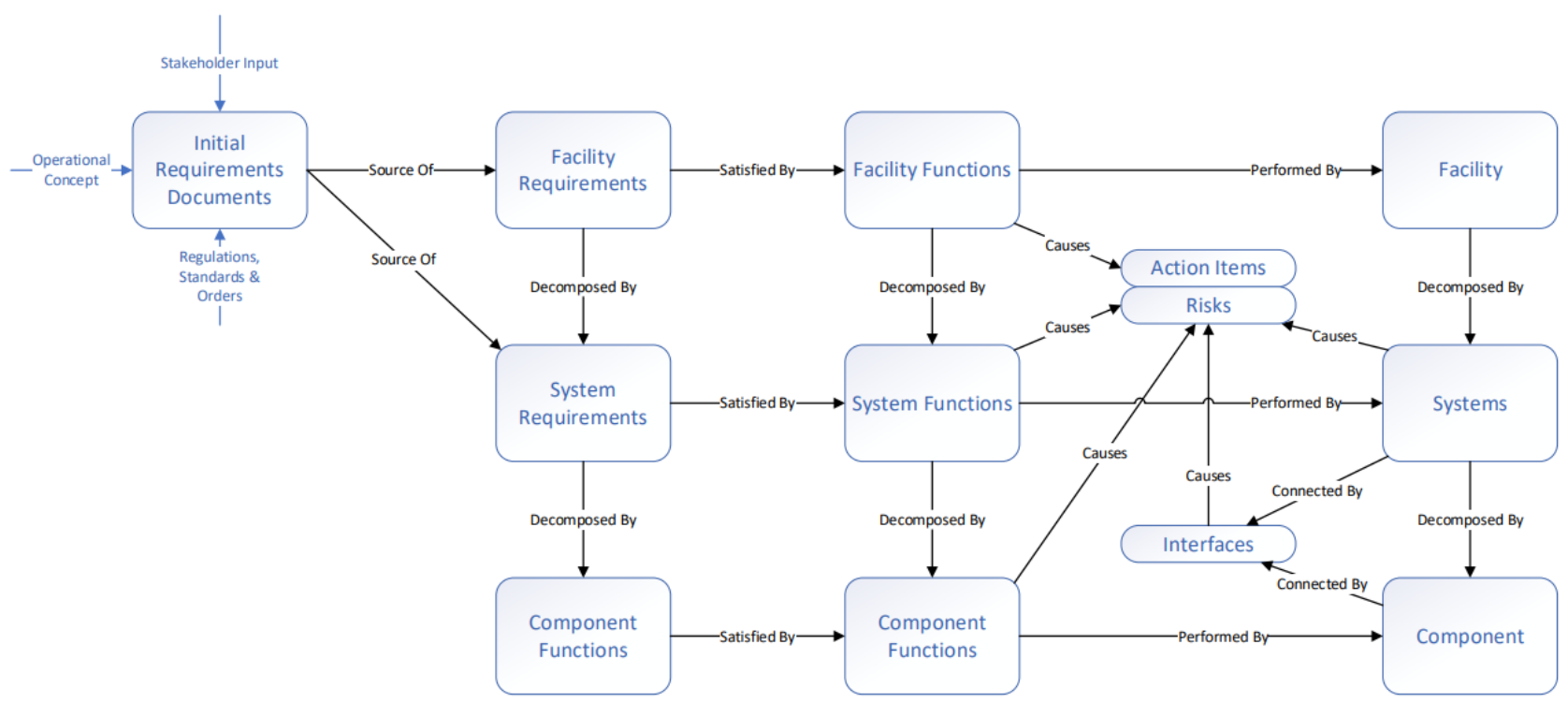

Figure 3. Completed data architecture of the MBSE process (Balsmeier and Core 2020).

Several of the advanced reactor developers also use Innoslate as their primary MBSE tool. Innoslate provides traceability, in a single model or linked models, via a digital thread from data sources, such as requirements in linked documents, through to system components or functions within the model. Collaboration between NRIC and developers with this tool facilitates effective and complete data exchange and shared focus.

Innoslate is a useful tool for multiple aspects of test bed and advanced reactor demonstration projects. It integrates requirements management, systems architectures, functional flow diagrams and process simulation, cost and schedule tracking for program management, action item tracking, and risk identification and mitigation. For potential test bed users, it assists with collecting test hardware to test bed interface requirements, calculating costs for nuclear energy test bed activities, and simplifying process simulation. Managing the project requirements, processes, and costs in Innoslate facilitates future activities in the test beds.

Through Innoslate, the project team follows the systems engineering process of identifying stakeholders and required functions with use cases and action diagrams, developing acceptable architectures and subsystems, then synthesizing the system design. Process flow diagrams can be created in the tool at appropriate levels of detail and simulated to evaluate overall system performance. During design iteration, Innoslate helps the team manage requirements, track action items, and mitigate risks. Once the design has matured to a sufficient level of detail, the project 
leverages the digital engineering integration between Innoslate and drafting tools (e.g., Autodesk) to advance the design to completion.

The following figure presents a top-level Innoslate diagram used for planning projects that will used the test beds under this NRIC and CTD IES initiative. The various elements of this illustrative figure are discussed in subsequent sections of this report.

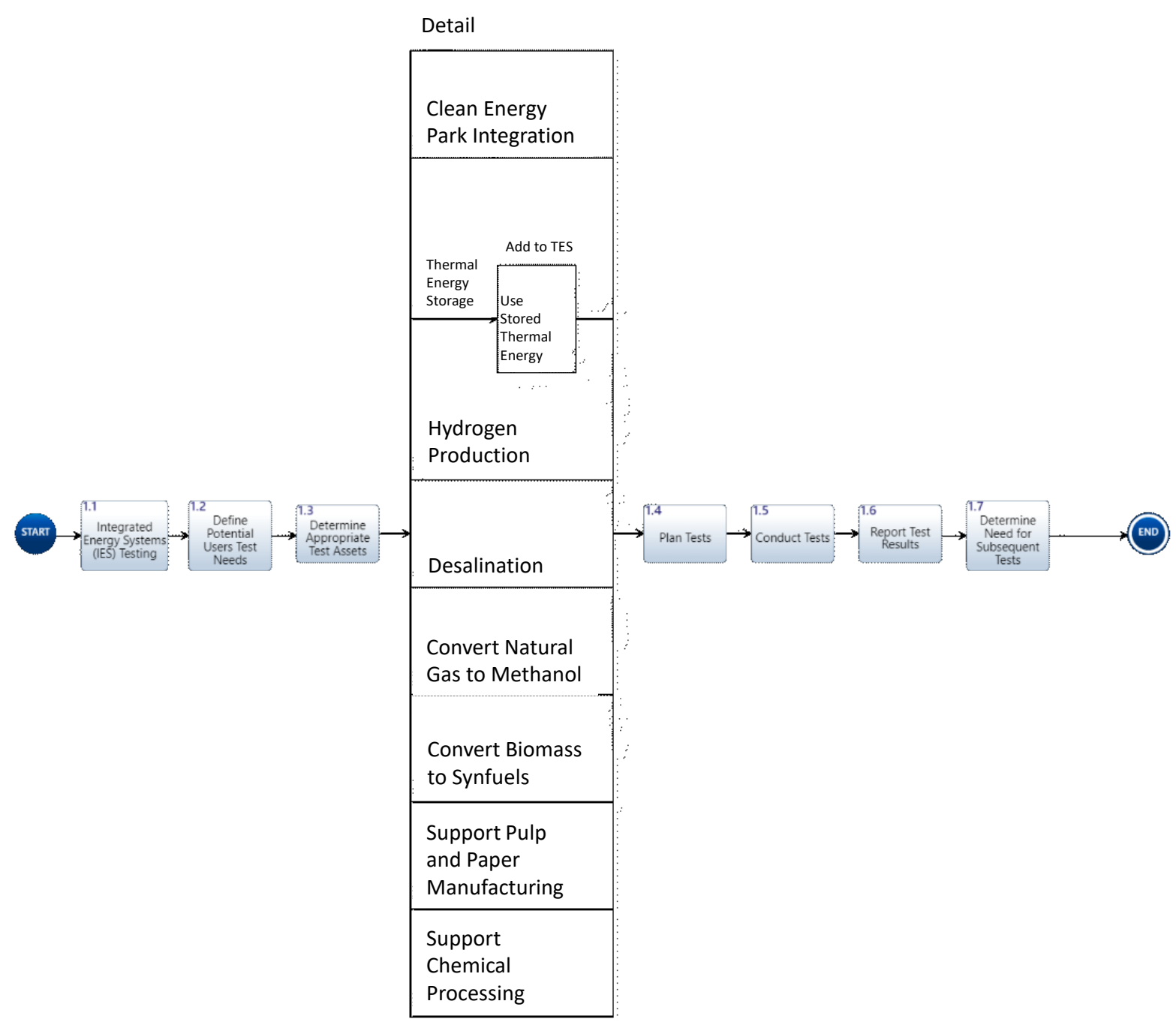

Figure 4. Illustrative Innoslate action diagram for NRIC and CTD IES demonstration projects.

\subsection{NRIC Projects and Demonstration Sites}

The following figure shows the locations of the microreactor demonstration project and two main test beds at INL relevant for the envisioned program with NRIC and CTD IES. Siting and permitting plans for these upcoming advanced nuclear demonstrations are discussed in Conner, Griffith, and Burdick (2020). 


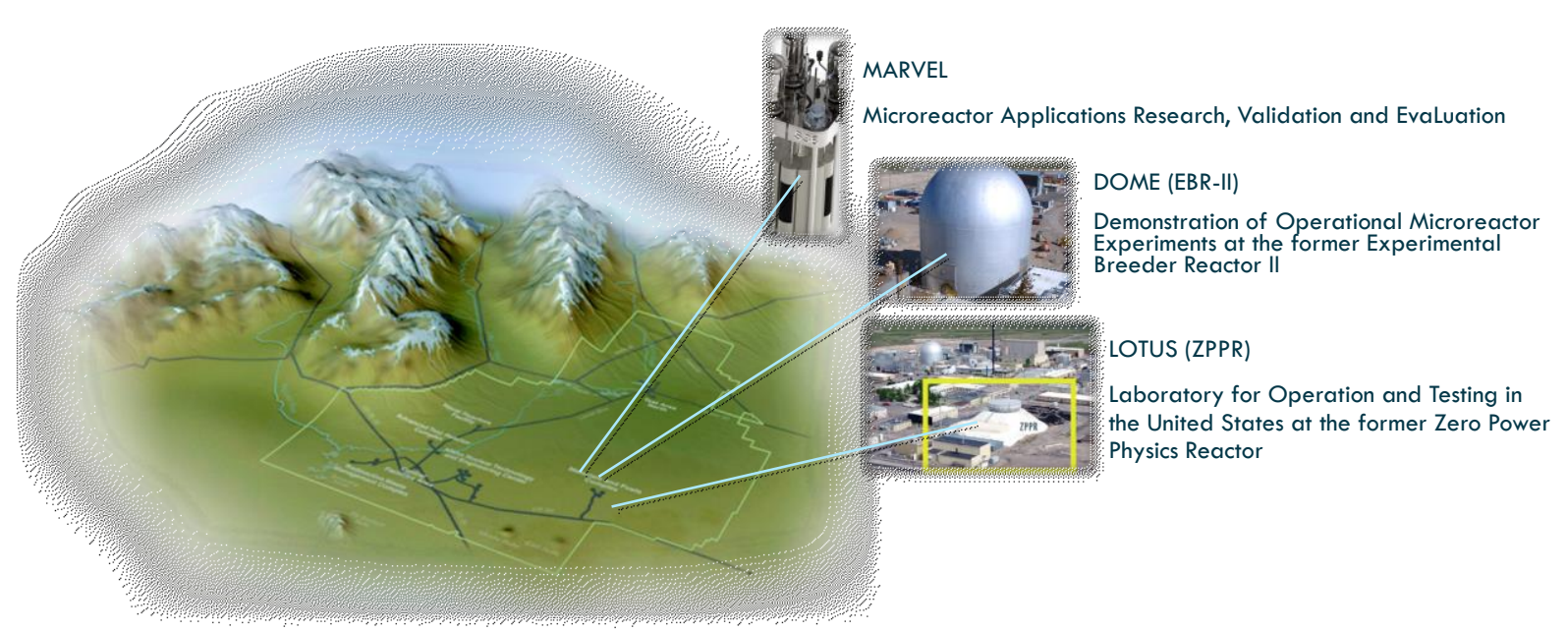

Figure 5. MARVEL, DOME, and LOTUS at INL

- The Microreactor Applications Research, Validation, and Evaluation (MARVEL) project under NRIC will build and demonstrate a Sterling Engine microreactor at a bay of the Transient Reactor Test Facility. MARVEL will have liquid sodium primary coolant, with temperature of around $500^{\circ} \mathrm{C}$. Its capacity will be $100 \mathrm{~kW}$ th, approximately equivalent to $20 \mathrm{~kW}_{\mathrm{e}}$. Its reactor control systems will consist of four independent vertical control drums and a central shutdown rod. The microreactor is expected to become operational in 2024 . (Arafat 2020) describes the MARVEL project goals and the microreactor design.

- The Demonstration of Operational Microreactor Experiments (DOME) test bed, at the site of the former Experimental Breeder Reactor II, would accommodate reactors generating up to $20 \mathrm{MW}_{\text {th }}$ using Safeguards Category 4 materials. The facility has an 80 -foot diameter, 1 foot-thick rebar-reinforced concrete walls with steel plating on the exterior, 4,800 square feet of floor space, and floor loading capacity of 3,750 psf. (Balsmeier and Burnett 2020) provide preliminary design analysis on the DOME test bed, and planning by NRIC is ongoing (content in the 2020 report is subject to change).

- A smaller test bed, the Laboratory for Operation and Testing in the United States (LOTUS) at the site of the former Zero Power Physics Reactor, would accommodate reactors generating up to $500 \mathrm{~kW}_{\text {th }}$ using plutonium fuels and/or highly enriched uranium. Based on these materials, the facility would be designated as Safeguards Category 1 with significantly tighter security requirements than DOME. The facility has 1,300 square feet of floor space, and floor loading capacity of 3,000 psf. (Balsmeier and Core 2020) provide preliminary design analysis on the LOTUS test bed, and planning by NRIC is ongoing (content in the 2020 report is subject to change).

DOME and LOTUS are expected to become operational for advanced nuclear demonstration projects by approximately 2023-2025 to fulfill NRIC's mission under the Nuclear Energy Innovation Capabilities Act to demonstrate at least two advanced nuclear demonstration projects by 2025 . NRIC is also supporting potential advanced nuclear demonstration sites at other national laboratories, universities, and additional locations.

As an example of NRIC's use of Innoslate for advanced reactor demonstration sites, Figure 6 illustrates the primary activities to prepare DOME and conduct tests. 


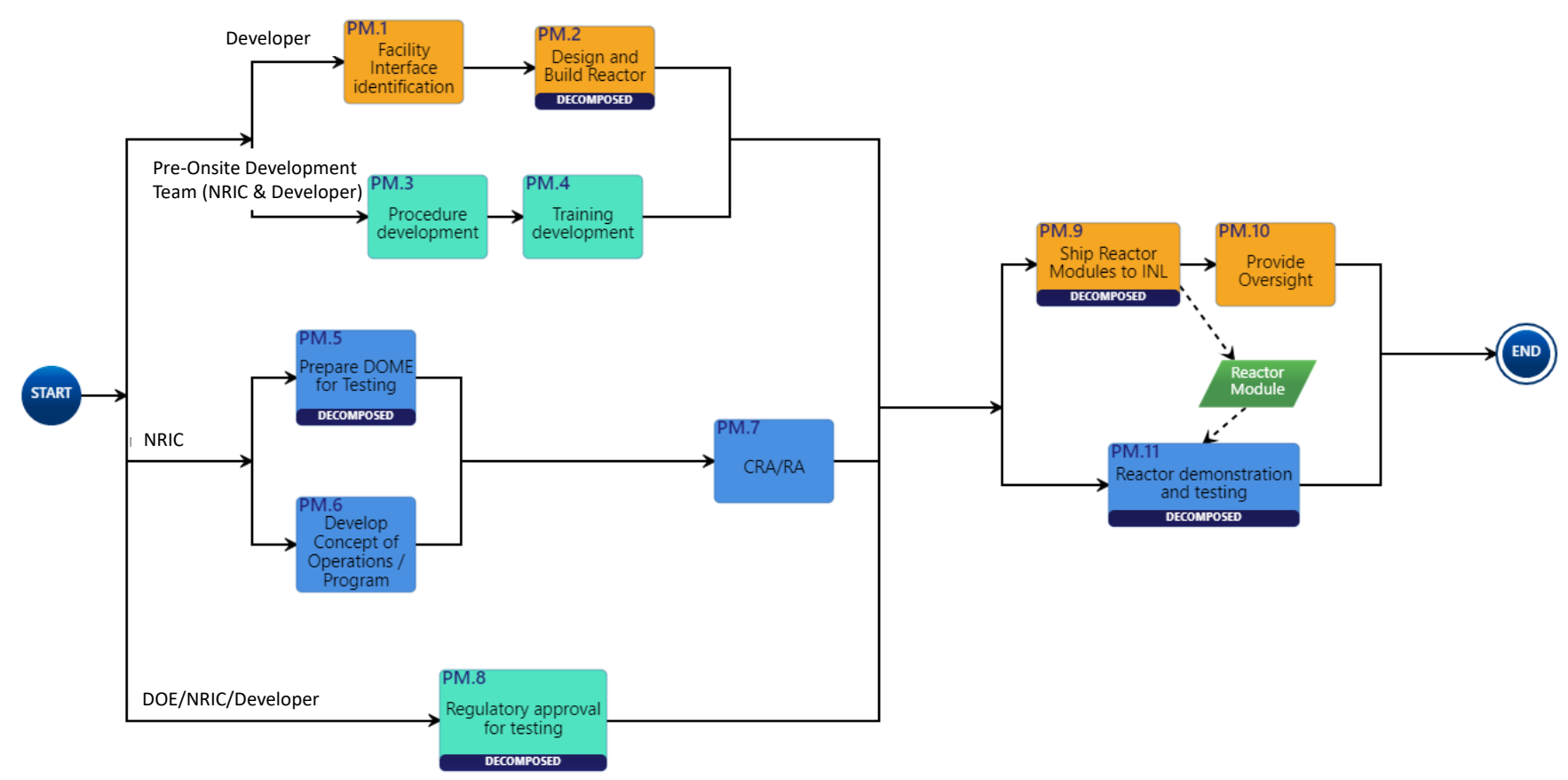

Figure 6. Innoslate diagram of primary test activities planned for DOME.

\subsection{Cost-Reduction Strategies for Advanced Nuclear Plants}

In addition to coordinating with advanced nuclear developers and preparing a network of demonstration infrastructure, NRIC supports identification and implementation of cost-reduction strategies to ensure the financial viability of commercial nuclear plants in future energy markets. In 2020, NRIC issued an EOI request and subsequent request for proposals to fund demonstration of advanced construction technologies (Finan 2020). Although some features of advanced nuclear plants could increase their costs per $\mathrm{kWe}$ (such as exotic materials or fuels for some designs and adverse economies of scale for small and micro designs), they could achieve cost reductions through combinations of inherent safety systems, design simplification, standardization, modularity, factory or shipyard manufacturing, additive manufacturing, novel construction techniques, fast installation, digital twins, remote monitoring, automation, and learning by experience across multiple unit deployments. The potential costs of advanced nuclear plants, along with cost reduction strategies from recent studies in this area, are discussed further in Appendix A. 


\section{Integrated Energy Systems}

IES incorporate multiple energy-generation resources and energy-use pathways to provide affordable, reliable, and resilient energy, simultaneously reducing GHG emissions (McMillan et al. 2016; Bragg-Sitton, Boardman, et al. 2020). Nuclear IES increase the value proposition of nuclear energy by increasing the flexibility of nuclear electricity generation, allowing it to better complement with variable renewables and to support controllable and flexible loads (e.g., water desalination, electric vehicle charging, hydrogen electrolysis); producing hydrogen or synthetic fuels as secondary revenue streams; and providing low-carbon heat for industrial processes. This also provides new mechanisms for decarbonizing the three largest sources of GHG emissions in the U.S.: the electric grid, transportation, and the industrial sector (McMillan et al. 2016).

The CTD IES program (https://ies.inl.gov) conducts R\&D to expand the role of nuclear energy beyond conventional nuclear power plants that produce electricity for the grid. As discussed in more detail below, possible direct applications of thermal energy from nuclear reactors include industrial processes, hydrogen production through high-temperature methods (e.g., hightemperature electrolysis), and desalination. The CTD IES program also considers strategies to ensure that electricity from nuclear plants will complement variable renewable resources in future low-carbon systems. In addition, thermal energy storage (such as sensible, latent, or other forms) could provide more flexibility for nuclear plants to provide electricity, hydrogen, or other services when they are most highly valued. Led by INL, the program encompasses researchers and facilities across several national laboratories. It involves detailed analysis of enabling technologies, such as thermal connections, heat exchangers, thermal energy storage media, heat augmentation alternatives, cutting-edge digital controls, hydrogen production pathways, and carbon conversion processes. It also provides close scrutiny of market scenarios and financial viability necessary to optimize IES design and operation. Figure 7 provides an overview of applications with nuclear-generated heat and electricity of interest and under development by the CTD IES program.

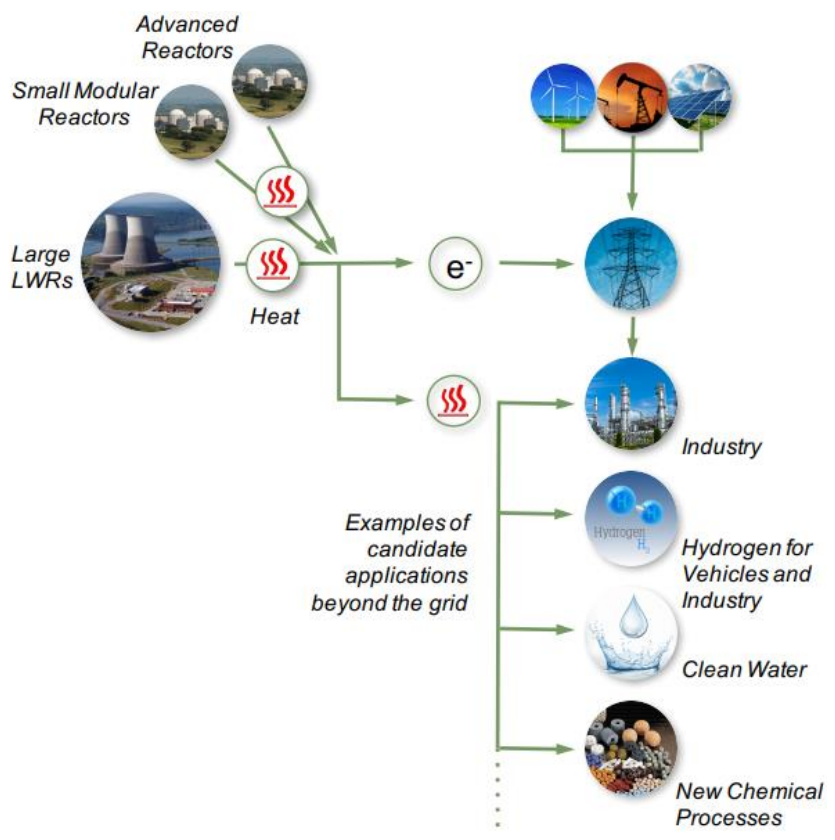

Figure 7. Overview of nuclear heat and electricity pathways being evaluated by the CTD IES program for the production of multiple energy products (Bragg-Sitton 2020). 
Nuclear IES can be configured to produce multiple energy products simultaneously and/or dynamically manage the dispatch of heat and electricity to vary production rates of different products according to market conditions. Figure 8 depicts some of the possible nuclear energy products; other products and processes are also possible. Some of the following diagrams include steam, but certain advanced reactor designs could use other fluids for their heat and cooling loops. To avoid net increases in $\mathrm{CO}_{2}$ emissions and atmospheric $\mathrm{CO}_{2}$ concentration, carbon in synthetic hydrogen-derived energy carriers (e.g., synthetic liquid fuels) would come from biomass or be extracted from the atmosphere (and any carbon stored in plastics or other solid consumer products would not be released to the atmosphere).

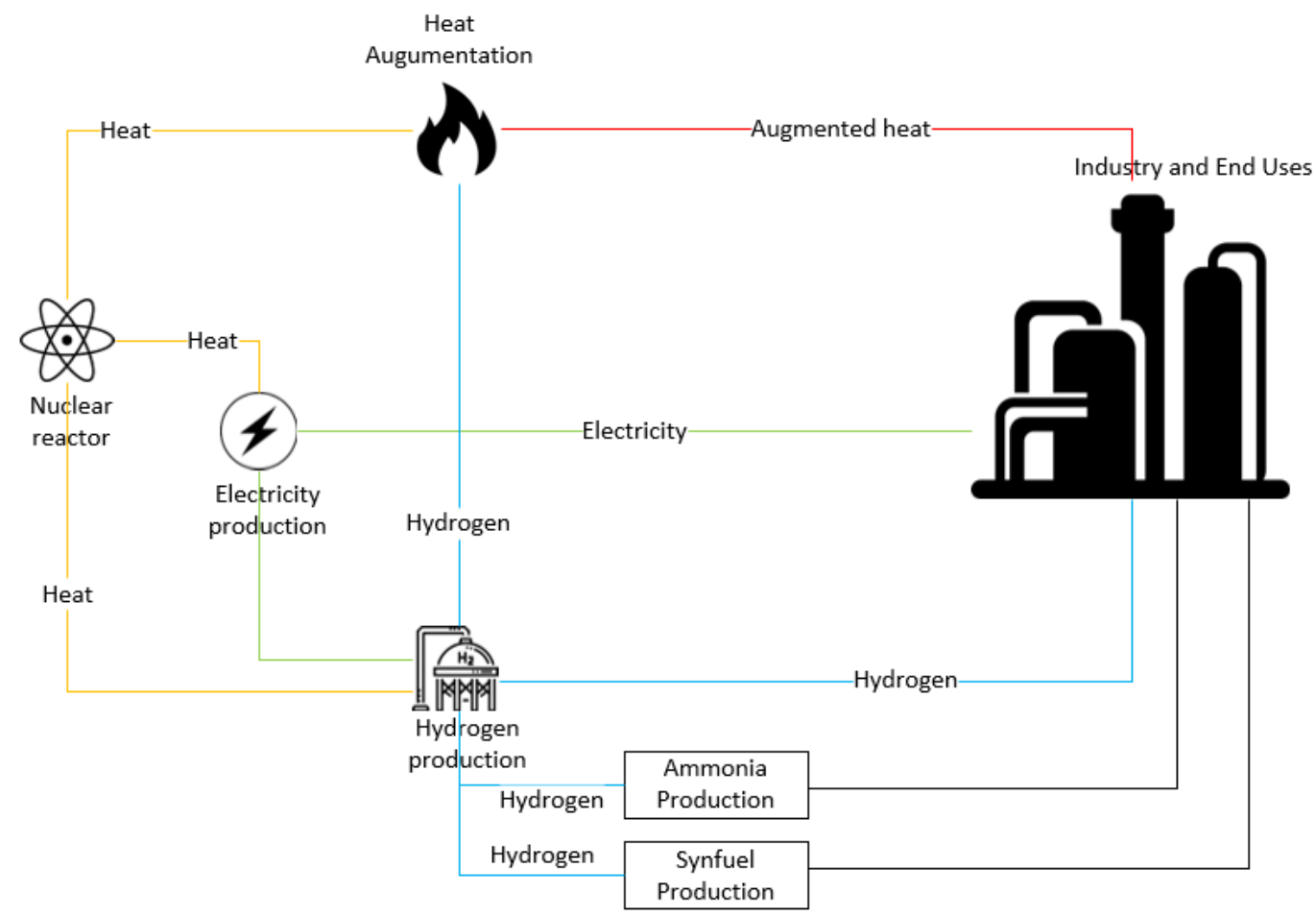

Figure 8. Summary of possible nuclear energy products.

\subsection{Nuclear Heat Production}

The most fundamental energy product from nuclear reactors is heat, as shown below in Figure 9. The primary loop transfers thermal energy produced in the reactor core through a heat exchanger to the secondary loop, which is connected with the heat customer. More complex energy production pathways from nuclear reactors, which are described in subsequent subsections, build upon this foundation. As discussed in Section 4, advanced nuclear plants colocated with industrial facilities or other users could provide heat for a wide range of needs. 


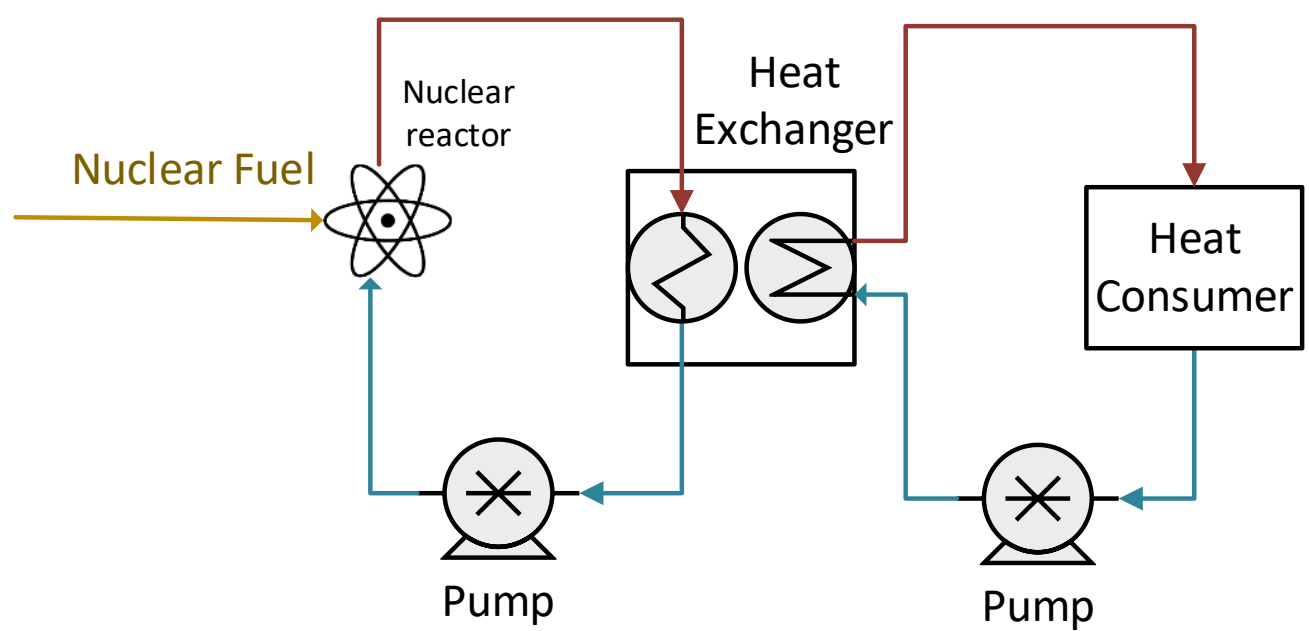

Figure 9. Generic nuclear heat production diagram.

From the perspective of energy conversion, thermal energy from nuclear reactors has an inherent advantage over resistance heating from renewables, combustion of hydrogen, or other heat sources (besides conventional combustion of fossil fuels), because other non-fossil heat sources would need to create the thermal energy via other processes that incur losses. Cost comparisons for assessing heat alternatives depend on many input parameters and assumptions. The following figure, reproduced from (Friedmann, Fan, and Tang 2019) at the Columbia University Center on Global Energy Policy, shows nuclear heat as the lowest-cost option, based on the assumed costs for nuclear (using published $\mathrm{n}^{\text {th }}$-of-a-kind cost targets for a water-cooled design) and other heat sources in the study. 


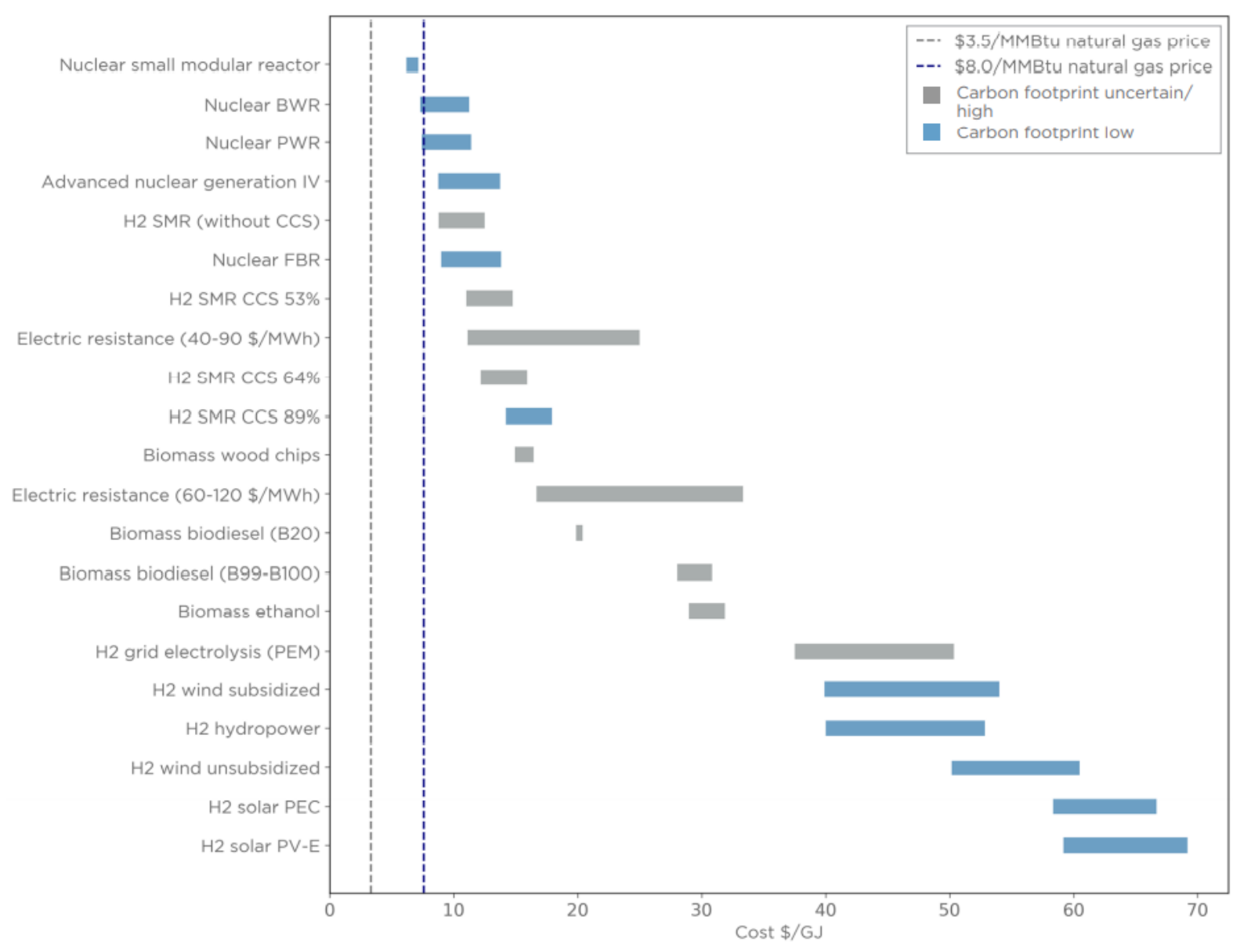

Figure 10. Estimated costs for delivered heat from clean energy sources (Friedmann, Fan, and Tang 2019).

\subsection{Nuclear Electricity Generation}

All existing nuclear reactors in the United States, with the exception of small research reactors, send their heat through a turbine/generator set to produce electricity for the grid. Figure 11 provides a generic electricity generation diagram. The CTD IES program encompasses R\&D activities on optimal electricity generation and delivery from nuclear plants to the grid and other coupled energy users, particularly within systems containing renewables and other clean energy resources. For example, an advanced reactor could be electrically coupled to a microgrid, providing dedicated power to systems requiring high reliability and resilience, such as data centers, electric transportation hubs, and military installations. Electricity consumption for industrial processes, which commonly occurs alongside fossil-fuel consumption at industrial facilities, is discussed in Section 4. 


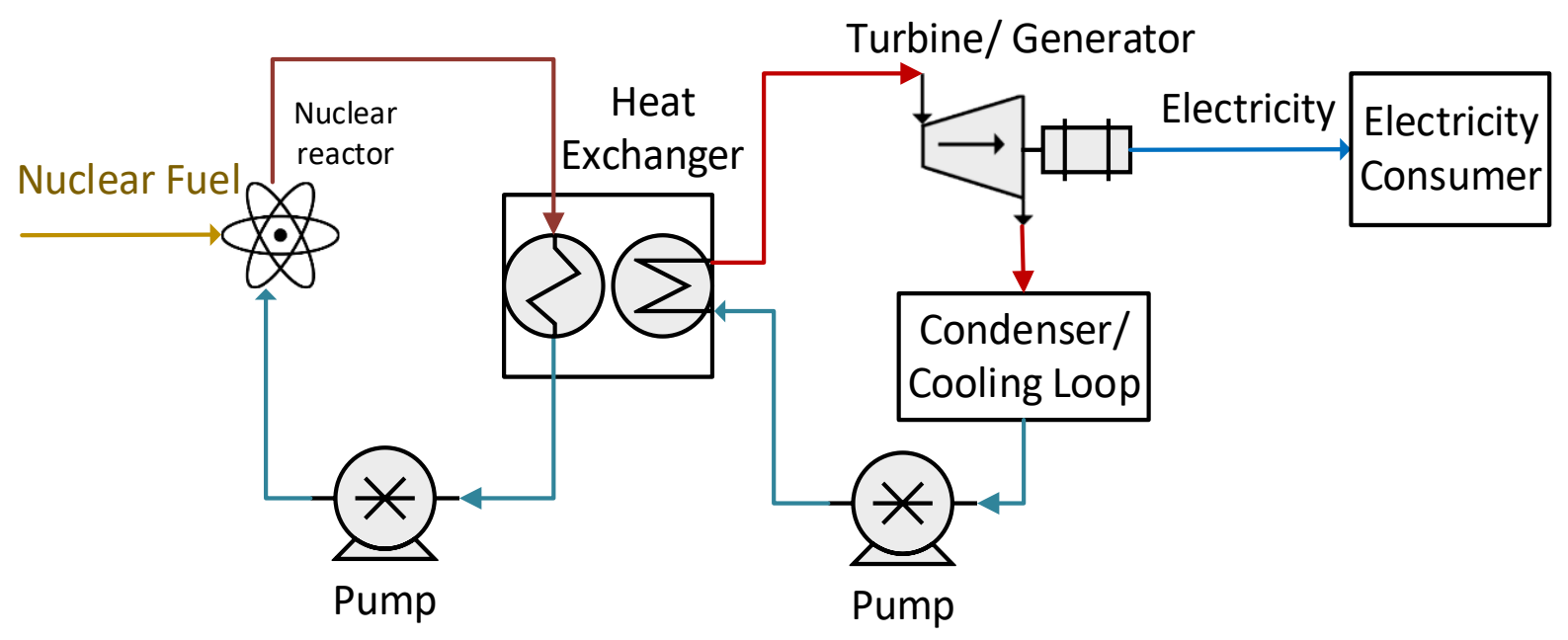

Figure 11. Generic nuclear electricity generation diagram.

\subsection{Nuclear Combined Heat and Power}

Figure 12 combines elements of previous figures to portray combined heat and power (CHP) from a nuclear plant. As discussed in subsequent sections, many industrial facilities require both heat (currently from fossil fuels or biomass) and electricity; these applications could use a colocated nuclear reactor which could provide clean energy to support these applications.

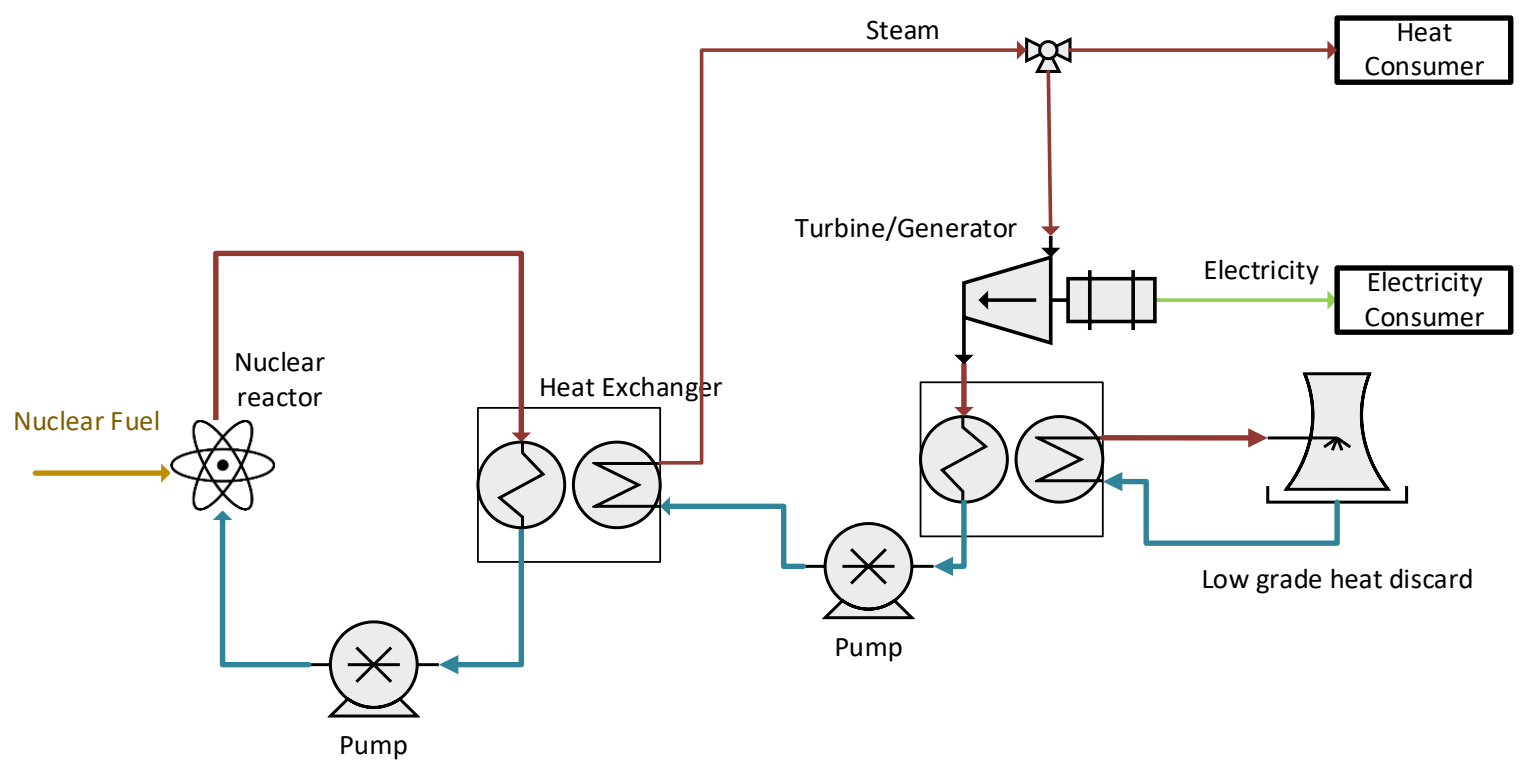

Figure 12. Generic nuclear heat and power diagram.

\subsection{Nuclear Hydrogen Production and Derived Energy Carriers}

Hydrogen is increasingly seen as a key component of future energy systems if it can be made without carbon dioxide emissions. Most hydrogen today is made by steam reforming of natural gas or coal gasification, both with $\mathrm{CO}_{2}$ emissions. Future demand is expected to be mainly for 
zero-carbon, "green" hydrogen. Clean hydrogen production could be accomplished by electrolysis using electricity from variable renewable sources or nuclear reactors. Lowtemperature electrolysis (LTE) of water to produce hydrogen occurs at ambient temperatures and requires about $55 \mathrm{kWh}$ per kilogram of hydrogen produced, which equates to a process efficiency of $60 \%$ (U.S. Department of Energy 2020). Efficiency could potentially increase to $70 \%$ with improved catalysts. LTE is undertaken on a fairly small scale today, producing only about $2 \%$ of world supply (International Energy Agency 2019). Abundant, clean, and low-cost hydrogen can be subsequently utilized in many aspects of the chemical industry, several of which (e.g., biomass gasification, synfuel production, and steel) are outlined in subsequent sections. Figure 13, reproduced from the DOE Hydrogen Program Plan (2020) for the $\mathrm{H}_{2} @$ Scale program, illustrates the current and potential uses of hydrogen from nuclear and other energy sources.

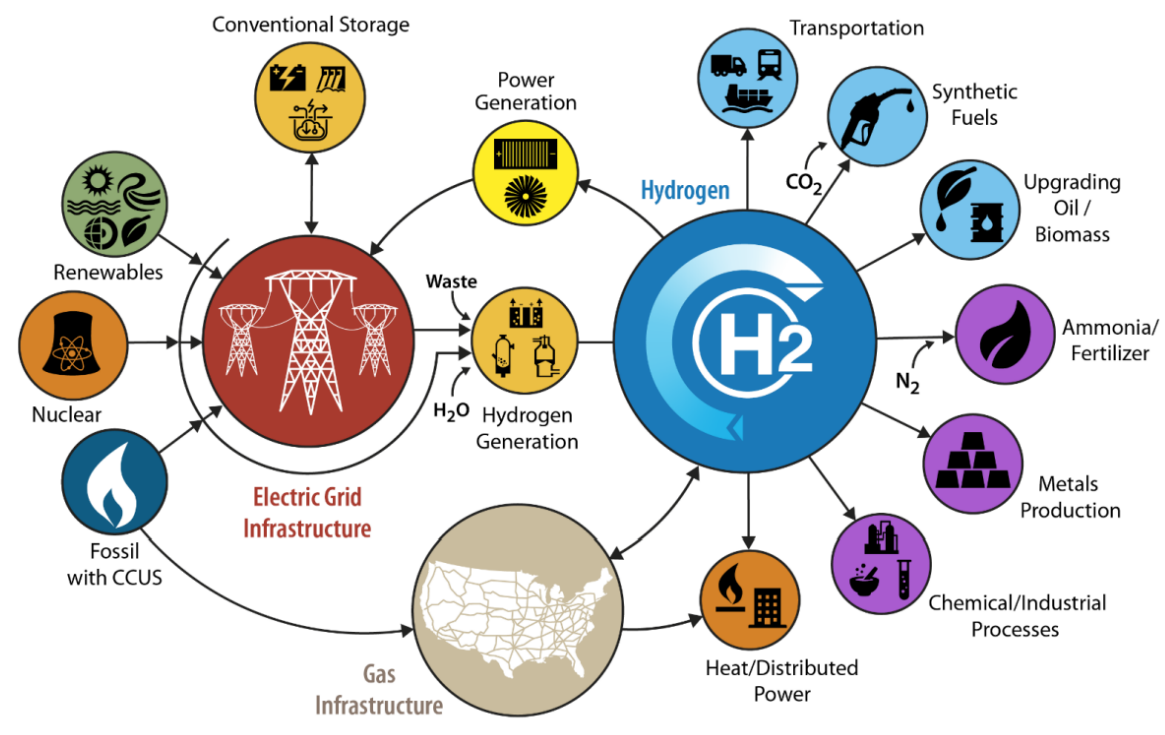

Figure 13. Linkages between energy resources and hydrogen (U.S. Department of Energy 2020).

Figure 14 shows a representative diagram for hydrogen production from nuclear energy using LTE. Early demonstrations of nuclear IESs are integrating LTE with existing LWRs to produce hydrogen as a secondary revenue source (Bragg-Sitton, Rabiti, et al. 2020; Idaho National Laboratory 2020), expected to be operational in 2021 and 2022, and a high temperature electrolysis demonstration at an existing LWR was announced in late 2020 for operation in 2022. 


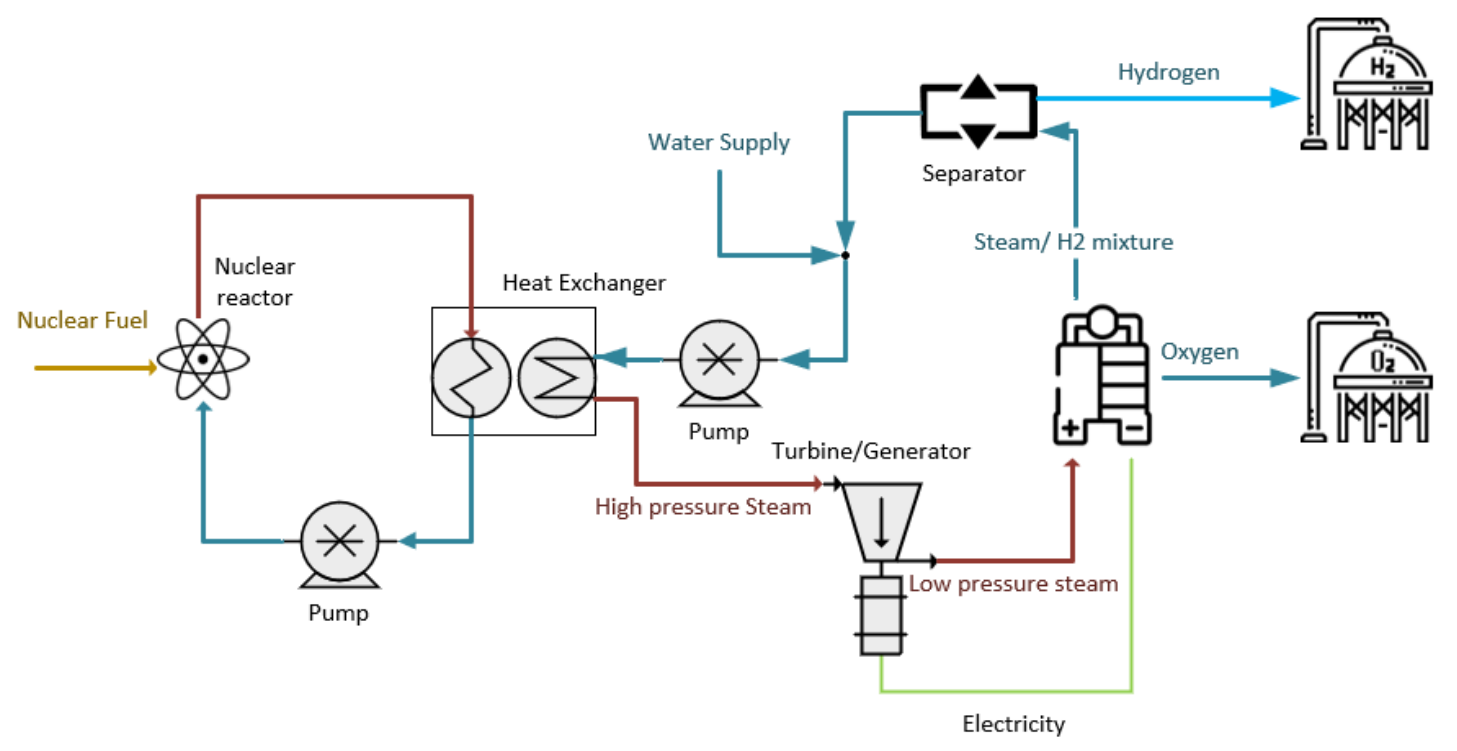

Figure 14. Generic nuclear hydrogen production diagram using LTE.

High-temperature electrolysis (HTE) uses solid oxide electrolysis cells to electrochemically separate hydrogen and oxygen in steam at temperatures around $800^{\circ} \mathrm{C}$, achieving a substantially higher efficiency than LTE (Bragg-Sitton, Rabiti, et al. 2020). The higher efficiency for HTE gives nuclear IES a significant advantage over renewables for hydrogen production. Higher capacity factors for nuclear reactors than variable renewables also provide an advantage for capital cost recovery (Ingersoll and Gogan 2020). Figure 15 illustrates nuclear hydrogen production using HTE. Studies on hydrogen production, markets, and test bed development in the CTD IES program include (Frick et al. 2019, Boardman et al. 2019, Talbot et al. 2020, Bragg-Sitton, Rabiti, et al. 2020).

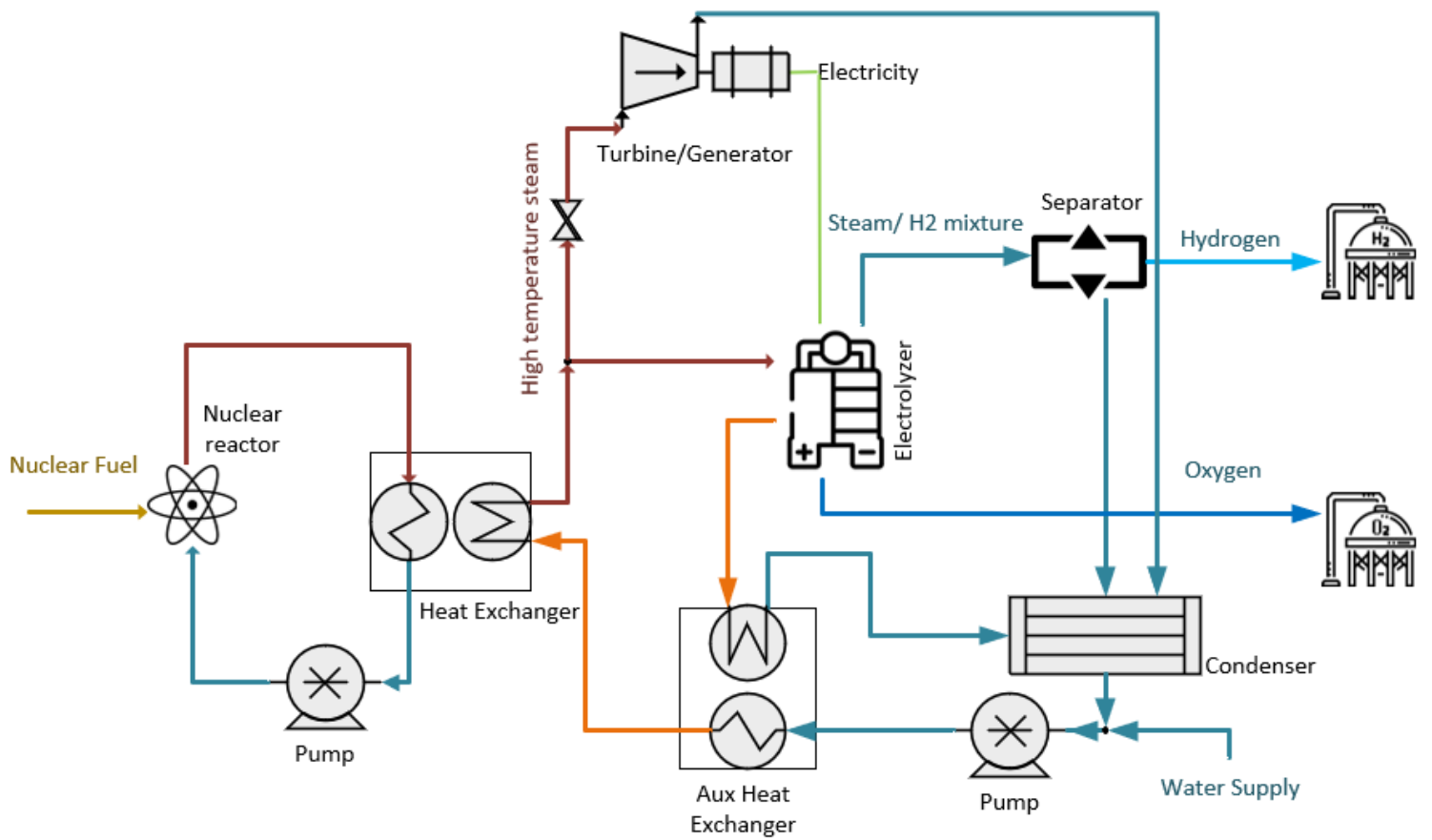

Figure 15. Generic nuclear hydrogen production diagram using HTE. 
Hydrogen is a highly versatile energy carrier that can be used immediately, stored, or transported to another site for use. Hydrogen from this process may also be used to create other energy carriers, such as synthetic hydrocarbon fuels (synfuels), ammonia, methanol, and synthetic methane.

\subsection{Nuclear Thermal Energy Storage}

Thermal energy storage could enhance the value of nuclear energy systems by storing thermal energy for later release when the value of heat, electricity, or other potential products is high. Figure 16 shows a nuclear reactor with representative thermal energy storage system. Studies on thermal energy storage in the CTD IES program include (Mikkelson et al. 2019, Forsberg, Sabharwall, and Gougar 2019, and Forsberg and Bragg-Sitton 2020).

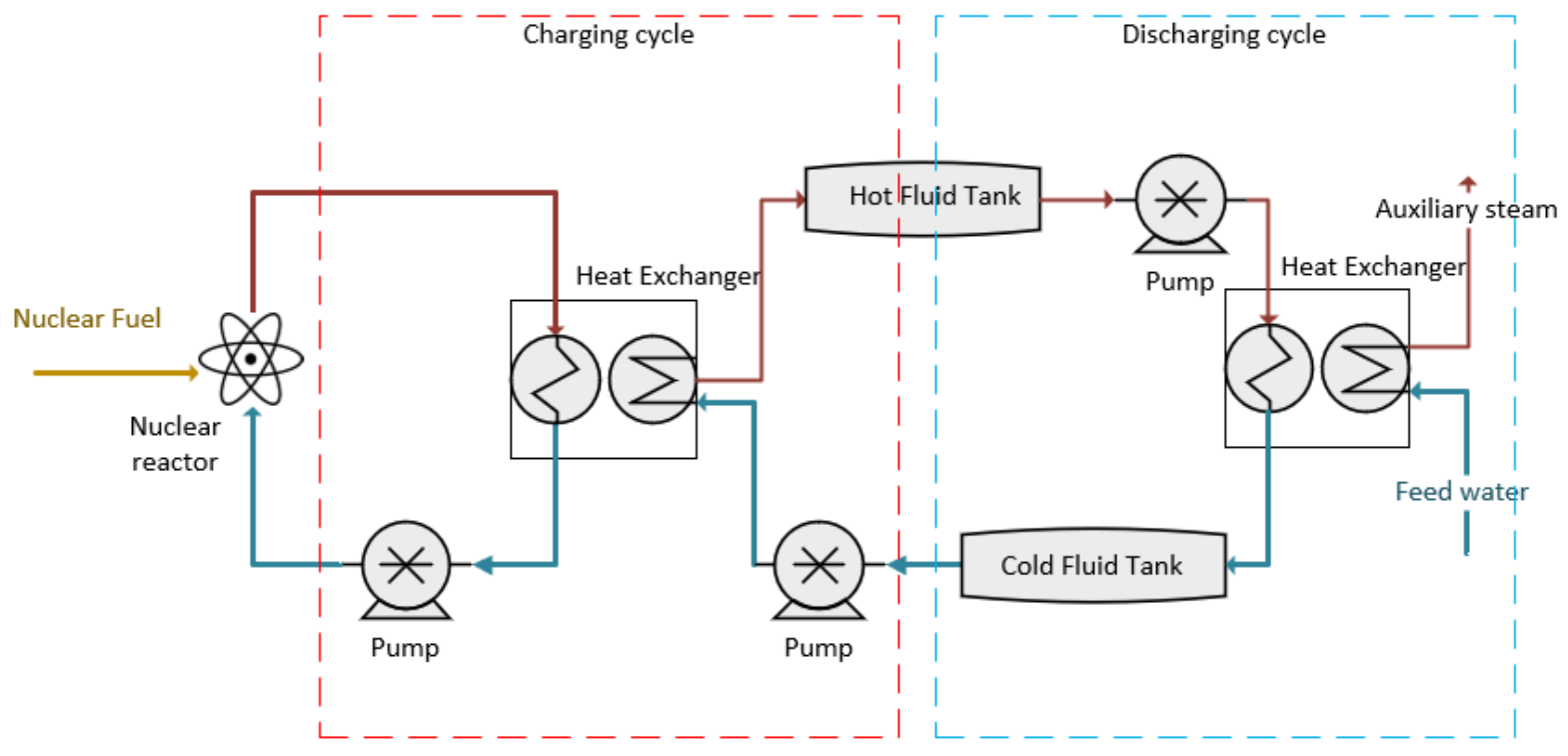

Figure 16. Generic thermal energy storage diagram.

As noted in Section 2, the advanced reactor designs being supported by the DOE Advanced Reactor Demonstration Program include the Natrium design by TerraPower and GE-Hitachi, which uses molten salt as thermal energy storage medium. The energy storage aspect of this demonstration project could serve as the basis for other designs and partnerships on nuclear and storage systems in the proposed NRIC / CTD IES demonstration program outlined in this report.

INL recently installed a Thermal Energy Distribution System (TEDS) as part of the Dynamic Energy Transport and Integration Laboratory (DETAIL), located at the Energy Systems Laboratory building complex. This oil-filled heat transfer system will be used to demonstrate and analyze thermal-energy-storage modes and transport to and from various co-located systems, will allow evaluation of hardware associated with off-take of thermal energy from a power plant, and provides a platform for verification and validation of various computational models of such a system. TEDS is equipped with a $200 \mathrm{~kW}$ controllable heater that can be driven variably to emulate how heat from a commercial power plant might be supplied. As shown in Figure 15, TEDS can be connected to various heat loads, such as an HTE test system (to be integrated in Summer 2021), as well as heat sources, such as the co-located Microreactor Agile Non-Nuclear Experimental Test (MAGNET) described in the next subsection. 


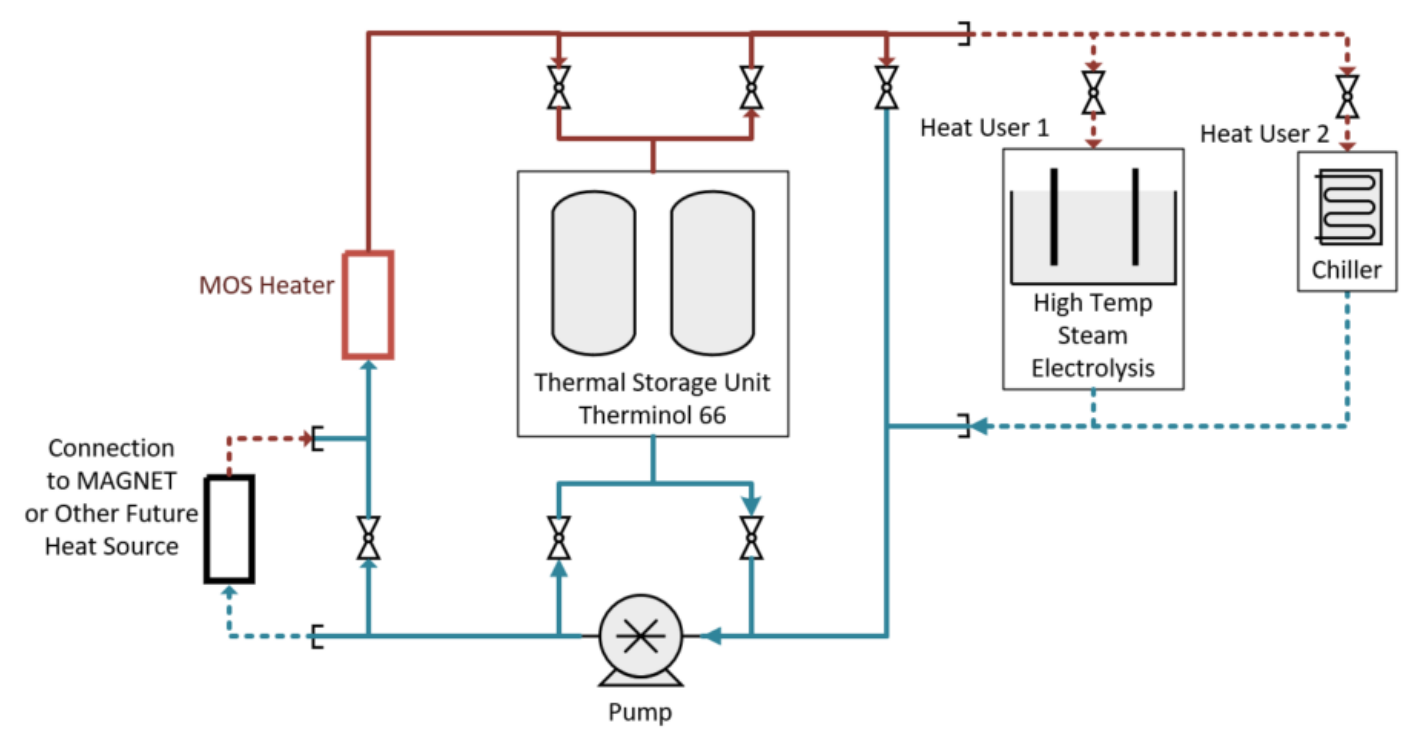

Figure 17. TEDS at INL's Energy Systems Laboratory.

Figure 18 provides a rendering of the hardware components of TEDS.

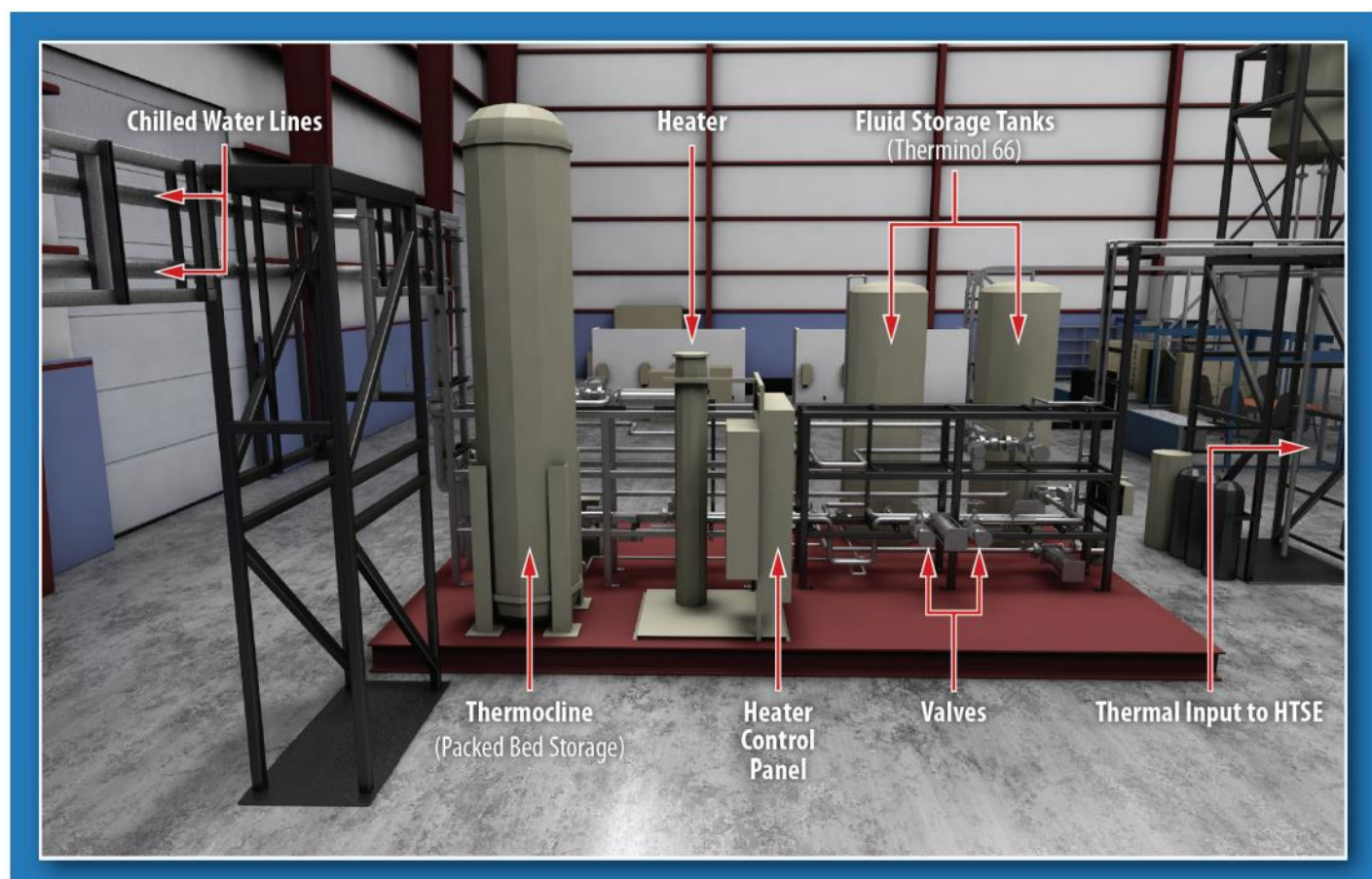

Figure 18. Rendering of TEDS at INL's Energy Systems Laboratory.

\subsection{MAGNET}

The DOE Microreactor program is currently building the Microreactor Agile Non-Nuclear Experimental Test Bed (MAGNET) at INL's Energy Systems Laboratory, which will be connected to and operated in conjunction with TEDS, thereby comprising a portion of the DETAIL facility. MAGNET includes a gas-cooled loop capable of supporting up to a $250 \mathrm{~kW}$ th heat removal from a microreactor test article. MAGNET is designed to utilize either nitrogen or helium with 
temperatures up to $650{ }^{\circ} \mathrm{C}$ and a pressure of 22 bar. As shown in Figure 19, the system combines a heat core, simulating a nuclear microreactor, with linkages envisioned in the future to a power conversion unit. A thermal link to TEDS has been designed and will be installed in fiscal year 2022. Morton et. al (2020) provide design details on MAGNET.

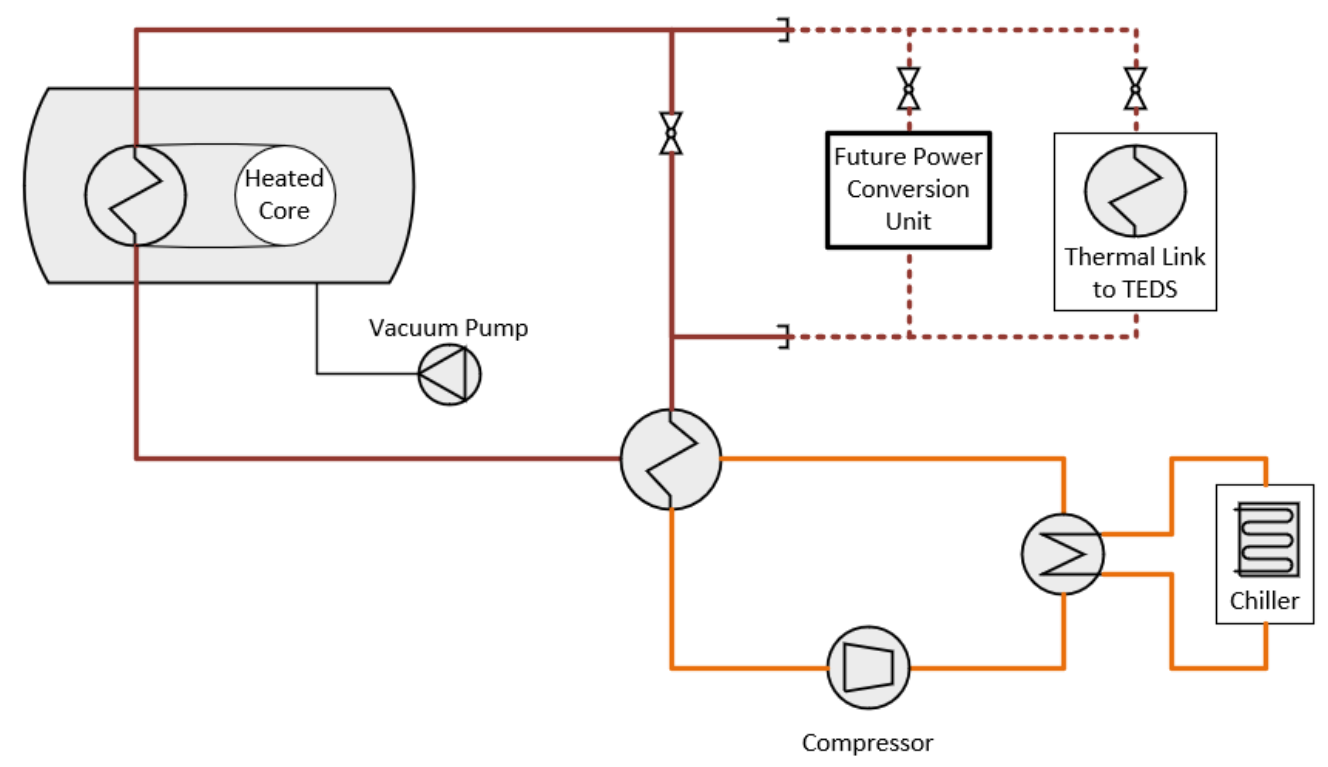

Figure 19. MAGNET at INL's Energy Systems Laboratory.

\subsection{Analytical Methodologies and Tools}

These and other applications of CTD IES may include one or more forms of thermal-, electrochemical-, or chemical-energy storage to dynamically balance multiple generation resources and loads, such as in systems with nuclear electricity generation, non-dispatchable (variable) renewable generation, and cyclical electrical loads. CTD IES may also actively manage controllable thermal and electrical loads, such as reverse-osmosis water desalination, hydrogen electrolysis, electric vehicle charging, or non-time-critical industrial processes, to balance loads with electricity and thermal resources. CTD IES tools for system design, analysis, and optimization, including Risk Analysis and Virtual Environment (RAVEN), Holistic Economic Resource Optimization Network (HERON), Tool for Economic Analysis (TEAL), and the Hybrid dynamic model repository, are open source online (https://raven.inl.gov, https://github.com/idaholab/HERON, https://github.com/idaholab/TEAL, https://github.com/idaholab/HYBRID). 


\section{Energy-Intensive Industries and Other End-Use Applications}

This section explores opportunities for nuclear CTD IES to provide heat, electricity, and hydrogen to industrial sectors to demonstrate the versatility of advanced nuclear technology beyond grid-connected power plants. Because of the smaller size, modularity, and factory production of advanced nuclear reactors, these modern technologies are expected to be more economically viable for and easier to integrate with industrial customers than large LWRs. The industries examined in this section are diverse in terms of end products and energy profiles, but each utilizes significant energy for process heat and has the potential to reduce its carbon emissions by transitioning to nuclear CTD IES technologies. The industries and subindustries examined in this section are shown in Table 1.

Table 1. Energy-intensive industries and subindustries

\begin{tabular}{lll} 
Industry & Subindustries & NAICS Code(s) \\
\hline Petroleum refining & Petroleum refineries & 324110 \\
Chemicals manufacturing & Ethyl-alcohol manufacturing & 325193 \\
& Plastics material and resin & 325211 \\
& Petrochemicals & 325110 \\
& Alkalis and chlorine & 325180 \\
& Nitrogenous fertilizer & 325311 \\
& All other basic chemicals & 325199 \\
Cement and lime production & Potash, soda ash, borates & 212391 \\
& Lime & 327410 \\
Primary metals & Cement & 327310 \\
Food production and gas supply & Wet corn milling & 331110 \\
& Gas supply & 311221 \\
Pulp and paper & Paper mills & 325120 \\
& Paperboard mills & 322121 \\
& Pulp mills & 322130
\end{tabular}

This section presents background on industrial processes, energy generation and utilization profiles for each industry, financial information, and assessments of hydrogen opportunities. Data are first presented in summary tables, and then explored in more detail in accompanying paragraphs. Additional materials are presented, including a discussion of heat relevance and graphical comparisons of industries' data. Finally, non-industrial, end-use applications are briefly discussed, and the section concludes with a summary table of nuclear CTD IES applicability across the energy-intensive industries and end-use applications.

\subsection{Energy-Intensive Industries}

The tables below introduce each industry, the characteristics of their energy generation and consumption, types of fuels used and primary processes within the industry, financial information, and hydrogen relevance. The paragraphs following each table provide more detail regarding the energy use in the industry and potential for hydrogen utilization. Industries are presented in order of total $\mathrm{CO}_{2}$ emissions, from greatest to smallest. 
The data under the "U.S. Industrial Facilities" header presents data from the 2019 U.S. Environmental Protection Agency (EPA) FLIGHT Greenhouse Gas Reporting Program (GHGRP). The dataset captures any U.S. industrial facilities with emissions greater than $25,000 \mathrm{MTCO}_{2}$ per year, accounting for over $85 \%$ of U.S. emissions.

The "Financial Information" section provides information regarding the size, expected growth, and gross margin of each industry. The data is a compilation of multiple sources and is meant to provide an overview of key financial characteristics. Historical and expected compound annual growth rate (CAGR) data show a smoothed measure of industry growth (or contraction) between two points in time. The number of publicly traded companies cell reflects the parent companies of the facilities represented in the EPA GHGRP dataset that are traded on stock exchanges (and privately held companies are excluded because their financial information is inaccessible to the public). Average gross margin represents the proportion of revenues retained after costs are incurred, and was calculated by taking a weighted average (by market capitalization) of gross margin across the publicly traded parent companies listed in the EPA GHGRP dataset.

The "Energy Information" section provides energy generation and utilization characteristics for each industry, using data from the DOE Advanced Manufacturing Office (AMO) 2014 Manufacturing Energy Consumption Survey. This section shows what proportion of direct fuel combustion, steam, and electricity are used within each industry, the types of fuels used, and the top end uses of energy.

Finally, the "Hydrogen Relevance" section provides a surface-level measure of hydrogen relevance for each industry - whether hydrogen is currently utilized within the industry and whether opportunities exist to expand hydrogen utilization. 


\subsubsection{Petroleum Refining}

\section{Petroleum Refining}

\section{U.S. Industrial Facilities (1)}

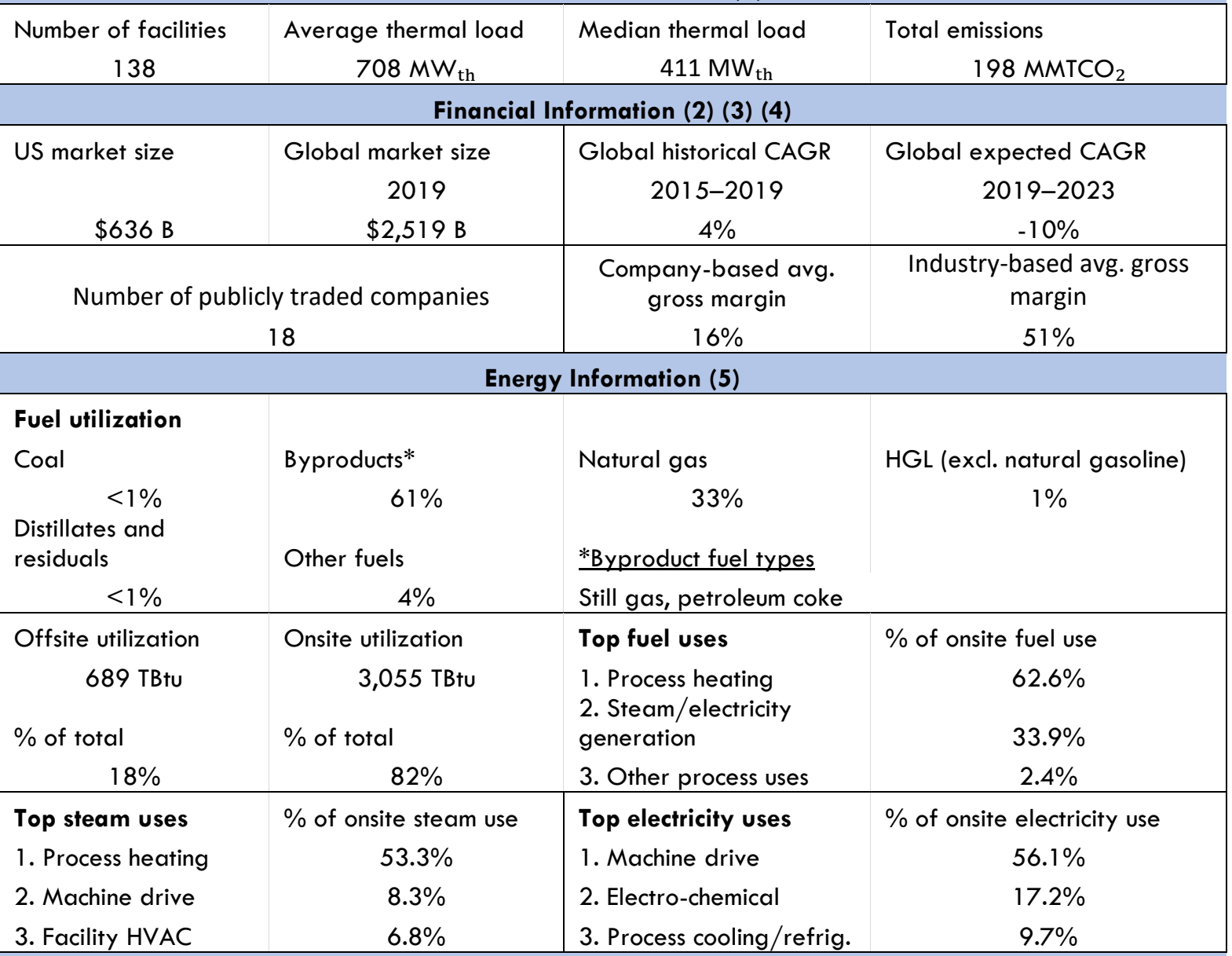

\section{Hydrogen}

Significant current utilization

Significant utilization opportunity

Sources:

1 U.S. EPA FLIGHT GHGRP 2019 data

2 U.S. Energy Information Administration, Employment and Shipments by Industry, and Income and Employment by Region 2020

3 Public financial data (as of February 5, 2021)

4 The Business Research Company, multiple reports

5 U.S. DOE AMO, Bandwidth documents and Sankey diagrams

Petroleum refineries process crude oil into higher-value products including gasoline, heating oil, and jet fuel. Sixty-one percent of fuels used within the industry are byproducts generated from refining processes. If refineries were to transition away from byproduct utilization in favor of a different energy source, the byproducts could potentially be upgraded and sold to generate an additional stream of revenue. Additionally, the industry could experience significant reductions 
in carbon emissions if it switched to a low-carbon energy source like nuclear. Carbon reductions could extend to the other carbon-emitting fuels utilized by the industry, mainly natural gas.

\subsubsection{Heat}

The petroleum refining industry has the largest thermal load of any of the studied industries larger even than the combination of the six sub-industries that make up the section of the chemical industry examined in this report. A large majority of steam used within the industry is generated onsite and used for process heating. Processes that utilize heat energy include atmospheric distillation $\left(350^{\circ} \mathrm{C}\right)$, visbreaking $\left(450^{\circ} \mathrm{C}\right)$, hydrotreating $\left(300-400^{\circ} \mathrm{C}\right)$, catalytic hydrocracking $\left(300^{\circ} \mathrm{C}\right)$, and catalytic reforming $\left(550^{\circ} \mathrm{C}\right)$ (MIT 2018; U.S. Department of Energy Office of Energy Efficiency and Renewable Energy 2015).

\subsubsection{Electricity}

While electricity comprises only a fraction $(6.5 \%)$ of onsite energy at petroleum refineries, it is still important for the overall industry, comprising $56.9 \%$ of energy input for machine drive (U.S. Department of Energy, Advanced Manufacturing Office 2018e). Fifty-eight TBtu of electricity was generated onsite through fueled $\mathrm{CHP} /$ cogeneration in the petroleum refining industry in 2014 (U.S. Department of Energy, Advanced Manufacturing Office 2018e). This generation could potentially be replaced with cogeneration from nuclear plants.

\subsubsection{Hydrogen}

Around one quarter of the world's hydrogen supply (around 10 million metric tons of hydrogen annually) is utilized to process petroleum into fuels like gasoline and diesel (Elgowainy et al. 2020; M. F. Ruth et al. 2020b). Currently, most of this hydrogen is generated through steam methane reforming, a relatively inexpensive but polluting process. While nuclear-generated hydrogen is currently more expensive than steam methane reforming, its cost is expected to drop in the future (World Nuclear Association 2021). A potential synergy exists if petroleum refineries utilize nuclear to provide heat and electricity needs at their facilities - the same nuclear reactors could also generate the hydrogen needed as a process input. Switching from steam methane reforming to nuclear-generated hydrogen would remove production cost sensitivity to natural gas prices and allow facilities to locate in areas not serviced by natural gas pipelines.

Figure 20 summarizes hydrogen supply and uses at U.S. refineries (Elgowainy et al. 2020). In the figure, SMR denotes steam methane reforming and HDT denotes hydrotreating. 


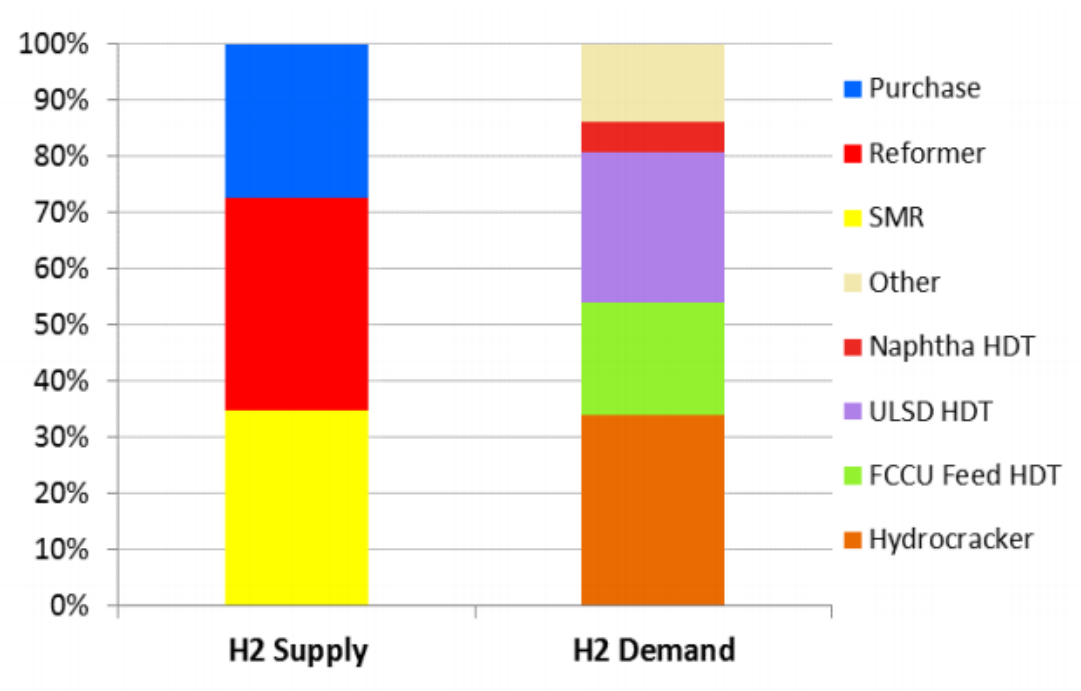

Figure 20. Summary of supply and demand for hydrogen at U.S. petroleum refineries (Elgowainy et al. 2020). 


\subsubsection{Chemicals Manufacturing}

\section{Chemicals Manufacturing}

U.S. Industrial Facilities (1)

\begin{tabular}{|c|c|c|c|}
\hline $\begin{array}{l}\text { Number of facilities } \\
472 \\
\end{array}$ & $\begin{array}{l}\text { Average thermal load } \\
150 \mathrm{MW}_{\mathrm{th}}\end{array}$ & $\begin{array}{c}\text { Median thermal load } \\
50 \mathrm{MW}_{\text {th }} \\
\end{array}$ & $\begin{array}{l}\text { Total emissions } \\
143 \mathrm{MMTCO}_{2}\end{array}$ \\
\hline \multicolumn{4}{|c|}{ Financial Information (2) (3) (4) } \\
\hline $\begin{array}{l}\text { US market size } \\
\qquad \begin{array}{r}2019 \\
\$ 530 \mathrm{~B}\end{array}\end{array}$ & $\begin{array}{c}\text { Global market size } \\
2019 \\
\$ 3,939 \mathrm{~B}\end{array}$ & $\begin{array}{c}\text { Historical CAGR (range } \\
\text { across subindustries) } \\
-6.4 \%-6.7 \%\end{array}$ & $\begin{array}{l}\text { Expected CAGR (range across } \\
\text { subindustries) }\end{array}$ \\
\hline \multicolumn{2}{|c|}{$\begin{array}{l}\text { Number of publicly traded companies } \\
\qquad 92\end{array}$} & $\begin{array}{c}\text { Company-based avg. gross } \\
\text { margin } \\
26 \%\end{array}$ & $\begin{array}{c}\text { Industry-based avg. gross } \\
\text { margin } \\
27 \% \\
\end{array}$ \\
\hline \multicolumn{4}{|c|}{ Energy Information (5) } \\
\hline \multicolumn{4}{|l|}{ Fuel utilization } \\
\hline Natural gas & Byproducts* & Coal & Distillates and residuals \\
\hline $73 \%$ & $13 \%$ & $9 \%$ & $<1 \%$ \\
\hline HGL (excl. natural gasoline) & Other fuels & *Byproduct fuel types & \\
\hline$<1 \%$ & $4 \%$ & Waste gas & \\
\hline Offsite utilization & Onsite utilization & $\begin{array}{l}\text { Top fuel uses } \\
\text { 1. Steam/electricity }\end{array}$ & $\%$ of onsite fuel use \\
\hline 1,806 TBtu & 2,736 TBtu & generation & $57.7 \%$ \\
\hline$\%$ of total & $\%$ of total & 2. Process heating & $31.8 \%$ \\
\hline $40 \%$ & $60 \%$ & 3. Machine drive & $4.1 \%$ \\
\hline Top steam uses & $\begin{array}{l}\% \text { of onsite steam } \\
\text { use }\end{array}$ & Top electricity uses & $\%$ of onsite electricity use \\
\hline 1. Process heating & $53.3 \%$ & 1. Machine drive & $56.1 \%$ \\
\hline 2. Machine drive & $8.3 \%$ & $\begin{array}{l}\text { 2. Electro-chemical } \\
\text { 3. Process cooling and }\end{array}$ & $17.2 \%$ \\
\hline 3. Facility HVAC & $6.8 \%$ & refrigeration & $9.7 \%$ \\
\hline \multicolumn{4}{|c|}{ Hydrogen } \\
\hline \multirow[t]{2}{*}{ Not applicable } & No current utilization & Limited current utilization & Significant current utilization \\
\hline & No utilization & $\begin{array}{l}\text { Limited utilization } \\
\text { opportunity }\end{array}$ & $\begin{array}{l}\text { Significant utilization } \\
\text { opportunity }\end{array}$ \\
\hline
\end{tabular}

Sources:

1 U.S. EPA, FLIGHT GHGRP 2019 data

2 U.S. Energy Information Administration, Employment and Shipments by Industry, and Income and Employment by Region 2020

3 Public financial data (as of February 5, 2021)

4 The Business Research Company, multiple reports

5 U.S. DOE AMO, Bandwidth documents and Sankey diagrams 
The chemical industry is both large and diverse, producing tens of thousands of products with various heat needs. This analysis examines multiple chemicals and products: ethyl alcohol, plastics and resin, petrochemicals, alkalis and chlorine, nitrogenous fertilizers, potash, soda ash and borates, and other basic chemicals.

\subsubsection{Heat}

The chemical industry requires heat for a wide variety of processes in the production of many different chemicals. Steam is utilized heavily within the industry and comprises $43.6 \%$ of input energy used for processes and non-processes. Process heating is the largest energy user within the industry, consuming 1,622 TBtu annually (U.S. Department of Energy, Advanced Manufacturing Office 2018b).

\subsubsection{Electricity}

Electricity comprises a much smaller share of overall energy inputs $(17.3 \%)$ and is used primarily for machine drive. Most electricity is generated offsite, with $27.2 \%$ of electricity being generated onsite through CHP/cogeneration (U.S. Department of Energy, Advanced Manufacturing Office 2018b).

\subsubsection{Hydrogen}

Hydrogen is an important chemical precursor within the chemical industry. For example, the petrochemical industry utilizes hydrogen to produce methanol, the fertilizer industry reacts nitrogen and hydrogen to produce ammonia, and the personal care industry uses hydrogen to saturate fats (Ramachandran and Menon 1998). In many cases, the hydrogen used in the chemical industry is produced via steam methane reforming, meaning that nuclear-generated hydrogen could support decarbonization in the sector. 


\subsubsection{Cement and Lime Production}

\begin{tabular}{|c|c|c|c|}
\hline \multicolumn{4}{|c|}{ Cement and Lime Production } \\
\hline \multicolumn{4}{|c|}{ U.S. Industrial Facilities (1) (a) } \\
\hline $\begin{array}{c}\text { Number of facilities } \\
141\end{array}$ & $\begin{array}{c}\text { Average thermal load } \\
338 \mathrm{MW}_{\text {th }}\end{array}$ & $\begin{array}{l}\text { Median thermal load } \\
250 \mathrm{MW}_{\text {th }}\end{array}$ & $\begin{array}{l}\text { Total emissions } \\
\qquad 90 \mathrm{MMTCO}_{2}\end{array}$ \\
\hline \multicolumn{4}{|c|}{ Financial Information (2) (3) (4) (b) } \\
\hline US market size & $\begin{array}{c}\text { Global market size } \\
2018 \\
\$ 439 \mathrm{~B}\end{array}$ & $\begin{array}{c}\text { Historical CAGR } \\
\qquad \begin{array}{c}2014-2018 \\
7 \% \\
\end{array}\end{array}$ & $\begin{array}{l}\text { Expected CAGR } \\
\qquad \begin{array}{c}2018-2022 \\
10 \% \\
\end{array}\end{array}$ \\
\hline Number of publicly & raded companies & $\begin{array}{c}\text { Company-based avg. gross } \\
\text { margin } \\
33 \%\end{array}$ & $\begin{array}{c}\text { Industry-based avg. gross } \\
\text { margin } \\
21 \%\end{array}$ \\
\hline \multicolumn{4}{|c|}{ Energy Information (5) (c) } \\
\hline \multicolumn{4}{|l|}{ Fuel utilization } \\
\hline $\begin{array}{l}\text { Coal } \\
\qquad 61 \% \\
\text { Distillates and residuals } \\
2 \%\end{array}$ & $\begin{array}{l}\text { Byproducts* } \\
\qquad 15 \% \\
\text { Other fuels } \\
10 \% \\
\end{array}$ & $\begin{array}{l}\text { Natural gas } \\
\qquad 8 \% \\
\text { *Byproduct fuel types } \\
\text { Petroleum coke, waste oils/ta }\end{array}$ & $\begin{array}{l}\text { Coke and breeze } \\
\qquad 5 \% \\
\text { and waste materials }\end{array}$ \\
\hline $\begin{array}{l}\text { Offsite utilization } \\
111 \text { TBtu } \\
\% \text { of total } \\
30 \%\end{array}$ & $\begin{array}{l}\text { Onsite utilization } \\
\qquad 260 \mathrm{TBtu} \\
\% \text { of total } \\
70 \%\end{array}$ & $\begin{array}{l}\text { Top fuel uses } \\
\text { 1. Process heating } \\
\text { 2. Steam/electricity } \\
\text { generation } \\
\text { 3. Onsite transportation (tie) } \\
\text { 3. Machine drive (tie) }\end{array}$ & $\begin{array}{l}\% \text { of onsite fuel use } \\
95.4 \% \\
3.1 \% \\
0.8 \% \\
0.8 \%\end{array}$ \\
\hline $\begin{array}{l}\text { Top steam uses } \\
\text { 1. Process heating } \\
\text { 2. Facility HVAC (tie) } \\
\text { 3. Other process uses (tie) }\end{array}$ & $\begin{array}{l}\text { \% of onsite steam use } \\
33.3 \% \\
16.7 \% \\
16.7 \% \\
\end{array}$ & $\begin{array}{l}\text { Top electricity uses } \\
\text { 1. Machine drive } \\
\text { 2. Process heating } \\
\text { 3. Process cooling and } \\
\text { refrigeration }\end{array}$ & $\begin{array}{l}\% \text { of onsite electricity use } \\
66.7 \% \\
17.9 \% \\
5.1 \%\end{array}$ \\
\hline \multicolumn{4}{|c|}{ Hydrogen } \\
\hline Not applicable & No current utilization & Limited current utilization & $\begin{array}{l}\text { Significant current } \\
\text { utilization }\end{array}$ \\
\hline & No utilization & $\begin{array}{l}\text { Limited utilization } \\
\text { opportunity }\end{array}$ & $\begin{array}{l}\text { Significant utilization } \\
\text { opportunity }\end{array}$ \\
\hline
\end{tabular}

Data type:

a Cement and lime

b Cement and concrete

c Cement manufacturing

Sources:

1 U.S. EPA, FLIGHT GHGRP 2019 data

2 U.S. Energy Information Administration, Employment and Shipments by Industry, and Income and Employment by Region 2020

3 Public financial data (as of February 5 2021)

4 The Business Research Company, multiple reports

5 U.S. DOE AMO, Bandwidth documents and Sankey diagrams 
Lime and cement are important materials for construction projects and decorative applications. Lime is utilized across multiple industries - in the production of glass, plastics, chemicals, paper products, and more. Cement is used in concrete and is produced by combining limestone, sand, and clay under high temperatures.

\subsubsection{Heat}

Process heating for cement manufacture consumes the largest percentage of onsite energy input of all the studied industries (83.2\%) (U.S. Department of Energy, Advanced Manufacturing Office $2018 \mathrm{a})$. The vast majority $(96.5 \%$ ) of process heating energy is provided by direct consumption of fossil fuels, creating carbon emissions. Given that the primary fuel utilized within the industry is coal (U.S. Department of Energy, Advanced Manufacturing Office 2018a), there exists a large opportunity to decarbonize the sector. However, manufacturing processes for lime and cement require temperatures of $1,200-1,500^{\circ} \mathrm{C}$ for the heating kiln (McMillan et al. 2016). These temperatures cannot be directly provided even by very high-temperature reactors (VHTRs) -topping heat would therefore be required if nuclear reactors are utilized for heat within the industry.

Steam is used minimally within the industry, with only 6 TBtu of steam generated annually (U.S. Department of Energy, Advanced Manufacturing Office 2018a).

\subsubsection{Electricity}

Electricity comprises $13.1 \%$ of input energy within the cement manufacture industry and is used primarily for machine drive and process heating. The industry generates $97.4 \%$ of its electricity offsite (U.S. Department of Energy, Advanced Manufacturing Office 2018a).

\subsubsection{Hydrogen}

Hydrogen can be utilized in several ways within the cement industry. To reduce carbon emissions, natural gas could be replaced or supplemented with hydrogen combustion to provide the high temperatures needed in production processes. Some cement companies have announced plans to introduce hydrogen to their fuel mix, but currently the opportunity is not widely utilized within the industry (CEMEX 2021). Hydrogen can also be used to produce synthetic fuels and plastics when combined with $\mathrm{CO}_{2}$ captured from cement plants (Perilli 2020). 


\subsubsection{Primary Metals Manufacturing}

\section{Primary Metals Manufacturing}

U.S. Industrial Facilities (1)

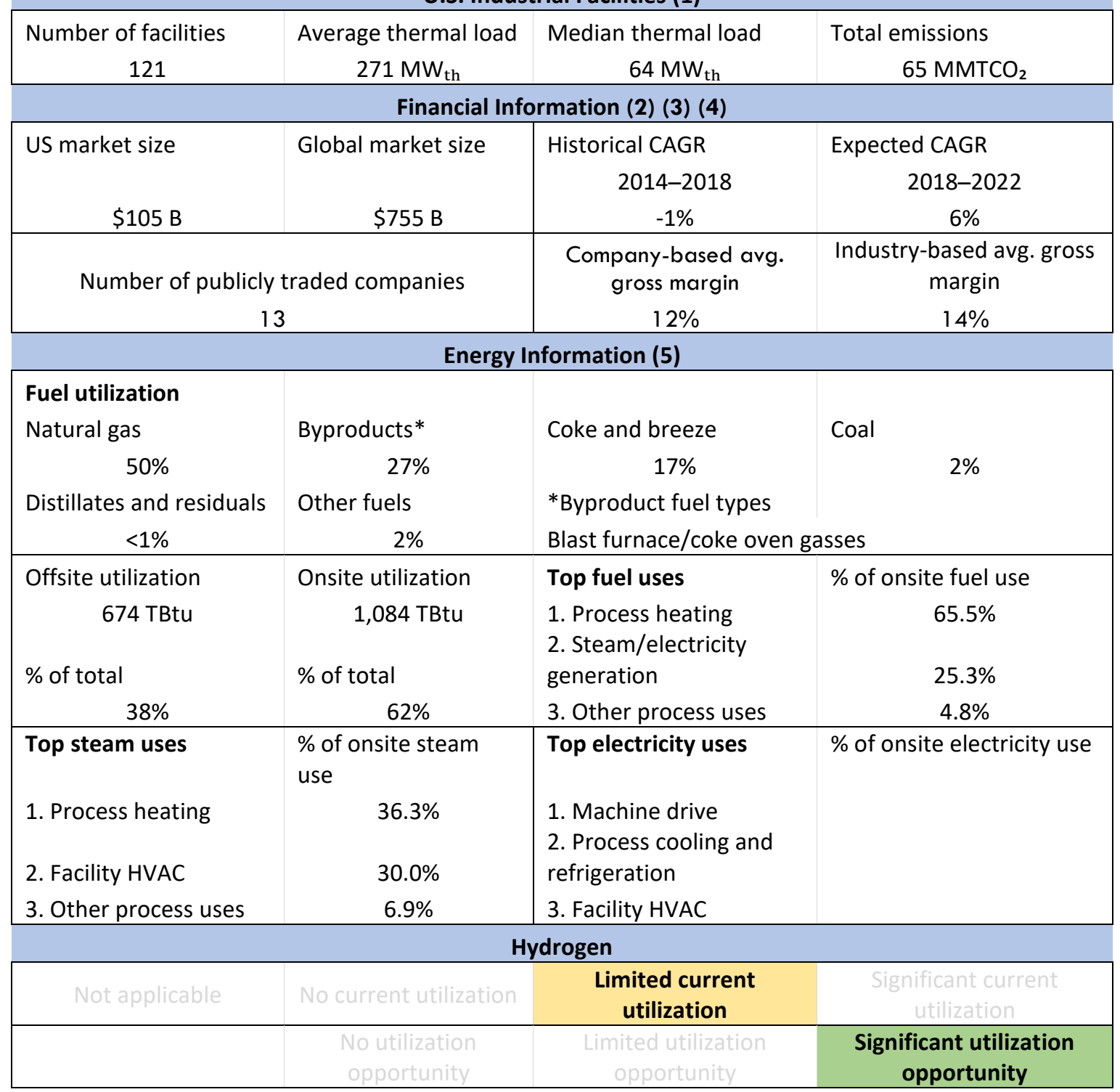

Sources:

\section{U.S. EPA, FLIGHT GHGRP 2019 data}

2 U.S. Energy Information Administration, Employment and Shipments by Industry, and Income and Employment by Region 2020

3 Public financial data (as of February 5, 2021)

4 The Business Research Company, multiple reports

5 U.S. DOE AMO, Bandwidth documents and Sankey diagrams

Iron and steel mills conduct a variety of industrial processes on raw materials to prepare them for sale or further modification. Processes are carried out at high temperatures, from $1,100^{\circ} \mathrm{C}$ to above $2,200^{\circ} \mathrm{C}$ (McMillan et al. 2016). While these temperatures are too high to be met by nuclear technologies without the addition of topping heat, electric arc furnaces are experiencing greater adoption throughout the industry. The large electricity needs of arc furnaces could 
potentially be met with nuclear technologies, and hydrogen required for processing of directreduced iron could be provided by nuclear-powered HTE (McMillan et al. 2016).

\subsubsection{Heat}

As stated above, the iron and steel industry has substantial high-temperature heat needs. Transitioning away from fossil fuels towards nuclear or nuclear-produced hydrogen could help reduce emissions and protect against natural gas price variability. Processes that require heat within the industry include ore agglomeration and cokemaking $\left(1100-1350^{\circ} \mathrm{C}\right)$, and hot rolling (800-1200+ ${ }^{\circ} \mathrm{C}$ ) (Campbell 2013). Many of the heat needs required by the iron and steel industry are higher than the temperatures offered from nuclear reactors - even VHTRs. Topping heat may therefore be required to reach necessary temperatures and could be provided via electricity or the combustion of nuclear-generated hydrogen.

Steam makes up a small percentage of the energy used within the industry $(14.8 \%)$, is primarily generated onsite, and is used primarily for process heating and facility HVAC (U.S. Department of Energy, Advanced Manufacturing Office 2018d). The steam generated via conventional boilers and $\mathrm{CHP} /$ cogeneration could also be generated by nuclear reactors, reducing dependency on fossil fuels and reducing industry emissions.

\subsubsection{Electricity}

Electricity comprises $22.2 \%$ of onsite energy consumption in the industry and is used primarily for process heating and machine drive. A large majority of electricity (93.8\%) is generated offsite (U.S. Department of Energy, Advanced Manufacturing Office 2018d).

\subsubsection{Hydrogen}

The steel industry currently accounts for 7-9\% of global $\mathrm{CO}_{2}$ emissions (World Nuclear Association 2021) and has an opportunity to reduce its carbon intensity by switching from carbon to hydrogen as the reducing agent. Hydrogen metallurgy can also reduce costs by increasing efficiency and reducing coke ratio (Liu et al. 2021). Advanced nuclear plants have the opportunity to simultaneously provide the heat, electricity, and hydrogen needs of the iron and steel industry. 


\subsubsection{Food Production and Gas Supply}

For this report, the food production industry and gas supply industry are combined because a significant proportion of total gas supply is used for food and beverage production processes, such as carbonizing, freezing, and preserving. Many food, beverage, and gas facilities are colocated or linked by infrastructure for these purposes. The food production industry is represented by wet corn milling, because of its large $\mathrm{CO}_{2}$ emissions and inclusion in McMillan et al. (2016).

\begin{tabular}{|c|c|c|c|}
\hline \multicolumn{4}{|c|}{ Food Production and Gas Supply } \\
\hline \multicolumn{4}{|c|}{ U.S. Industrial Facilities (1) (a) } \\
\hline $\begin{array}{c}\text { Number of facilities } \\
98\end{array}$ & $\begin{array}{c}\text { Average thermal load } \\
112 \mathrm{MW}_{\text {th }}\end{array}$ & $\begin{array}{c}\text { Median thermal load } \\
121 \mathrm{MW}_{\text {th }}\end{array}$ & $\begin{array}{l}\text { Total emissions } \\
45 \mathrm{MMTCO}_{2}\end{array}$ \\
\hline \multicolumn{4}{|c|}{ Financial Information (2) (3) (4) (5) } \\
\hline $\begin{array}{l}\text { US market size (a) } \\
\$ 20 M\end{array}$ & $\begin{array}{l}\text { Global market size } \\
\text { (b) } \\
2020 \\
\$ 5,839 \mathrm{~B} \\
\end{array}$ & $\begin{array}{c}\text { Historical CAGR (b) } \\
2015-2019 \\
5.7 \% \\
\end{array}$ & $\begin{array}{c}\text { Expected CAGR (b) } \\
2019-2023 \\
6.1 \% \\
\end{array}$ \\
\hline $\begin{array}{l}\text { Number of publicly tra } \\
6 \\
\end{array}$ & led companies (a) & $\begin{array}{c}\text { Company-based avg. } \\
\text { gross margin (a) } \\
22 \% \\
\end{array}$ & $\begin{array}{c}\text { Industry-based avg. } \\
\text { gross margin (b) } \\
32 \% \\
\end{array}$ \\
\hline \multicolumn{4}{|c|}{ Energy Information (6) (b) } \\
\hline \multicolumn{4}{|l|}{ Fuel utilization } \\
\hline $\begin{array}{l}\text { Natural gas } \\
\qquad 69 \%\end{array}$ & $\begin{array}{l}\text { Coal } \\
13 \%\end{array}$ & $\begin{array}{l}\text { Biomass } \\
\qquad 11 \%\end{array}$ & $\begin{array}{l}\text { Distillates and residuals } \\
\qquad 3 \%\end{array}$ \\
\hline HGL (excl. natural gasoline) & Byproducts* & Other fuels & *Byproduct fuel types \\
\hline$<1 \%$ & $<1 \%$ & $3 \%$ & Waste gas \\
\hline Offsite utilization & Onsite utilization & $\begin{array}{l}\text { Top fuel uses } \\
\text { 1. Steam/electricity }\end{array}$ & $\%$ of onsite fuel use \\
\hline 868 TBtu & 894 TBtu & generation & $68.3 \%$ \\
\hline$\%$ of total & $\%$ of total & 2. Process heating & $21.4 \%$ \\
\hline $49 \%$ & $51 \%$ & 3. Facility HVAC & $4.6 \%$ \\
\hline Top steam uses & $\begin{array}{l}\% \text { of onsite steam } \\
\text { use }\end{array}$ & Top electricity uses & $\begin{array}{l}\% \text { of onsite electricity } \\
\text { use }\end{array}$ \\
\hline 1. Process heating & $55.4 \%$ & $\begin{array}{l}\text { 1. Machine drive } \\
\text { 2. Process cooling and }\end{array}$ & $45.5 \%$ \\
\hline 2. Facility HVAC & $8.1 \%$ & refrigeration & $26.9 \%$ \\
\hline 3. Other process uses & $6.7 \%$ & 3. Facility HVAC & $9.4 \%$ \\
\hline \multicolumn{4}{|c|}{ Hydrogen } \\
\hline Not applicable & No current utilization & $\begin{array}{c}\text { Limited current } \\
\text { utilization }\end{array}$ & $\begin{array}{c}\text { Significant current } \\
\text { utilization }\end{array}$ \\
\hline & $\begin{array}{l}\text { No utilization } \\
\text { opportunity }\end{array}$ & $\begin{array}{c}\text { Limited utilization } \\
\text { opportunity }\end{array}$ & $\begin{array}{c}\text { Significant utilization } \\
\text { opportunity }\end{array}$ \\
\hline
\end{tabular}

Data type:

a Wet corn milling and gas supply

b Food and beverage

Sources:

1 U.S. EPA, FLIGHT GHGRP 2019 data 
2 U.S. Energy Information Administration, Employment and Shipments by Industry, and Income and Employment by Region 2020

3 Public financial data (as of February 5 2021)

4 The Business Research Company, multiple reports

5 Cision PR Newswire

6 U.S. DOE AMO, Bandwidth documents and Sankey diagrams

McMillan et al. (2016) provide information regarding the wet corn milling industry, stating that it is very energy intensive as compared to other food manufacturing processes. This industry prepares corn grain to produce corn oil, fiber, and starch, utilizing temperatures around $175^{\circ} \mathrm{C}$ for steeping and drying.

The gas supply industry produces industrial organic and inorganic gasses including helium, hydrogen, oxygen, chlorofluorocarbons and more. Energy is used within the industry for process heating, process cooling, and machine drive.

\subsubsection{Heat}

As stated above, the wet corn milling industry utilizes heat to dry and prepare corn kernels for separation into oils, starches, fibers, and proteins. While the heat required by the industry is relatively low temperature, many processes take a significant amount of time - one reason why the industry is energy intensive compared to other food industries. Because of the low temperature heat needs, energy could be provided by any nuclear reactor design with let-down of delivered heat. Heat is also used in the gas supply industry to facilitate many processes; for example, in high-temperature steam electrolysis to produce hydrogen.

\subsubsection{Electricity}

Electricity is primarily used for machine drive and process cooling and refrigeration within the wet corn milling industry. In the gas supply industry, electricity is primarily utilized for machine drive - for example, gas compressors (U.S. Energy Information Administration 2021). Within the food and beverage industry as a whole, electricity is primarily generated offsite $(98 \%)$ and is utilized primarily for machine drive and process cooling (U.S. Department of Energy, Advanced Manufacturing Office 2018c).

\subsubsection{Hydrogen}

Hydrogen plays a large role in the gas supply industry, where it is both a final product and a chemical precursor. Hydrogen is produced via multiple processes within the industry, primarily steam methane reforming of natural gas. Hydrogen production and uses are covered in more depth throughout the report. 


\subsubsection{Pulp and Paper Manufacturing}

\section{Pulp and Paper Manufacturing}

U.S. Industrial Facilities (1) (a)

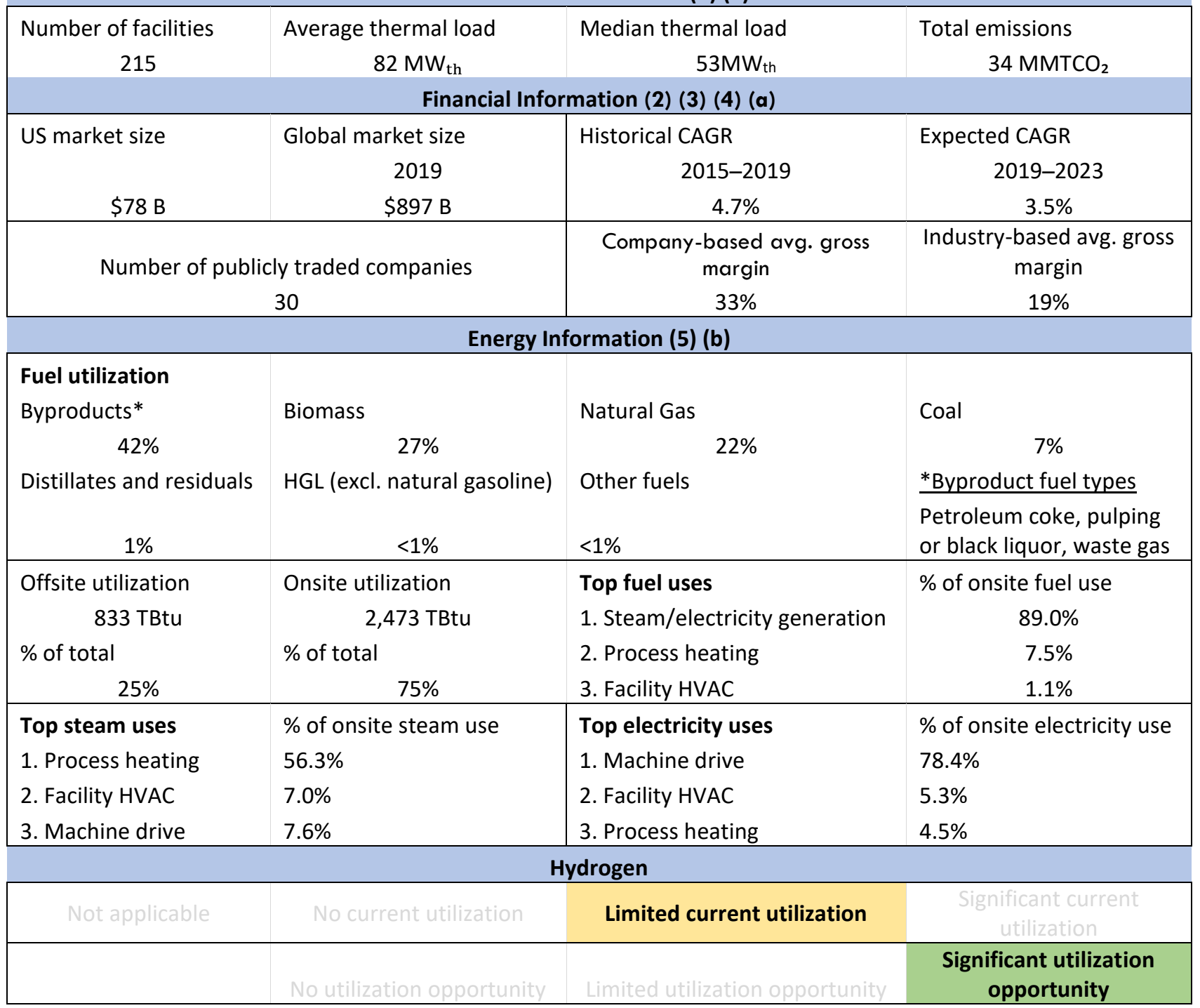

Data type:

a Pulp and paper

b Forest products

Sources:

1 U.S. EPA, FLIGHT GHGRP 2019 data

2 U.S. Energy Information Administration, Employment and Shipments by Industry, and Income and Employment by Region 2020

3 Public financial data (as of February 5, 2021)

4 The Business Research Company, multiple reports

5 U.S. DOE AMO, Bandwidth documents and Sankey diagrams 
The manufacture of paper products involves both mechanical and chemical processes, many of which require heat as an energy input. Similar to the petroleum industry, many manufacturers of paper products or intermediaries combust byproducts as a heat source - byproducts that could potentially otherwise be upgraded and sold to generate additional revenue. In 2014, around $42 \%$ of fuels utilized onsite were byproducts, the vast majority of which $(95.2 \%)$ were pulping or black liquor (toxic byproducts of pulp manufacture). Byproducts such as black liquor could be upgraded to jet fuel or other products that are energy-dense, shippable, and storable (cellulosic products in their basic form deteriorate if stored outside or shipped). Black liquor can be upgraded to syngas via gasification and further upgraded to dimethyl ether, liquid fuels, methanol, ethanol, and other mixed alcohols (National Energy Technology Laboratory n.d.). These synergies could potentially double biomass byproduct sales, reduce the need for refractory maintenance, and allow the industry to sell to other higher-value industries (Dale 2021; National Energy Technology Laboratory n.d.).

\subsubsection{Heat}

While the pulp and paper industry has significant heat needs, its share of energy input utilized for process heating is the smallest of the industries studied $(37.0 \%)$. The majority of heat energy needs are met with steam $(80.3 \%)$, with fuels providing a smaller percentage $(17.7 \%)$, and electricity providing the remainder. Onsite steam generation is largely completed through $\mathrm{CHP} /$ cogeneration $(82.1 \%)$ with the remainder being provided by conventional boilers. A small amount of steam (3.6\% of total steam generation) is generated offsite. The paper industry requires relatively low-temperature heat inputs, with processes utilizing sub- $300^{\circ} \mathrm{C}$ heat (MIT 2018).

\subsubsection{Electricity}

Electricity comprises about a sixth of energy utilized onsite ( $16.1 \%$ of total energy input) and is primarily utilized for machine drive. Most electricity is generated offsite $(66.2 \%)$, and nearly all electricity generated onsite is produced through CHP/cogeneration (97.4\%).

\subsubsection{Hydrogen}

As stated previously, the pulp and paper industry heavily utilizes process byproducts (namely black liquor) as fuels. As a whole, the industry produces over 200 million tons of black liquor a year, which could subsequently be gasified to produce syngas and then combined with hydrogen and used as a feedstock in the production of drop-in petrol or other high-quality fuels (Jafri et al. 2020). This shows a clear opportunity for co-location of nuclear plants, which could provide the heat, electricity, and hydrogen needed by pulp and paper plants to not only produce their primary products, but also commercialize byproducts for additional revenue. 


\subsection{Cross-Industry Analysis}

\subsubsection{Emissions, Facilities and Thermal Needs}

Figure 21 compares the size of subindustries using three metrics: average thermal load per facility, number of facilities, and total subindustry emissions. While each subindustry is relevant for integration with nuclear CTD IES technologies, the larger subindustries present larger opportunities (e.g., more reactors/larger reactors).

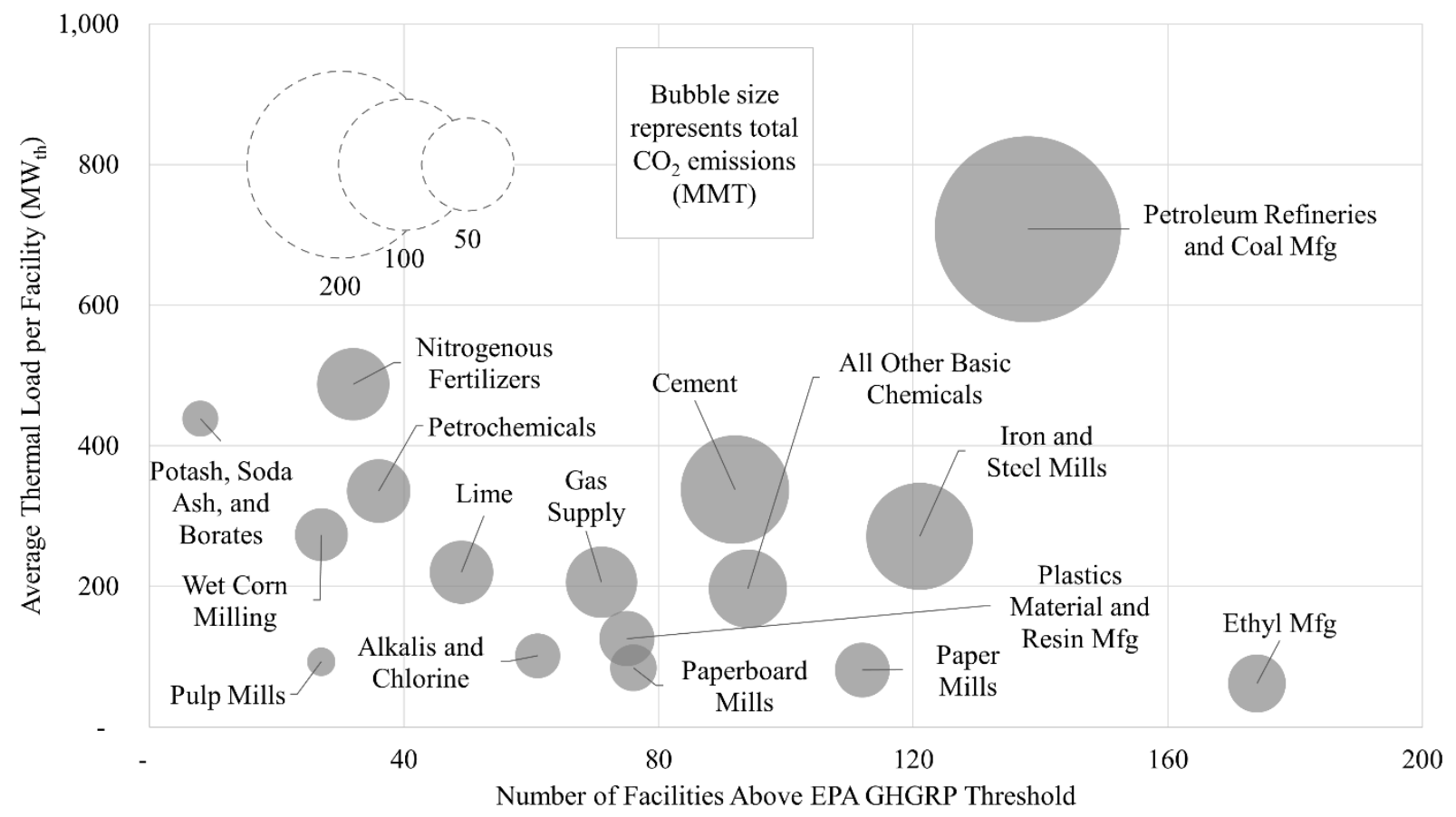

Figure 21. Emissions, energy, and facility data for subindustries

\subsubsection{Industry Energy Histograms}

To compare the number and heat demand of facilities within each industry, facilities were binned to create industry-level histograms. These histograms show, for example, whether an industry has many small facilities, many large facilities, or a more even distribution. Histograms are presented below: 
Petroleum Refineries

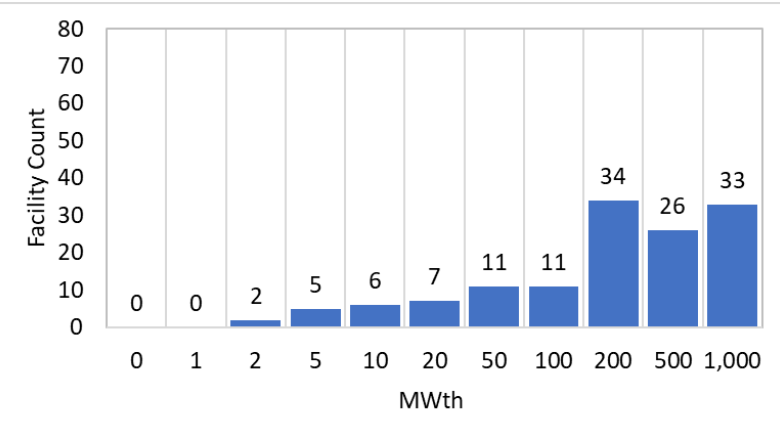

Ethyl Manufacturing

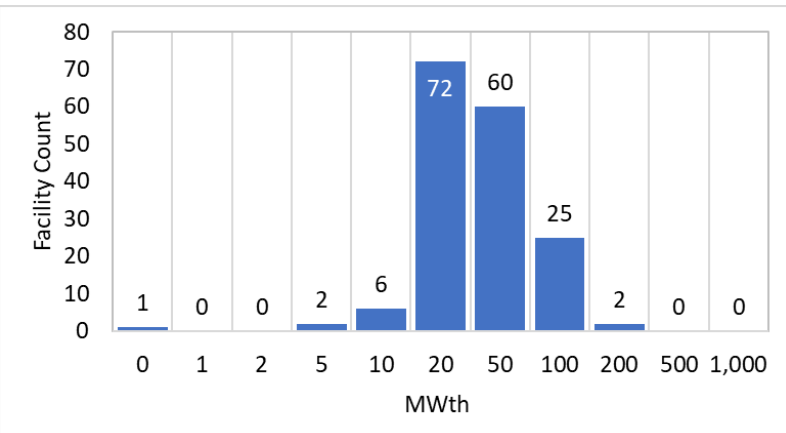

Plastics and Resin

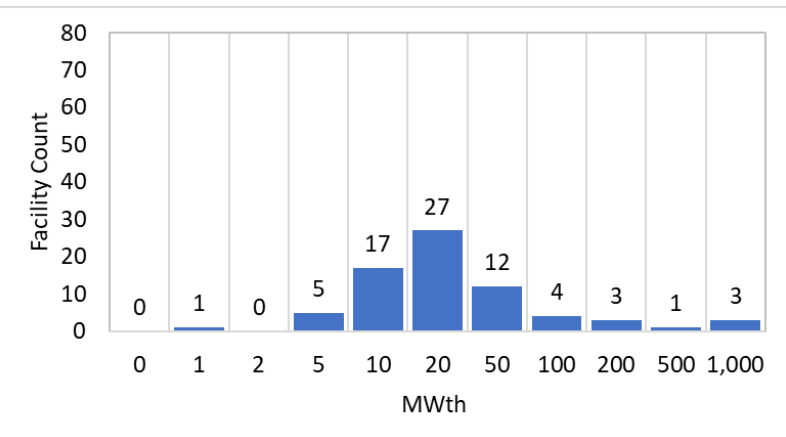

Petrochemicals

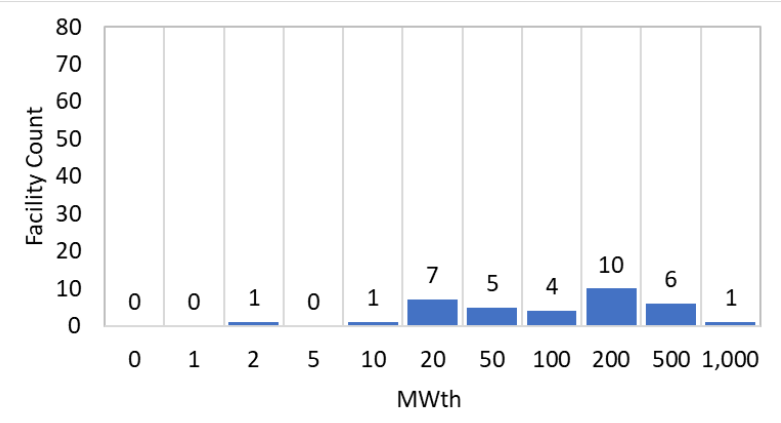

Alkalis and Chlorine

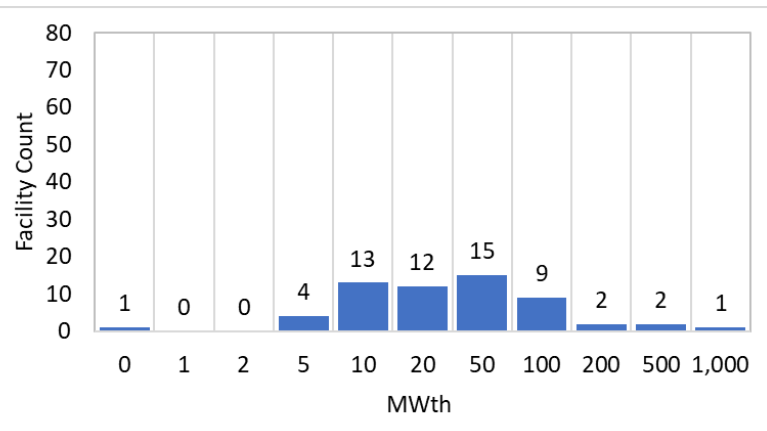

\section{Nitrogenous Fertilizers}

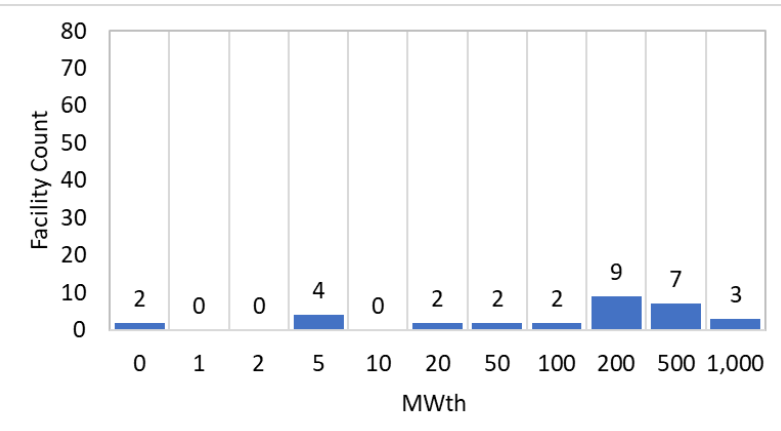

\section{Other Basic Chemicals}

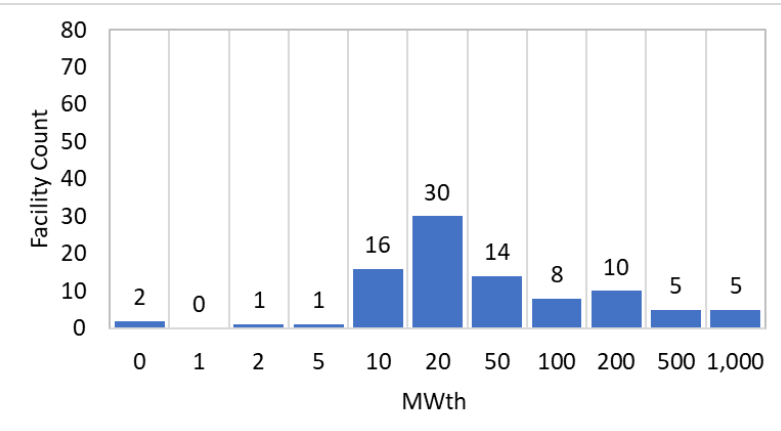

Potash, Soda Ash, and Borates

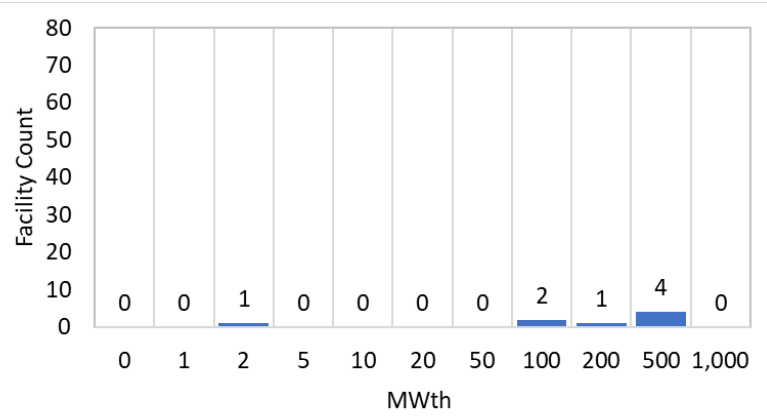




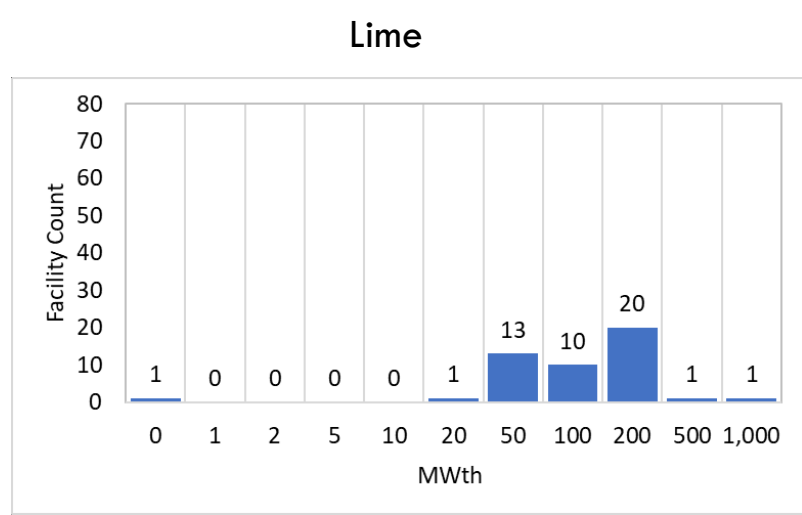

\section{Cement}

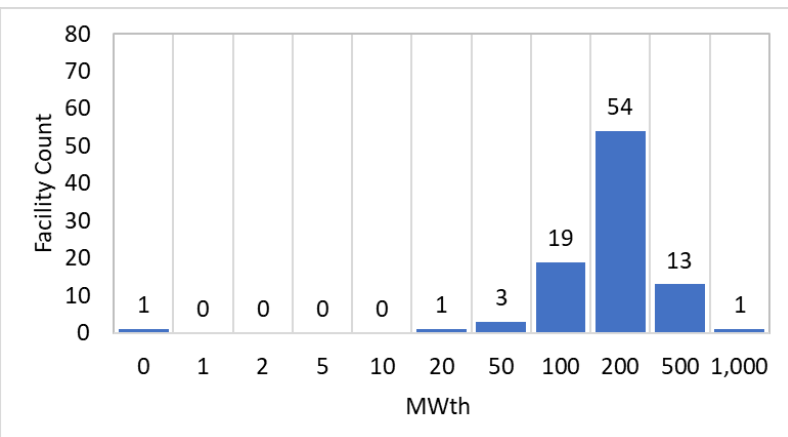

Iron and Steel Mills

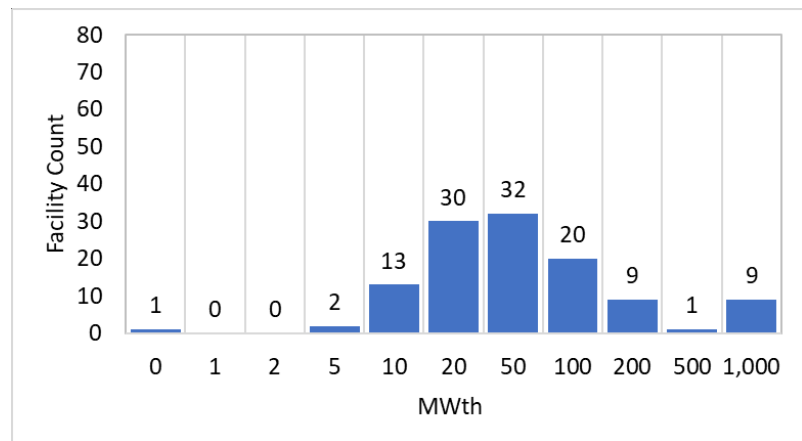

Wet Corn Milling

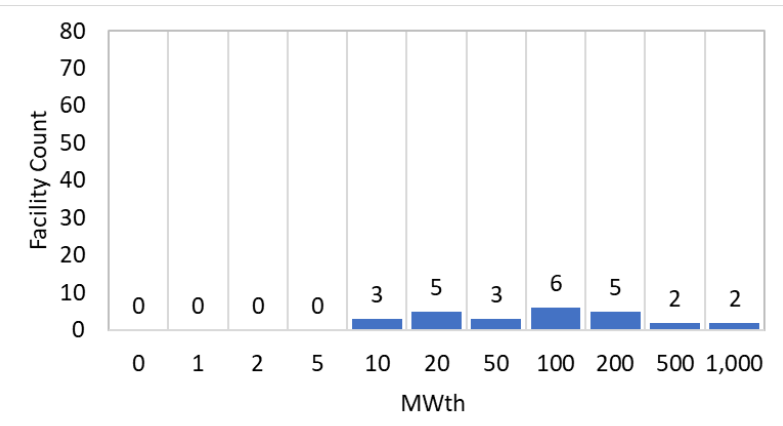

Gas Supply

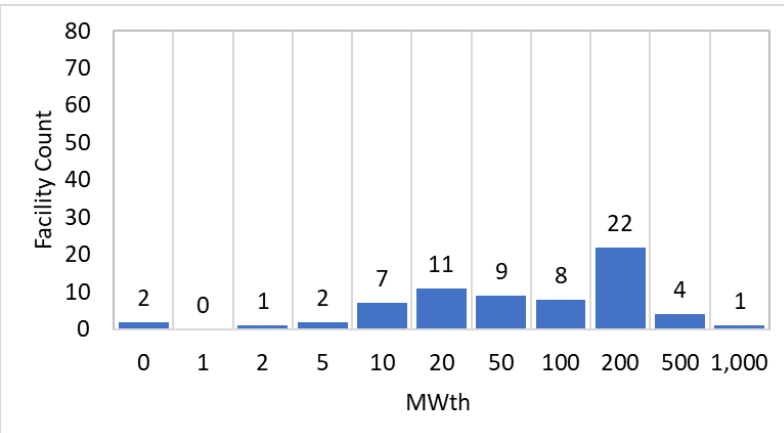

\section{Paper Mills}

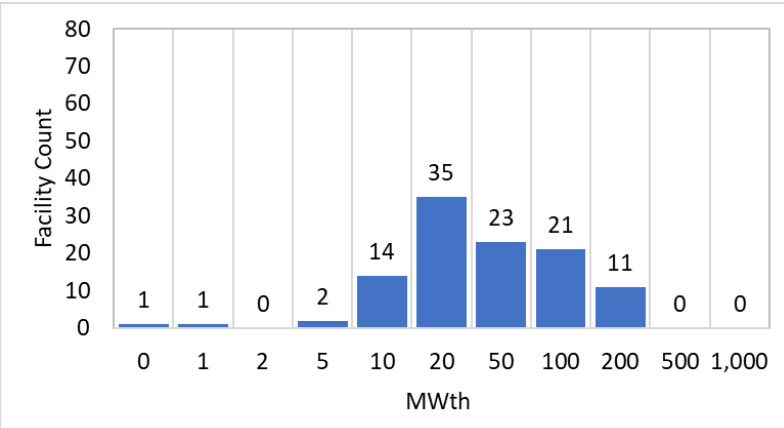

\section{Paperboard Mills}

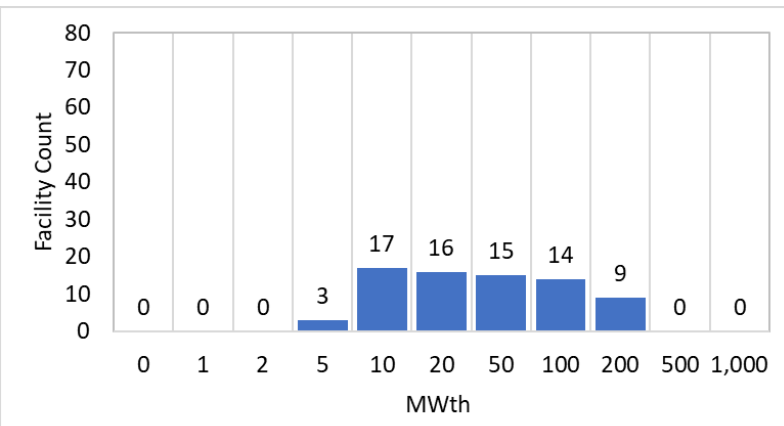

\section{Pulp Mills}

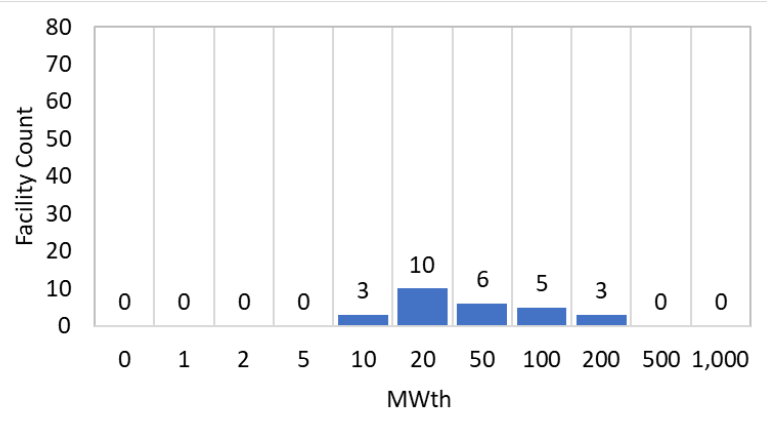




\subsubsection{Potential Number of Reactors}

Figure 22 shows the potential number of nuclear reactors for industrial facilities based on the histograms of heat demand and DOE's reactor size categories discussed in Section 2 (converted from electric capacity to approximate thermal capacity). The potential number of microreactors reflects the number of industrial facilities with heat demand less than $35 \mathrm{MW}_{\text {th }}$, the bars for small modular reactors reflect facilities between 35 and $530 \mathrm{MW}_{\text {th }}$ and the bars for full-sized reactors reflect facilities above $530 \mathrm{MW}_{\text {th. }}$. The figure indicates that there is a considerable market for nuclear reactors of each size category to support industrial decarbonization.

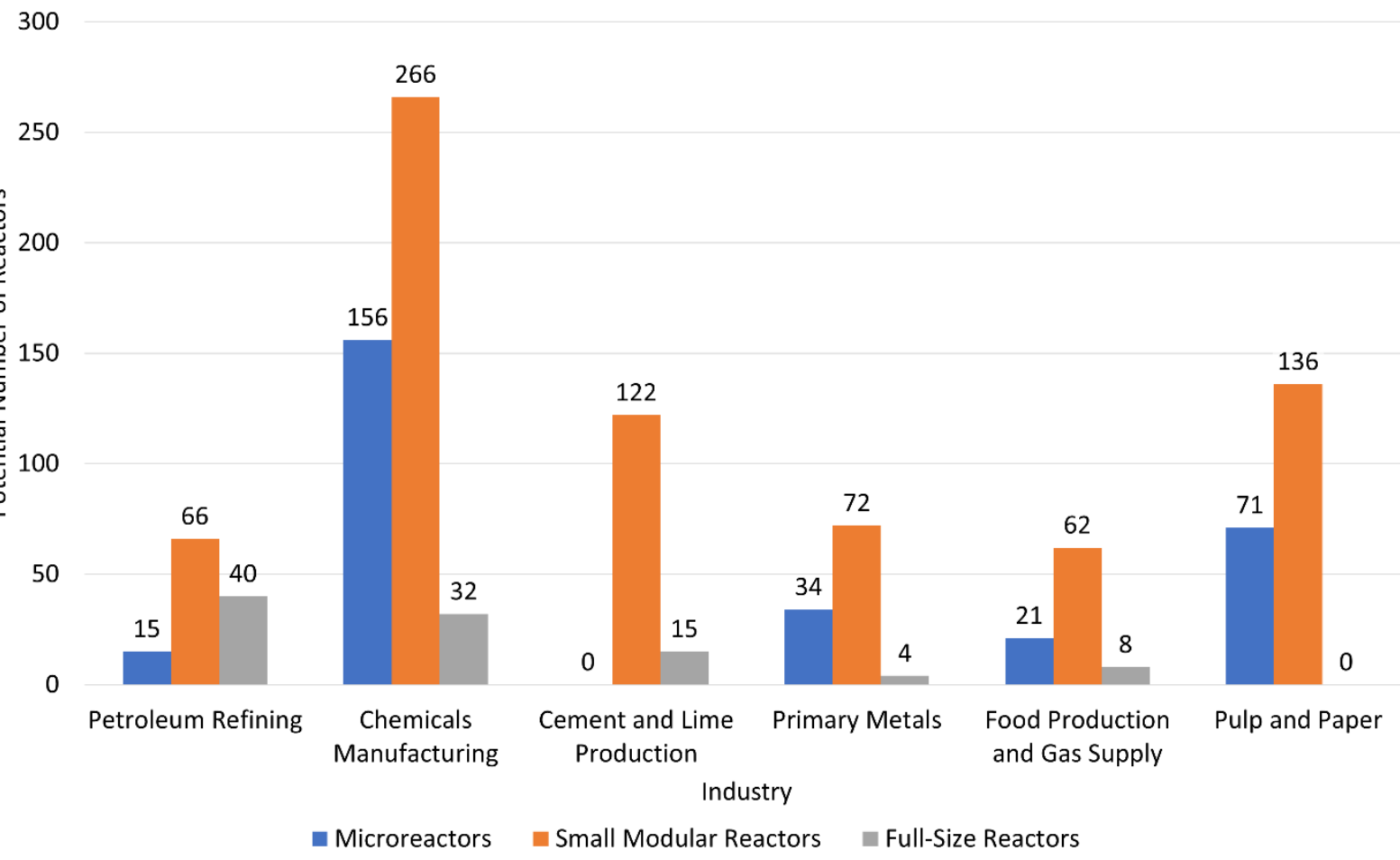

Figure 22. Potential addressable market by industry based on energy needs.

\subsubsection{Alignment with Advanced Reactor Temperatures}

IES using advanced nuclear reactors enable time-varying output of thermal energy that can be used for more than electricity generation. By providing low-carbon heat directly to industrial processes, nuclear IES provide the industrial sector with a means to replace fossil-fuel heat sources and achieve further GHG emissions reductions beyond process-efficiency improvements alone (McMillan et al. 2016). Figure 23 illustrates the temperature ranges of process heat required in the selected industries described above and compares them to the output temperature limits of different nuclear reactor designs, discussed in Section 2. (The figure excludes low-temperature water desalination and hydrogen production and other processes outside the relevant temperature range for advanced reactors.) As the figure indicates, advanced reactors produce higher temperatures than LWRs, and therefore have a greater potential to replace existing industrial heat sources. Combined with an efficient, high-temperature heat transport system, such as solar industrial process heat (SIPH) systems used with solar concentrators, MSRs and HTGRs are expected to be capable of supplying process heat for most processes in these industries without the need for topping heat. Where necessary, low-carbon heat augmentation can be supplied electrically or with chemical heat pumps to allow lower temperature reactors to support higher 
temperature processes (Bragg-Sitton, Rabiti, et al. 2020). Also, the use of advanced reactors in industries or plants with processes requiring lower temperatures provides the opportunity for bottoming processes, such as electricity production. In light of these findings, none of the industries in Figure 23 should be excluded from consideration for thermally coupled nuclear IES, based on temperature compatibility alone.

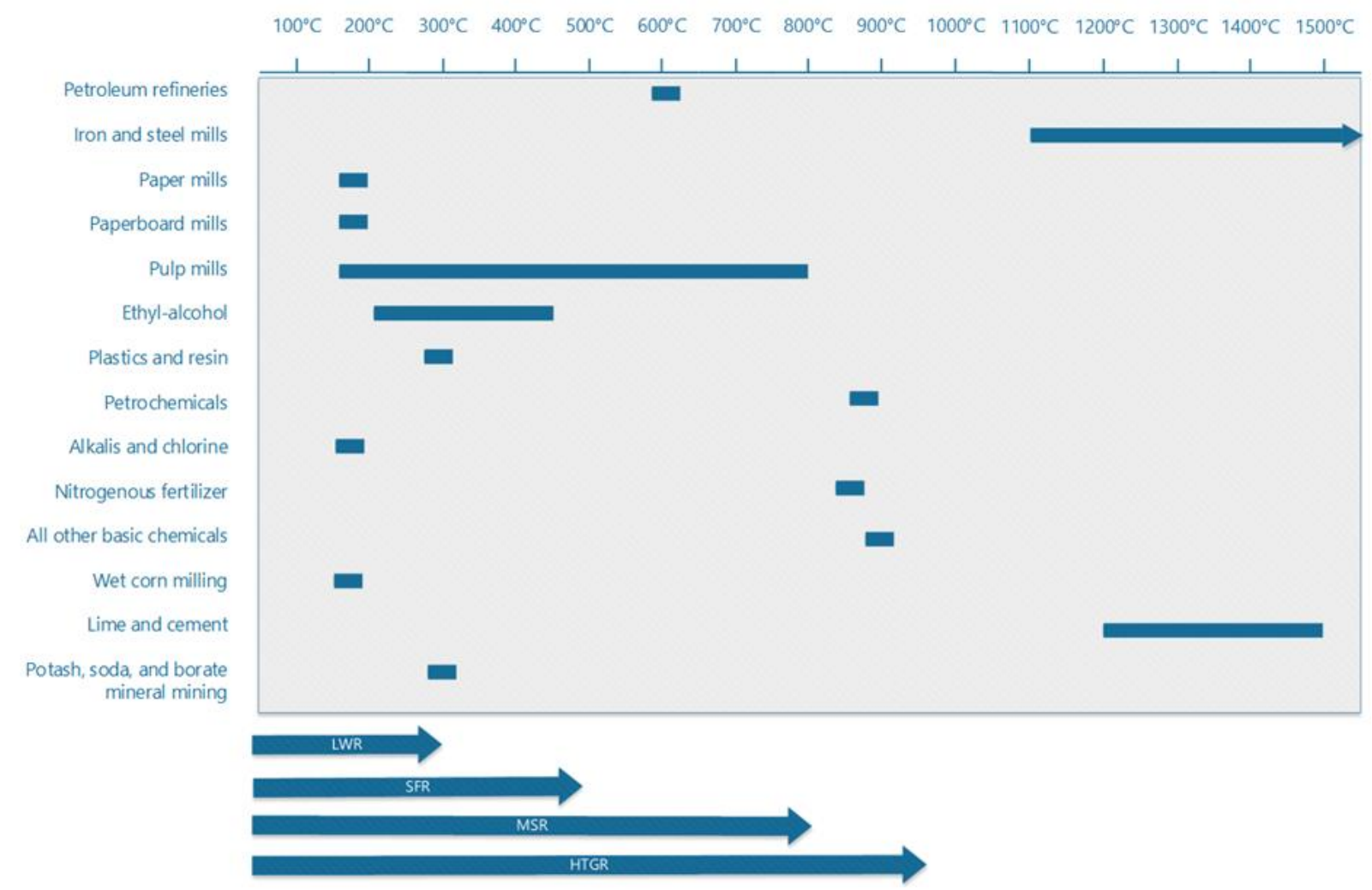

Figure 23. Comparison of industrial process heat ranges to output temperature limits of nuclear reactors (McMillan et al. 2016) and (MIT 2018).

Heat transport is a factor that should be considered to appropriately pair nuclear IES technology to an industrial process. Heat transfer distance and the working fluid can both be limiting factors when considering industrial process-heat input requirements and system compatibility.

\subsection{Potentiall Additional Applications for Advanced Reactors}

The following potential additional applications for advanced reactors are considered separately from the preceding analysis because they do not align closely with the energyintensive facilities and NAICS codes in the EPA GHGRP dataset. Instead, these additional applications are broader in scope and relate more to the possible future evolution of low-carbon energy systems. In coming decades, these applications could be much more significant, and the IES program has performed detailed studies of utilizing nuclear energy in these areas.

\subsubsection{Summary of Hydrogen Uses and Markeł}

As previously discussed, hydrogen has many uses, including as an energy carrier and a chemical feedstock. Currently, $95 \%$ of hydrogen produced in the U.S. is generated through steam 
methane reforming of natural gas, a process that generates $\mathrm{CO}_{2}$. However, when generated in a low-carbon manner (e.g., through nuclear-based electrolysis), hydrogen can be produced with minimal carbon emissions (Ingersoll and Gogan 2020). Many studies have shown how nucleardriven LTE and HTE could economically produce clean hydrogen (Boardman et al. 2019; M. F. Ruth et al. 2020a; M. Ruth et al. 2017; Frick et al. 2019). Hydrogen had a global market worth of $\$ 16.6 \mathrm{~B}$ in 2019 and a high expected CAGR: 13.8\% between 2019 and 2024 (The Business Research Company 2019). Merchant hydrogen production, where hydrogen is produced by the gas supply industry as a final product, is responsible for $28 \mathrm{MMT} \mathrm{CO}_{2}$, with 51 plants exceeding EPA reporting thresholds (U.S. Environmental Protection Agency 2019). Hydrogen is also produced in other industries to meet their own demand; GHG emissions from these processes are included in those industries' overall emissions figures shown above.

\subsubsection{Transportation}

The transportation sector was included in this review because it is one of the three largest sources of greenhouse gas emissions in the U.S., responsible for $28 \%$ of the nation's GHG emissions in 2018 (U.S. Environmental Protection Agency 2018)..$^{3}$ In part to address this issue, automobile, bus, and truck manufacturers have introduced electric vehicles (EVs) in volume production and fuel-cell vehicles (FCVs) in limited quantities. EV and FCV adoption is predicted to increase dramatically over the next two decades-the global EV market having an expected CAGR of $16.4 \%$ between 2019 and 2024 and a market size of $\$ 224.9 B$ in 2018 (The Business Research Company 2020). Increased EV charging and FCV fueling needs will increase demand for electricity and hydrogen that can be met with nuclear IES.

A demonstration of a transportation hub could include the following elements:

- Transmission of heat and electricity to a high-temperature electrolyzer

- Storage of heat, electricity, and/or hydrogen

- Electric and fuel cell vehicles, such as heavy-duty electric and fuel cell trucks in freightcarrier fleets

- Time-varying dispatch of heat, electricity, and hydrogen to meet intermittent demand for high-power EV charging and high-capacity hydrogen FCV fueling, facility demand for heat and electricity, and to provide grid services.

\subsubsection{Mining}

Mines are often large users of industrial heat for processes including drying, steam generation, and ore processing. In addition, many mines are isolated from larger grids and thus rely on fossil fuels to generate needed energy. Mines were included in this analysis because of their relevance to advanced reactor concepts.

A demonstration of this application could include the following elements:

- Transport of heat to and integration with unit operations or other loads (e.g., material pre-processing)

3 By some accounts, the transportation sector surpassed the electric grid to become the largest contributor of GHG emissions in the U.S. around 2019. Due to reduced travel during the COVIDI9 pandemic, transportation-related GHG emissions have since dropped below the electric grid and industrial sector levels (Energy Information Administration 2021). 
- Emulation of industrial thermal and electrical loads, using real-world data describing the end user's operations, to represent fluctuations in demand due to cyclical processes and seasonal and diurnal environmental conditions

- Time-varying dispatch of heat and electricity as plant energy demand changes.

\subsubsection{Carbon Conversion}

Synthetic fuels (synfuels) are any fuels "produced from coal, natural gas or biomass feedstocks through chemical conversion" and are substitutes for crude oil or processed fuels (U.S. Energy Information Administration 2006). Generation of synfuels is typically completed by combining carbon from gasified coal or biomass with hydrogen that is usually produced by steam methane reformation of natural gas, which creates $\mathrm{CO}_{2}$ emissions. Nuclear energy can provide both the hydrogen and some of the heat energy needed for synfuel generation while avoiding the emission of $\mathrm{CO}_{2}$ to the atmosphere. Integration with nuclear power provides multiple avenues for utilization of generated energy, increased capacity factors and overall economic competitiveness. Generated synfuels could be sold or burned to produce heat, steam, or electricity (Worsham et al. 2021).

\subsubsection{Desallination}

Freshwater insecurity is identified as "one of the greatest threats facing humans in the coming century. By 2030, half of the world is expected to be living in water-stressed conditions, given current climate change scenarios" (Wutich 2020). This stresses the need for efficient desalination processes that remove minerals from saline water, making it potable or preparing it for use in agriculture or industry. There are a variety of pathways to desalination that include use of either electrical or thermal energy or both, making it a candidate application for nuclear IES (Kucera 2019). In fact, nuclear-driven desalination is already deployed commercially outside the U.S., and INL has completed studies with electric utility Arizona Public Service to evaluate use of excess energy from the Palo Verde Generating Station for desalination (World Nuclear Association 2020; Epiney et al. 2019). Currently, desalination is not typically carbon-free. Global $\mathrm{CO}_{2}$ emissions from desalination were estimated to be 76 MMT in 2015. Table 2 shows specific $\mathrm{CO}_{2}$ emissions from desalination for three processes that are common today. Multi-effect distillation (MED) and multi-stage flash (MSF) are low-pressure, thermal processes. Reverse osmosis (RO) is a mechanical process that requires high-pressure pumps that are driven electrically or by combustion engines or turbines.

Table 2: $\mathrm{CO}_{2}$ emissions per cubic meter of produced water for different desalination technologies

$\begin{array}{lll}\text { Technology } & \mathrm{CO}_{2} \text { emissions }\left(\mathrm{kg} \mathrm{CO}_{2} / \mathrm{m}^{3}\right) & \text { Total electrical energy }\left(\mathrm{kWh} / \mathrm{m}^{3}\right) \\ \text { MED } & 0.3-26.9 & 17.9 \\ \text { MSF } & 0.3-34.7 & 23.4 \\ \text { RO (seawater) } & 0.08-4.3 & 5\end{array}$

Source: (Cornejo et al. 2014; jia et al. 2019)

In 2020, a cumulative total of $\$ 1.99 \mathrm{~B}$ was invested in seawater and brackish water desalination in North America, including both membrane-based RO and thermal processes. The CAGR of this investment was high: $22.1 \%$, between 2015 and 2020 in the same region (The Business Research Company and Runte 2016). Desalination is a common-sense application of nuclear energy; nuclear assets produce a steady stream of energy that can create fresh water reliably and at a constant rate. Desalination assets can also be operated as flexible demand, 
scaling output to match market conditions. This can increase the ability of energy systems to use larger percentages of variable renewable energy without increasing the requirements for fossilbased balancing generation.

\subsubsection{Electricity and Other Energy Systems}

\subsubsection{Thermal Energy Storage}

Thermal energy storage systems include steam accumulators, sensible-heat fluid systems, packed bed, hot rock, and geologic systems (MIT 2018). Although only a nascent industry, thermal energy storage is a key component of nuclear IES because of the flexibility it provides to thermal energy systems. When coupled with nuclear assets, thermal storage systems allow nuclear plants to operate at higher capacity factors, increasing economic competitiveness. It also enables integration of nuclear energy with renewable energy generation, industrial end users, and backup systems. Thermal energy storage also decouples energy users from the nuclear system, reducing the potential for radioactive contamination of products to essentially zero.

\subsubsection{Industrial Energy Parks}

Industrial energy parks geographically concentrate energy consumption and generation for the service of multiple industrial customers, often utilizing existing infrastructure and integrating newer technologies. The wide potential range of thermal energy needs makes industrial energy parks a common-sense application for advanced reactor concepts.

A demonstration of this application could include the following elements:

- Transport of heat to and integration with one or more plant unit operations

- Emulation of plant thermal and electrical loads, based on real-world data describing operation of the end user's plant, to represent fluctuations in demand due to batch processing and other cyclical operations

- Time-varying dispatch of heat, electricity, and hydrogen production as plant energy demand changes and to provide grid services (e.g., renewables integration, demand response). 


\subsection{Summary of Industries and Applications}

Table 3 provides an overview of industry relevance based on underlying data. The green cells represent high relevance, while the yellow cells represent medium relevance. While all studied industries are relevant, this table shows the strengths of each industry. The "nuclear-enabled hydrogen" row also captures products derived from hydrogen, including synfuels and ammonia.

Table 3: Industry relevance measures.

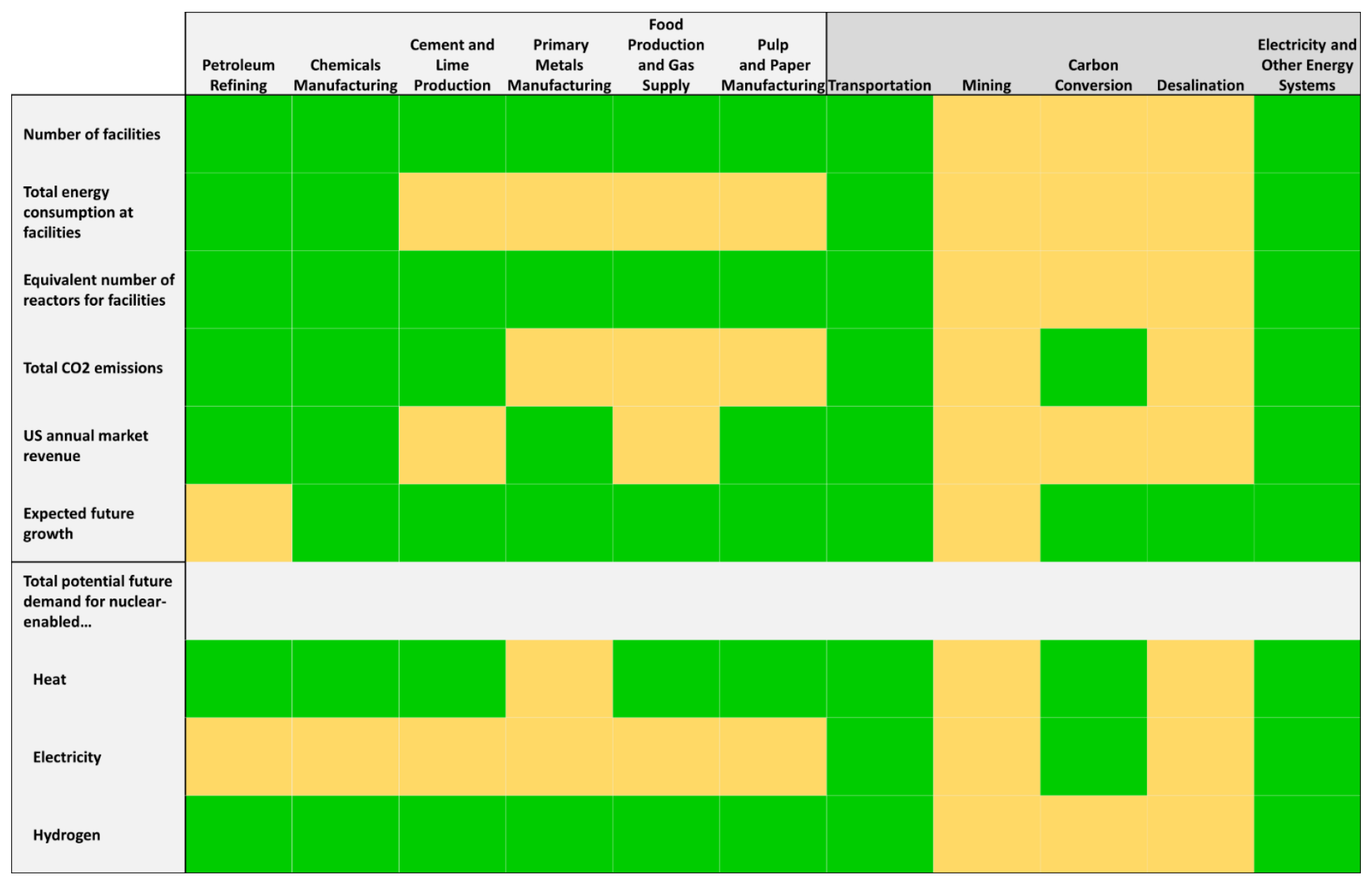




\section{Multiphase Demonstration Program and Pre-conceptual Designs}

This section describes the phases envisioned for the demonstration program and presents preconceptual design scenarios that combine NRIC and CTD IES capabilities, including test beds in place or under development, with specific needs for energy-intensive industries or other end-use applications.

\subsection{Pre-Phase (Phase 0): Planning and Analysis}

The demonstration program would begin in 2021 by establishing collaborative relationships among NRIC, CTD IES, and industry stakeholders who submit responses to the EOI request, as well as other possible partners. The pre-phase would involve developing specific plans for the demonstration program in light of EOI input submittals and conducting necessary analyses in preparation for the subsequent phases.

\subsection{Phase 1: Nuclear Energy Emulation}

The first phase, beginning in late 2021, would utilize existing test beds at INL's Energy Systems Laboratory, as described in Section 3, to emulate the use of nuclear reactor heat (using controllable electric heaters) for one or more innovative applications. This phase would enable technology developers and other industry stakeholders to test and demonstrate equipment and processes, such as hydrogen production technologies and thermal energy storage media, for later integration into advanced nuclear systems. Partnering with industry stakeholders in Phase 1 to identify focus areas for collaboration, design system interfaces, address materials and supply chain gaps, highlight key challenges, and demonstrate "proof of principle" would lay a strong foundation for further phases with fission-generated energy. Greenwood et al. (2020) provide an example of nuclear energy emulation for chemical facilities.

\subsection{Phase 2: Microreactor Demonstrations}

The second phase of the demonstration program will utilize one or both microreactor test beds currently under development at INL. Partnering with industry stakeholders on microreactor applications would advance the demonstration program by coupling critical systems concurrent with construction of larger advanced nuclear systems.

As discussed in Section 3, MAGNET will simulate operating parameters and processes for microreactor concepts with electrical heaters used to emulate a nuclear reactor. MAGNET will become fully operational in Summer 2021 and integrated with TEDS in Fall 2021, thereby comprising a portion of the DETAIL facility.

As a subsequent full demonstration, MARVEL will involve building and operating a nuclear microreactor at a bay of the Transient Reactor Test Facility, as discussed in Section 2. It is expected to be complete in 2024.

\subsection{Phase 3: Pilot-Scale Advanced Reactor Demonstrations}

Demonstrating novel uses of heat, electricity, and other products from advanced reactors at pilot scale in Phase 3 is important because using an actual reactor, rather than an emulated one, introduces realistic dynamics, system interactions, and environmental conditions not possible in modeling and non-nuclear, laboratory-scale testing. NRIC IES demonstration will benefit individual partners and the industry as a whole by verifying designs and control strategies, validating performance and cost models, and identifying unforeseen challenges and opportunities. 
Figure 24 summarizes the potential uses for nuclear energy products as examples of industries and applications that could participate in the Phase 3 demonstration projects with advanced reactors. The colors of the arrows leading to the use cases correspond to the nuclear energy products in the center of the figure. The figure shows their U.S. $\mathrm{CO}_{2}$ emissions in 2019 at the far right as proxy for fossil fuel consumption and need for clean energy solutions. The use cases marked with asterisks have pre-conceptual design scenarios in the following subsections.

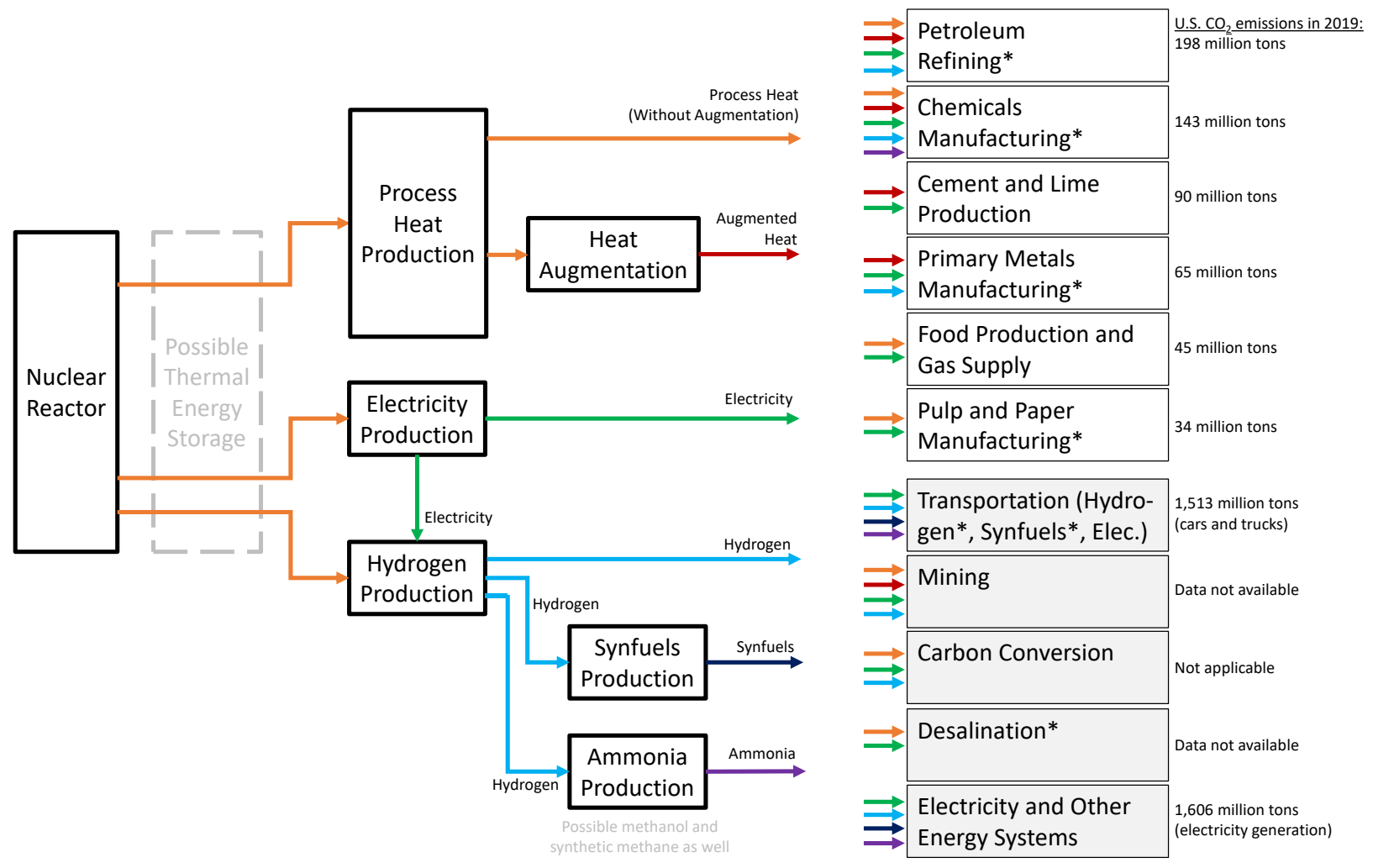

Figure 24. Linking advanced reactors and nuclear-generated products with use cases.

\subsubsection{Nuclear Desalination}

Potable water is in short supply in many parts of the world. Lack of it is set to become a constraint on development in some areas. Nuclear energy is already being used for desalination and has the potential for much greater use. Nuclear desalination is generally cost-competitive with using fossil fuels. According to the International Atomic Energy Agency, "only nuclear reactors are capable of delivering the copious quantities of energy required for large-scale desalination projects" in the future (IAEA 2015). Figure 25 shows a pre-conceptual design scenario for nuclear desalination. The advantage of using nuclear energy for the desalination process is its constant and steady demand for energy. Thermally driven desalination processes requires very low temperature and can be put on standby without adverse effect. Therefore, it is beneficial to balance the electrical load and absorb excess nuclear energy generation during periods of low demand. 


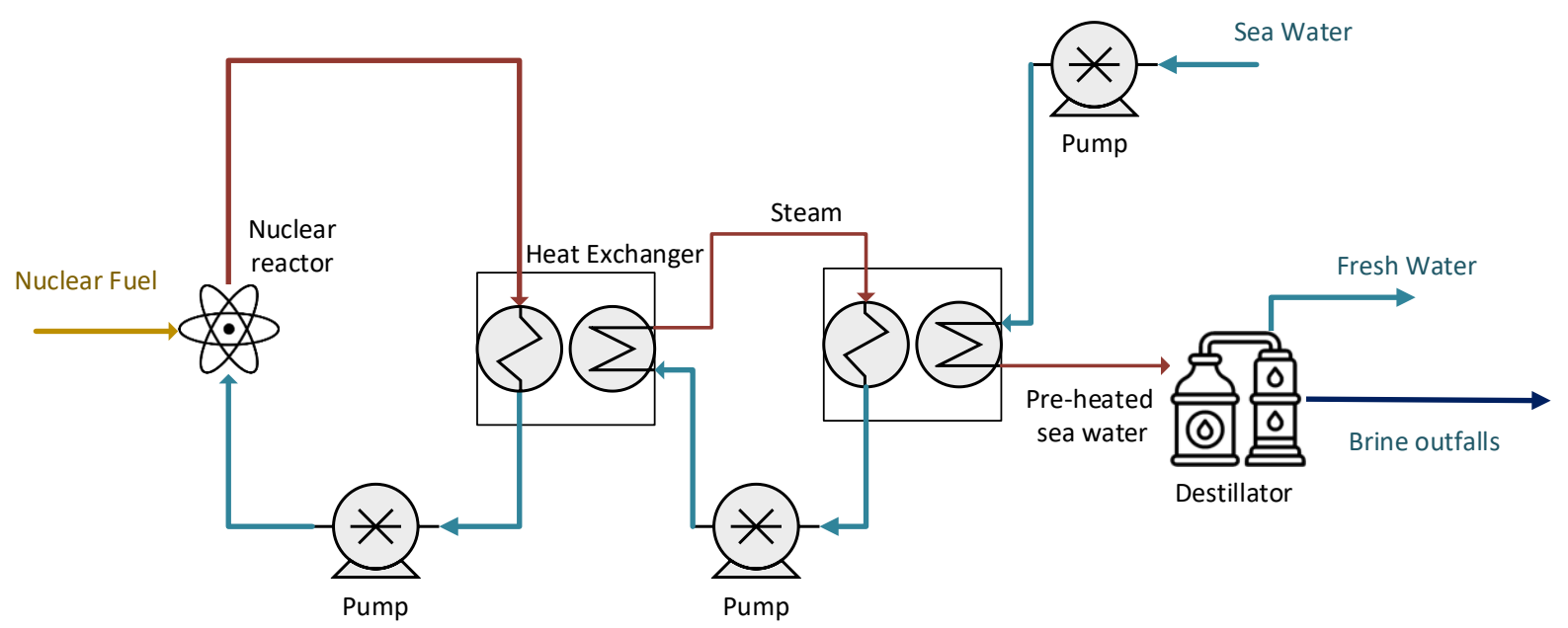

Figure 25. Thermally driven nuclear desalination.

\subsubsection{Nuclear Combined Heat and Power for Paper Facility}

A CHP system with nuclear IES could serve the energy needs of pulp and paper facilities, as analyzed in (Worsham and Terry 2020). Figure 26 illustrates this pre-conceptual design scenario.

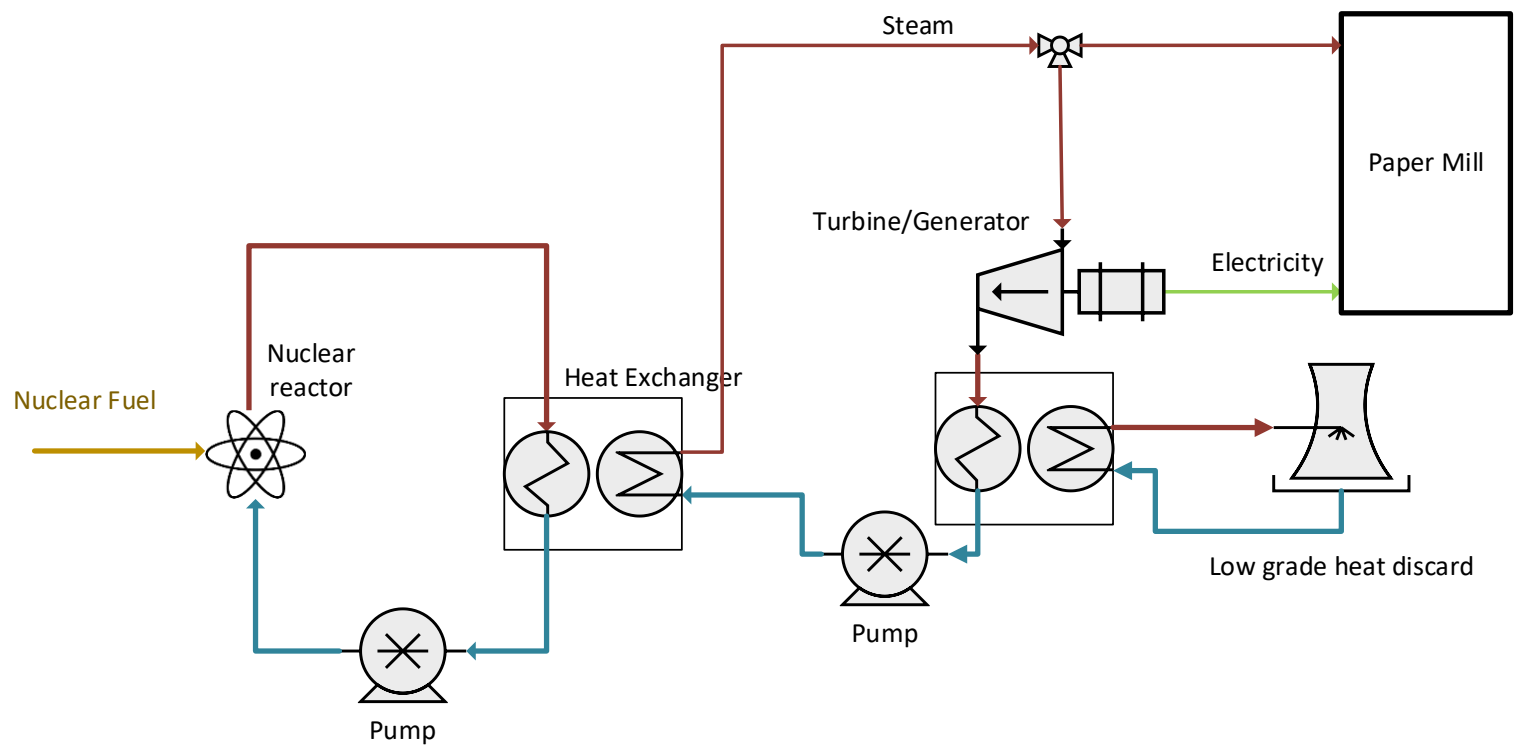

Figure 26. Nuclear CHP for a paper facility.

\subsubsection{Nuclear Hydrogen Production}

Generic diagrams for nuclear hydrogen production using LTE or HTE were shown in Section 3. The HTE diagram is reproduced below as a pre-conceptual design component for hydrogen usage in energy-intensive industries or other applications. 


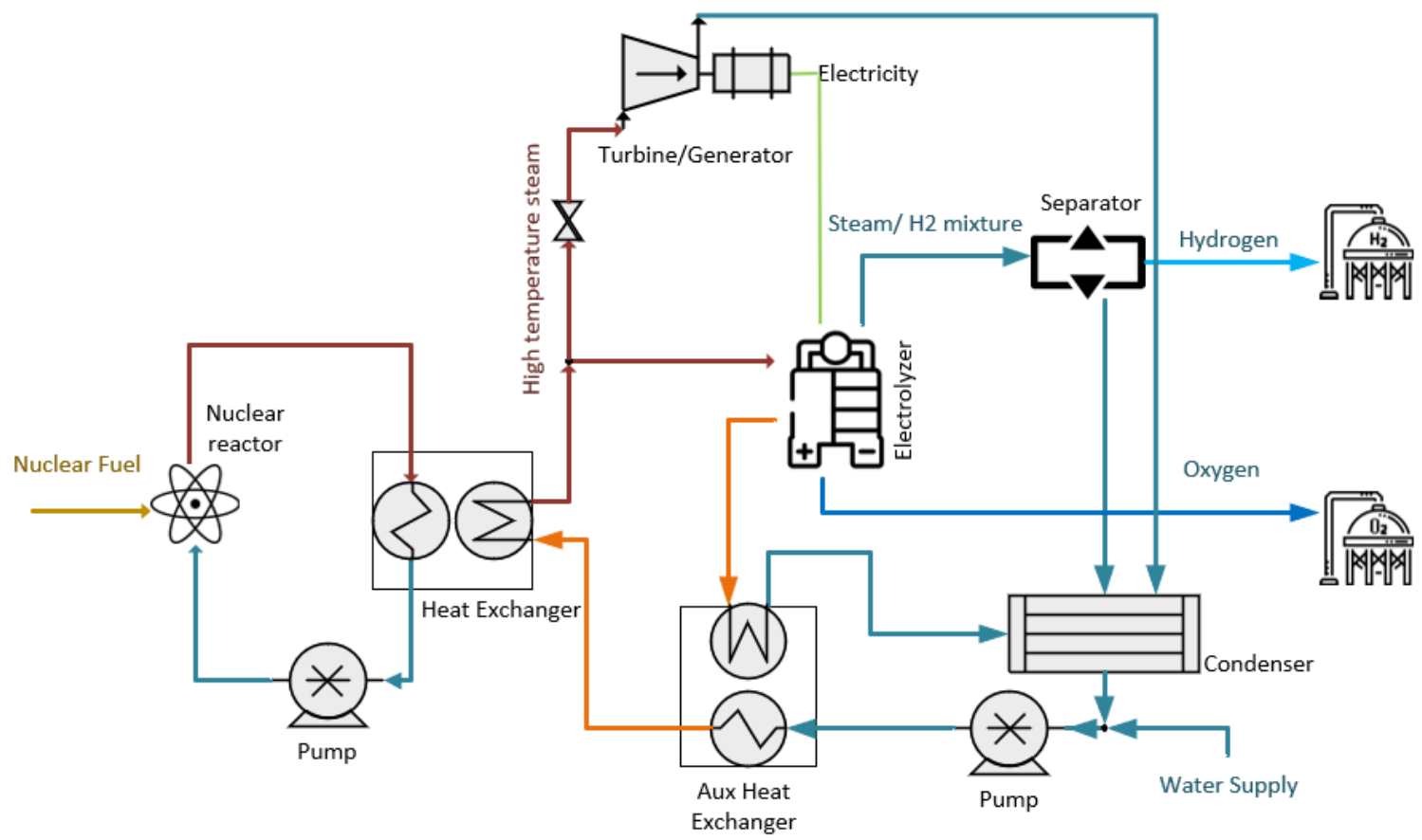

Figure 27. Nuclear hydrogen production using HTE.

\subsubsection{Iron and Steel Manufacturing}

One of the energy-intensive industries that could use hydrogen for its processes is iron and steel manufacturing. Efforts are being made in this industry to improve sustainability by reducing GHG emissions while diversifying energy sources. Near-term approaches focus on making the existing processes more efficient and carbon-leaner, whereas longer term strategies are directed to developing breakthrough processes utilizing low-carbon energy, non-fossil electricity, and feedstock such as hydrogen or biomass. The potential application of nuclear hydrogen and electricity is included in these strategies (IAEA 2017). Figure 28 illustrates nuclear-enabled hydrogen production for steel manufacturing using an example process with nuclear electricity powering the arc furnace. Alternative HTE processes with both thermal and electrical input, which would achieve higher efficiencies, are also possible. 


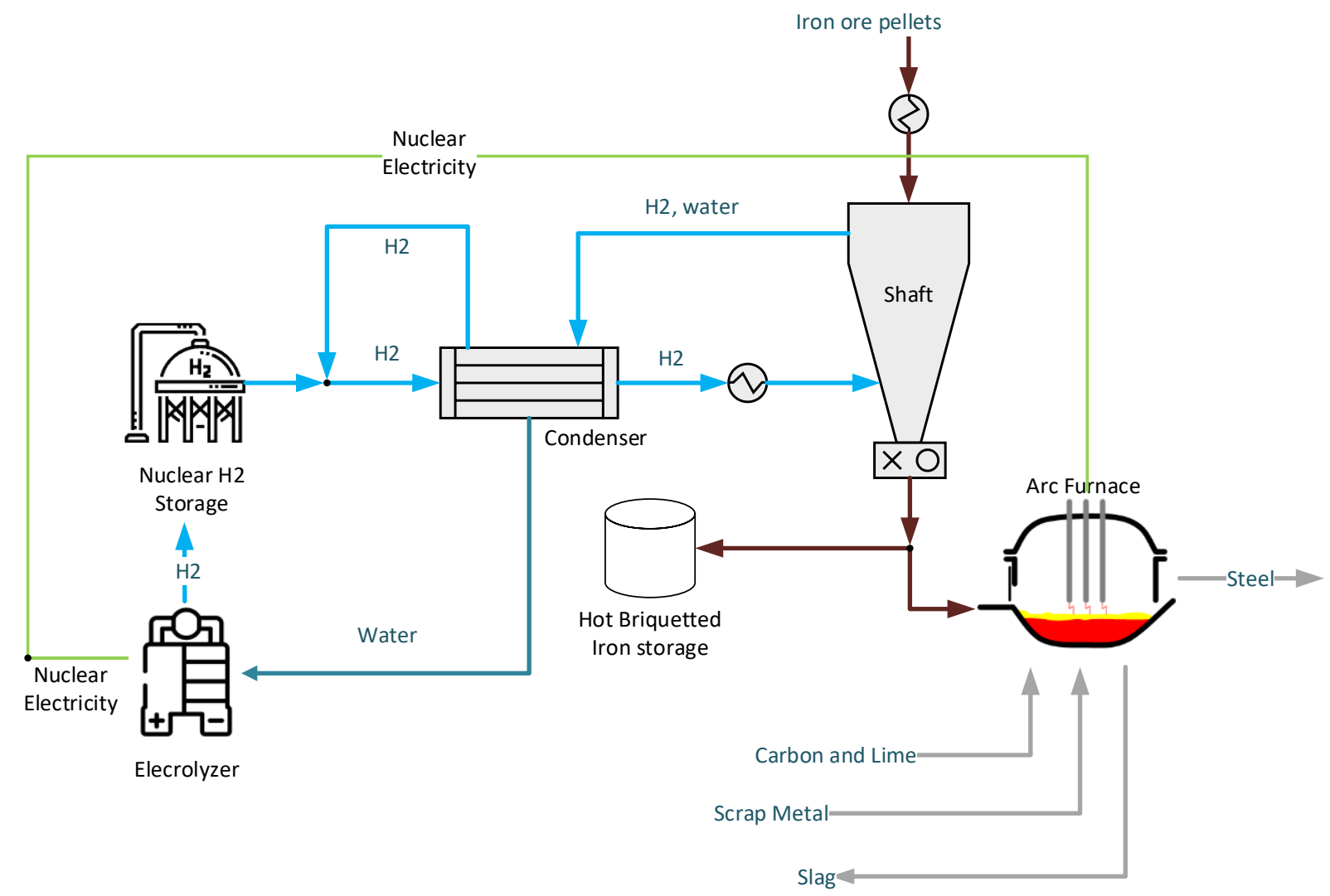

Figure 28. Nuclear hydrogen production for steel manufacturing.

\subsubsection{Fertilizer Manufacturing}

Ammonia is one of the most highly produced inorganic chemicals. There are numerous largescale ammonia production plants worldwide, producing a total of 175 million tons of ammonia in 2016. Today, most ammonia is produced on a large scale by the Haber-Bosch process, an artificial nitrogen fixation process, which requires nitrogen and hydrogen. Nitrogen is obtained by air liquification. A typical modern ammonia-producing plant first converts natural gas, liquified petroleum gas, or petroleum naphtha into gaseous hydrogen. This step can be completely eliminated if hydrogen is obtained via electrolysis using nuclear-generated electricity.

\subsubsection{Nuclear Oil Production and Refining}

Petroleum (or crude oil) is a main feedstock for several critical chemicals. Two primary products of oil refineries are olefins and aromatics. Olefins and aromatics are the building-blocks for a wide range of materials such as solvents, detergents, and adhesives. Olefins are the basis for polymers and oligomers used in plastics, resins, fibers, elastomers, lubricants, and gels. As noted in Section 4 based on EPA data, 138 U.S. oil refineries consume approximately 4,000 TBtu of energy annually, and their energy consumption could increase as refineries shift their production from gasoline to processing heavier feedstock requiring more energy to refine. Both energy demand and $\mathrm{CO}_{2}$ emissions can be greatly reduced by refining in situ, where carbon residue would remain underground, sequestered as carbon solids. A nuclear reactor would transfer high-temperature heat to oil shale via liquid-metal or liquid-salt transportation loops (Oil and Gas Journal 2008). 


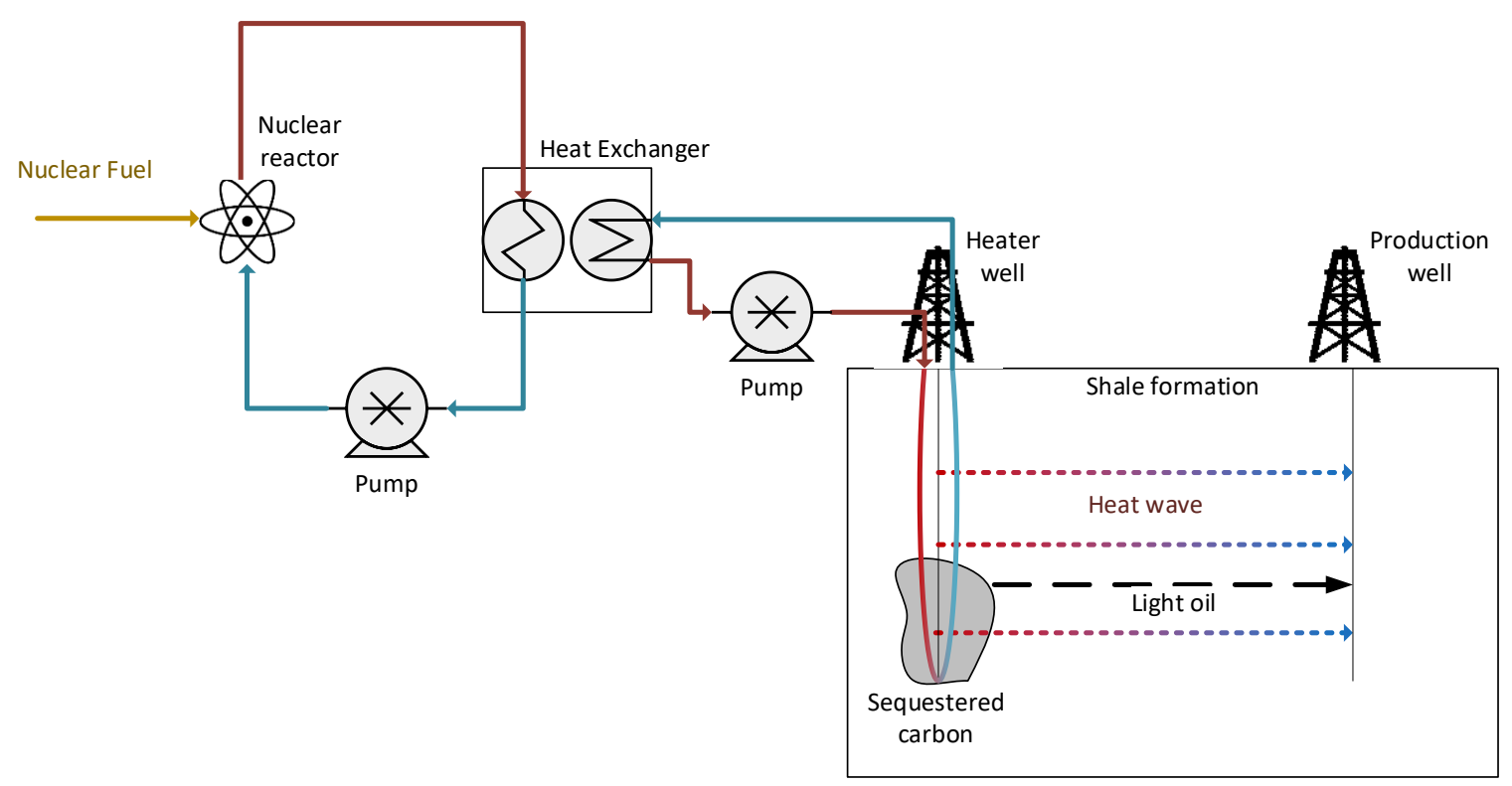

Figure 29. In situ oil production and refining.

Conventional oil refining processes can also benefit from nuclear heat. The most common type of catalytic reforming unit has three reactors, each with a fixed bed of catalyst. The feed mixture is heated to the reaction temperature $\left(495-520^{\circ} \mathrm{C}\right)$ and totally vaporized before the reactants enter the first reactor. Eliminating fire heaters in this process and replacing them with a nuclear heat source will make this process greener and more energy efficient.

Hydrotreating, the reaction of organic compounds in the presence of high-pressure hydrogen to remove oxygen (deoxygenation) along with other heteroatoms (nitrogen, sulfur, and chlorine), is an important process to ensure purity of feedstock. Currently hydrogen for this process is obtained by natural gas conversion, which also can be replaced with clean nuclear hydrogen.

\subsubsection{Nuclear Biomass Gasification}

Biomass-derived syngas can typically be obtained from gasification of agricultural and forestry residues, along with industrial wastes such as black liquor, which is a major biomasscontaining waste produced in pulp and paper manufacturing regions worldwide. The biomass gasification process involves high temperature (generally $600-900^{\circ} \mathrm{C}$ or even higher) partial oxidation of biomass in the presence of a gasifying agent (air, oxygen, steam, $\mathrm{CO}_{2}$, or mixtures of these components). The resulting product is a low-to-medium heating value fuel gas called syngas or producer gas that contains $\mathrm{CO}, \mathrm{H}_{2}, \mathrm{CO}_{2}$, and $\mathrm{CH}_{4}$ in various proportions. Syngas is obtained after suitable purification and conditioning stages of the raw gases produced by biomass gasification. (Pandey et al. 2015, 213-50) Syngas is later used for production of fuels and chemicals. Syngas can be converted to a variety of industrial products via the Fischer-Tropsch process: alkanes, alkenes, alcohols, synthetic naphtha, synthetic middle oil distillates (diesel fuel and kerosene), lubricating oils, and synthetic waxes (Krylova 2014).

Figure 30, which draws on Knighton et al. (2020), shows integration of nuclear energy with chemical polymer production as a pre-conceptual design scenario. As discussed in Section 4, (Worsham et al. 2021) describe a process using nuclear energy to gasify coal to produce methanol or other carbon-containing products with lower carbon emissions in the production process than fossil-based methods. 


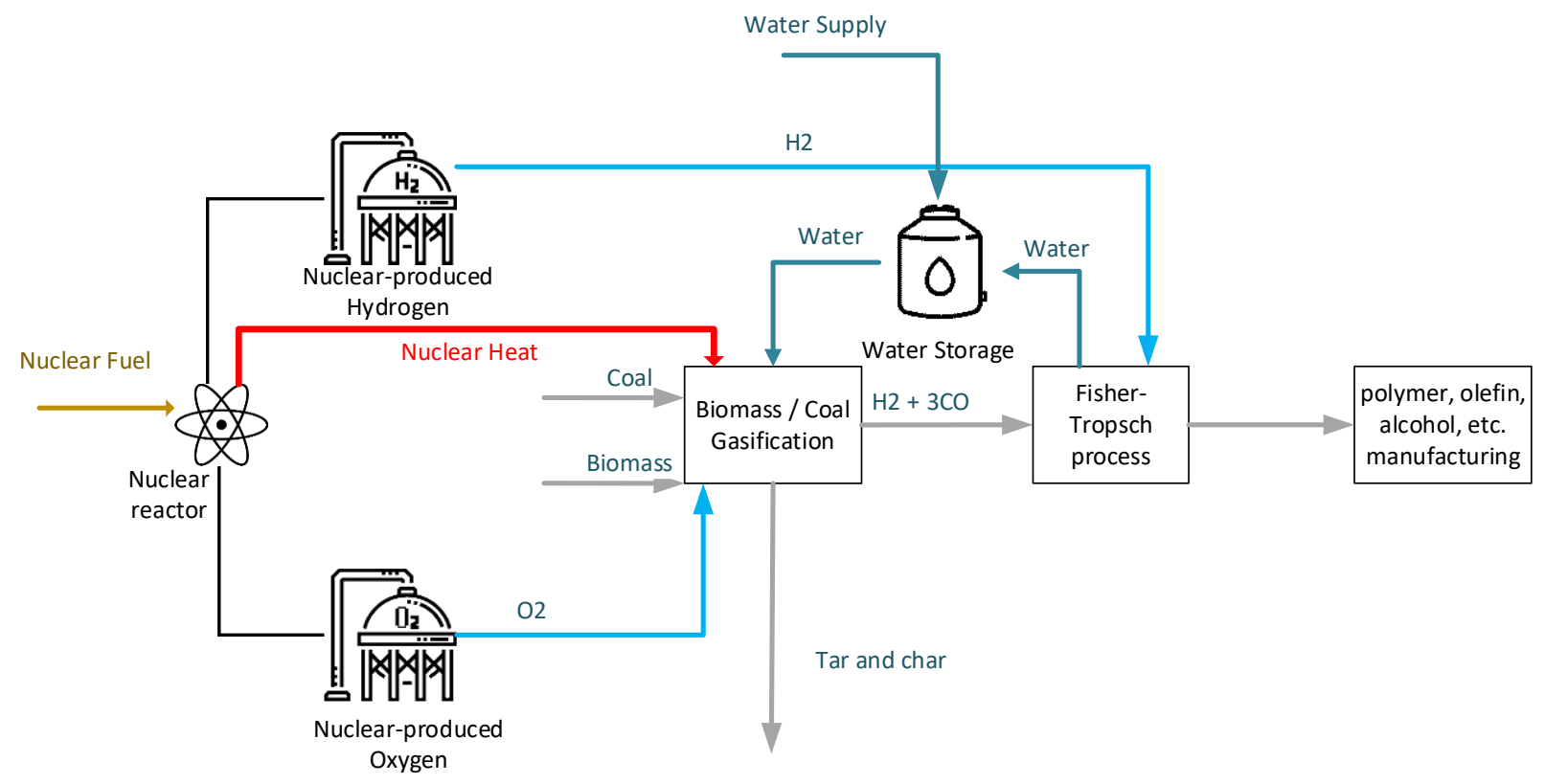

Figure 30. Integration of nuclear energy with chemical polymer production.

Atmospheric $\mathrm{CO}_{2}$ can be sequestered by the water-gas shift (WGS) reaction, a reversible process to convert $\mathrm{H}_{2}$ and $\mathrm{CO}_{2}$ to generate $\mathrm{CO}$ and $\mathrm{H}_{2} \mathrm{O}$. The WGS reaction is exothermic; hence, the reaction equilibrium shifts towards conversion of $\mathrm{CO}_{2}$ and $\mathrm{H}_{2}$ to syngas with increasing temperatures. Nuclear-produced hydrogen and nuclear heat can be employed for this process. The resulting product of the WGS is syngas, which can be used in the Fischer-Tropsch process or other catalytic conversion process to obtain high-volume chemicals. Figure 31 depicts this process as a pre-conceptual design.

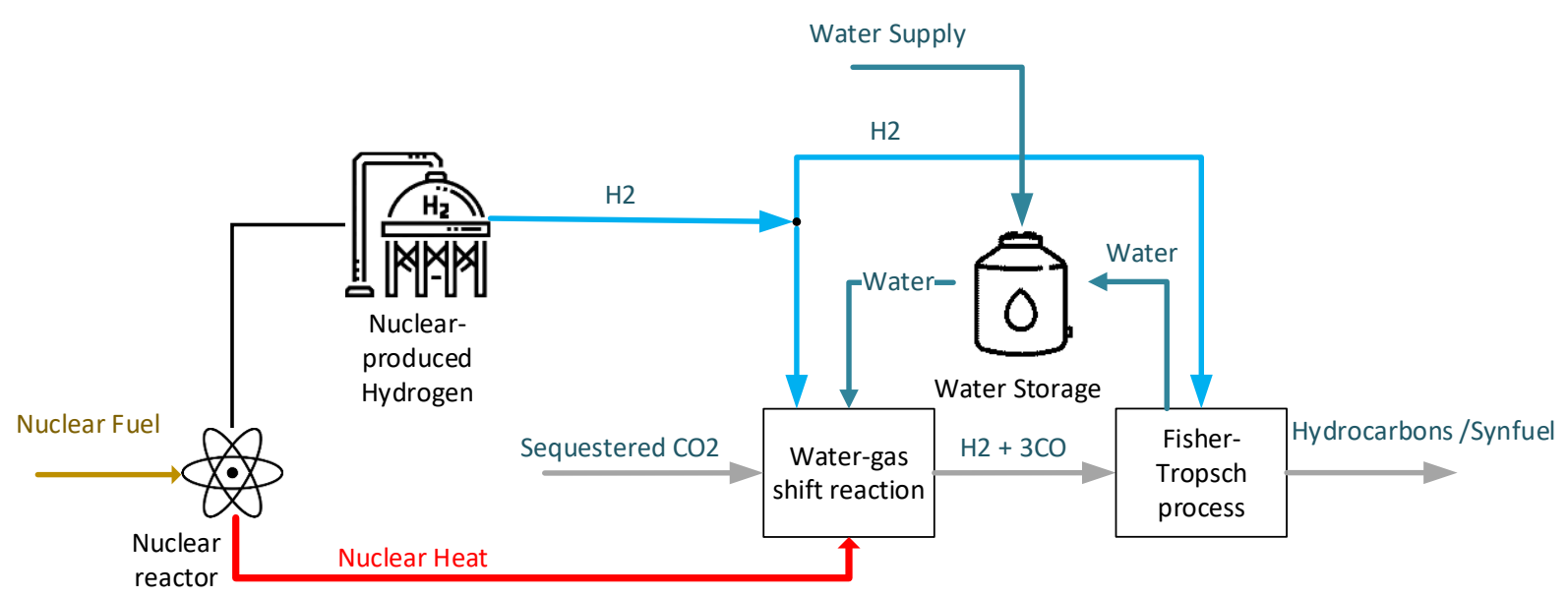

Figure 31 . WGS reaction to capture $\mathrm{CO}_{2}$ and produce syngas.

\subsection{Further Considerations for Planning and Interfaces}

Down-selection of design scenarios for the demonstration program, with input from industry stakeholders who respond to the EOI, should reflect and advance NRIC's mission. To inspire the market, NRIC will favor applications that demonstrate the versatility of advanced nuclear technologies and make a large economic and environmental impact. To empower innovators, NRIC will provide a first-of-a-kind demonstration platform capable of addressing multiple system 
integration issues, multiple energy resources, and multiple energy-use paths. Finally, to ensure successful outcomes, NRIC will favor applications that create synergy with NRIC advanced reactor demonstrations, leverage existing relationships with reactor developers and end users, and build on CTD IES research and development efforts.

NRIC seeks to develop an IES test bed platform, in collaboration with the CTD IES program, that interfaces with its advanced reactor test beds to allow industry partners to integrate commercial IES components with an advanced reactor and power conversion unit. Notionally, interfaces would be designed, and physical facilities identified, to accommodate thermal or electrochemical (i.e., battery) energy transport and storage systems, electrolysis systems, hydrogen storage systems, industrial process systems, or other components identified through industry partnerships.

The platform also may be capable of hosting a pilot-scale representation of an end-use process that consumes heat and/or electricity, installed or constructed in partnership with an industry end user. Alternatively, the platform could include surrogate thermal and electrical loads that can be controlled to represent one or more type of industrial unit operation, process, or facility.

One major challenge for IES integration with the grid and industrial energy systems is matching the dynamic performance of an IES application (e.g., ramp rate of thermal and electrical output) with requirements of the processes, systems, or markets which the system is intended to serve. Therefore, NRIC and CTD IES aim to design and implement a test bed with generation resources, energy storage systems, loads, interfaces, and controls using dynamic performance characteristics that are representative of commercial systems. Also, the test bed may be capable of testing, measuring, and controlling the systems under transient conditions.

NRIC and CTD IES may also develop a digital twin of the nuclear IES application to be demonstrated. The digital twin would virtually represent the broader energy system, establish boundary conditions and external control signals for the hardware control systems, and acquire real-time system performance data. Locations and data linkages for the digital twin would be assessed in further planning stages.

Functional requirements and additional technical details describing this platform will be developed in future work, in coordination with prospective industry partners. 


\section{References}

Arafat, Yasir. 2020. "Microreactor Applications Research, Validation \& EvaLuation (MARVEL) Project." Presented at GAIN-NEI-EPRI Microreactor Workshop, Virtual, August 2020. https://gain.inl.gov/GAINEPRINEI_MicroreactorProgramVirtualWorkshopPres/Day-1 Presentations/Day-1.05-Arafat_MicroreactorApplicationsTestingMARVEL, 18Aug2020.pdf.

Balsmeier, Aaron. 2020. "NRIC EBR-II Test Bed Pre-Conceptual Design Report." INL/EXT-2059733, Idaho National Laboratory. https://inldigitallibrary.inl.gov/sites/sti/sti/Sort_26698.pdf.

Balsmeier, Aaron and Gregory Core. 2020. "ZPPR Test Bed (ZTB) Pre-Conceptual Design Report." INL/EXT-20-59741, Idaho National Laboratory. https://inldigitallibrary.inl.gov/sites/sti/sti/Sort_26762.pdf.

Bedsworth, Lovise W. and Ellen Hanak. 2013. "Climate Policy at the Local Level: Insights from California." Global Environmental Change 23 (3): 664-77. https://doi.org/10.1016/i.gloenvcha.2013.02.004.

Bloomberg NEF. 2020. "Hydrogen Economy Outlook - Key Messages." Last modified March 30, 2020. https://data.bloomberglp.com/professional/sites/24/BNEF-Hydrogen-EconomyOutlook-Key-Messages-30-Mar-2020.pdf.

Boardman, Richard D, Cristian Rabiti, Stephen G Hancock, Daniel S Wendt, Konor L Frick, Shannon Bragg-Sitton, Hongqiang Hu, et al. 2019. "Evaluation of Non-Electric Market Options for a Light-Water Reactor in the Midwest. Light Water Reactor Sustainability Program." INL/EXT-19-55090, Idaho National Laboratory. https://doi.org/10.2172/1559965.

Bragg-Sitton, Shannon, Richard Boardman, Cristian Rabiti, and James O'Brien. 2020.

"Reimagining Future Energy Systems: Overview of the US Program to Maximize Energy Utilization via Integrated Nuclear-Renewable Energy Systems." International Journal of Energy Research 44 (10): 8156-69. https://doi.org/10.1002/er.5207.

Bragg-Sitton, Shannon, Cristian Rabiti, Richard Boardman, James O'Brien, Terry Morton, Su Jong Yoon, Jun Soo Yoo, Konor Frick, and Piyush Sabharwall. 2020. "Integrated Energy Systems: 2020 Roadmap." INL EXT-20-57708, Idaho National Laboratory. https://doi.org/10.2172/1670434.

Campbell, F. C. 2013. "1.8.1.3 Hot Rolling." In Metals Fabrication - Understanding the Basics. ASM International. https://app.knovel.com/hotlink/pdf/id:kt00U9L5O3/metals-fabricationunderstanding/hot-rolling.

Conner, Alison M., George W. Griffith, and Stephen Jeffrey Burdick. 2020. "National Reactor Innovation Center NRC Early Site Permit Roadmap." INL/EXT-20-60069, Idaho National Laboratory.

Core, Greg. 2020. "Demonstration Reactor Test Beds." Presented at National Lab Capabilities Webinar, Virtual, June 2020.

https://gain.inl.gov/NationalLabCapabilitiesWebinarPresentations/06-Core,NRICDemonstrationReactorTestBeds-NLCWebinar_04Jun2020.pdf.

Cornejo, Pablo, Mark Santana, David Hokanson, James Mihelcic, and Qiong Zhang. 2014. "Carbon Footprint of Water Reuse and Desalination: A Review of Greenhouse Gas Emissions and Estimation Tools." Journal of Water Reuse and Desalination 4 (4): 238-252. https://doi.org/10.2166/wrd.2014.058.

Dale, Bruce. 2021. "Markets and Economic Requirements for Fission Batteries and Other Nuclear Systems Session 1." January 14, 2021. 
Deloitte Insights. 2020. "The Shift toward Electrification in Industrials | Deloitte Insights." Last modified August 12, 2020. https://www2.deloitte.com/us/en/insights/industry/powerand-utilities/electrification-in-industrials.html.

Elgowainy, Amgad, Maryanne Mintz, Uisung Lee, Thomas Stephens, Pingping Sun, Krishna Reddi, Yan Zhou, et al. 2020. "Assessment of Potential Future Demands for Hydrogen in the United States." ANL-20/35, Argonne National Laboratory.

Epiney, Aaron S., James D. Richards, Jason K. Hansen, Paul W. Talbot, Pralhad Hanumant Burli, Cristian Rabiti, and Shannon M. Bragg-Sitton. 2019. "Case Study: Integrate Nuclear Water Desalination-Regional Potable Water in Arizona." INL/EXT-19-5573, Idaho National Laboratory. https://doi.org/10.2172/1597896.

Finan, Ashley. 2020a. "National Reactor Innovation Center Advanced Construction Initiative EOI." Presented at Nuclear Energy Institute Webinar, Virtual, May 2020. https://gain.inl.gov/SiteAssets/NRIC/NRIC-AdvancedConstructionTechnologiesSlides.pdf. . 2020b. "NRIC Program Update Slides." September 29, 2020." NL/CON-20-60061 Rev. 0., Idaho National Laboratory. https://inldigitallibrary.inl.gov/sites/sti/sti/Sort_26937.pdf. 2021. "U.S. Advanced Reactor Demonstrations \& NRIC. ARPA-E Annual Fission Meeting, Virtual, February 2021. https://arpa-e.energy.gov/sites/default/files/2021 03/Day2_Finan.pdf."

Forsberg, Charles W., Piyush Sabharwall, and Hans D. Gougar. 2019. "Heat Storage Coupled to Generation IV Reactors for Variable Electricity from Base-Load Reactors: Workshop Proceedings." INL/EXT-19-54909, Idaho National Lab. https://doi.org/10.2172/1575201.

Frick, Konor L., Paul W. Talbot, Daniel S. Wendt, Richard D. Boardman, Cristian Rabiti, Shannon M Bragg-Sitton, Mark Ruth, Daniel Levie, Bethany Frew, and Amgad Elgowainy. 2019. "Evaluation of Hydrogen Production Feasibility for a Light Water Reactor in the Midwest." INL/EXT-19-55395 Rev. 1,ldaho National Lab. https://doi.org/10.2172/1569271.

Friedmann, S Julio, Zhiyuan Fan, and Ke Tang. 2019. "Low-Carbon Heat Solutions for Heavy Industry: Sources, Options, and Costs Today." Columbia University Center on Global Energy Policy. https://www.energypolicy.columbia.edu/sites/default/files/fileuploads/LowCarbonHeat-CGEP_Report_100219-2_0.pdf.

Goulder, Lawrence H., and Andrew R. Schein. 2013. "CARBON TAXES VERSUS CAP AND TRADE: A CRITICAL REVIEW." Climate Change Economics 04 (03): 1350010. https://doi.org/10.1142/S2010007813500103.

Greenwood, Michael Scott. 2020. "Integrated Energy System Investigation for the Eastman Chemical Co. Kingsport, TN Facility." ORNL Report, Oak Ridge National Lab.

IAEA. 2015. "New Technologies for Seawater Desalination Using Nuclear Energy." IAEA-TECDOC1753, International Atomic Energy Agency. https://wwwpub.iaea.org/MTCD/Publications/PDF/TE-1753_web.pdf.

- 2017. Industrial Applications of Nuclear Energy. Vienna: IAEA. https://wwwpub.iaea.org/MTCD/Publications/PDF/P1772_web.pdf.

Idaho National Laboratory. 2020. "Private-Public Partnership Will Use Nuclear Energy for Clean Hydrogen Production." INL (blog). Last modified November 9, 2020. https://inl.gov/article/xcel-energy-inl-hydrogen-production.

Ingersoll, Eric, and Kirsty Gogan. 2020. "Missing Link to a Livable Climate: How HydrogenEnabled Synthetic Fuels Can Help Deliver the Paris Goals."." Accessed April 22, 2021. https://www.lucidcatalyst.com/hydrogen-report.

Jafri, Yawer, Elisabeth Wetterlund, Sennai Mesfun, et al. 2020. "Combining Expansion in Pulp Capacity with Production of Sustainable Biofuels - Techno-Economic and Greenhouse Gas 
Emissions Assessment of Drop-in Fuels from Black Liquor Part-Streams." Applied Energy 279 (December): 1 15879. https://doi.org/10.1016/i.apenergy.2020.115879.

Jia, Xuexiu, Jiři J. Klemeš, Petar S. Varbanov, and Sharifah R. Wan Alwi. 2019. "Analyzing the

Energy Consumption, GHG Emission, and Cost of Seawater Desalination in China." Energies 12 (3): 463. https://doi.org/10.3390/en 12030463.

Knighton, L. Todd, Amey Shigrekar, Daniel S Wendt, and Brian Murphy. 2020. "Markets and Economics for Thermal Power Extraction from Nuclear Power Plants Aiding the Decarbonization of Industrial Processes." INL/EXT-20-58884 Rev. 1, Idaho National Laboratory.

Krylova, A. Yu. 2014. "Products of the Fischer-Tropsch Synthesis (A Review)." Solid Fuel Chemistry 48: 22-35. https://doi.org/10.3103/S0361521914010030.

Kucera, Jane. 2019. Desalination: Water from Water. Vol. 2. Salem: Wiley-Scrivener.

Lester, Richard K. 2015. "A Roadmap for US Nuclear Energy Innovation." Issues in Science and Technology (blog). December 29, 2015. https://issues.org/a-roadmap-for-u-s-nuclearenergy-innovation/.

Liu, Wenguo, Haibin Zuo, Jingsong Wang, Qingguo Xue, et al. 2021. "The Production and Application of Hydrogen in Steel Industry." International Journal of Hydrogen Energy 46 (17): 10548-69. https://doi.org/10.1016/i.ijhydene.2020.12.123.

McMillan, Colin, Richard Boardman, Michael McKellar, Sabharwall Piyush, et al. 2016. "Generation and Use of Thermal Energy in the U.S. Industrial Sector and Opportunities to Reduce Its Carbon Emissions." INL/EXT-16-39680, Idaho National Laboratory. https://doi.org/10.2172/1334495..

Mikkelson, Daniel, Konor Frick, Shannon Bragg-Sitton, et al. 2019. "Initial Performance Evaluation and Ranking of Thermal Energy Storage Options for Light Water Reactor Integration to Support Modeling and Simulation." INL/EXT-19-56504, Idaho National Laboratory. https://inldigitallibrary.inl.gov/sites/sti/sti/Sort_21823.pdf.

MIT. 2018. The Future of Nuclear Energy in a Carbon-Constrained World: An Interdisciplinary MIT Study. Cambridge: MIT Energy Initiative.

Morton, Terry James, James E O'Brien, and Jeremy Lee Hartvigsen. 2020. "Functional and Operating Requirements for the Microreactor Agile Non-Nuclear Experimental Test Bed (MAGNET)." INL/EXT-20-58104, Idaho National Lab.

National Energy Technology Laboratory. n.d. "Biomass and Municipal Solid Waste (MSW) Gasification." Netl.Doe.Gov. Accessed February 8, 2021 a. https://www.netl.doe.gov/research/Coal/energysystems/gasification/gasifipedia/biomass-msw.

—. n.d. "Black Liquor Gasification." Netl.Doe.Gov. Accessed February 8, 2021 b. https://www.netl.doe.gov/research/Coal/energysystems/gasification/gasifipedia/blackliquor.

Oil and Gas Journal. 2008. "Nuclear Heat Advances Oil Shale Refining in Situ." Last modified August 11, 2008. https://www.ogi.com/general-interest/hse/article/17218478/nuclearheat-advances-oil-shale-refining-in-situ.

Pandey, Ashok, Thallada Bhaskar, Michael Stöcker, and Rajeev Sukumaran. 2015. Recent Advances in Thermochemical Conversion of Biomass. Amsterdam: Elsevier.

Ramachandran, Ram, and Raghu K. Menon. 1998. "An Overview of Industrial Uses of Hydrogen." International Journal of Hydrogen Energy 23 (7): 593-98. https://doi.org/10.1016/S0360-3199(97)00112-2.

Ruth, Mark, Dylan Cutler, Francisco Flores-Espino, and Greg Stark. 2017. "The Economic Potential of Nuclear-Renewable Hybrid Energy Systems Producing Hydrogen." NREL/TP-6A5066764, National Renewable Energy Laboratory. https://doi.org/10.2172/1351061. 
Ruth, Mark F., Paige Jadun, Nicholas Gilroy, Elizabeth Connelly, Richard Boardman, A. J. Simon, Amgad Elgowainy, and Jarett Zuboy. 2020a. "The Technical and Economic Potential of the H2@Scale Hydrogen Concept within the United States." https://doi.org/10.2172/1677471.

Science Based Targets. n.d. "Companies Taking Action." https://sciencebasedtargets.org/companies-taking-action.

Smart, John, and Ashley Finan. 2020. "National Reactor Innovation Center Strategy for Advancing Nuclear Integrated Energy Systems." INL/EXT-20-59882, Idaho National Laboratory. https://inldigitallibrary.inl.gov/sites/sti/sti/Sort_26938.pdf.

Stoots, Carl M, Alexander Duenas, Shannon M Bragg-Sitton, Jun Soo Yoo, Piyush Sabharwall, and James E O'Brien. 2018. "Thermal Energy Delivery System Design Basis Report." INL/EXT18-51351, Idaho National Lab. https://doi.org/10.2172/1756571.

Stuckenberg, David, and Anthony Contento. 2018. "Water Scarcity: The Most Understated Global Security Risk." Last modified May 18, 2018. https://harvardnsj.org/2018/05/water-scarcity-the-most-understated-global-securityrisk/.

The Business Research Company. 2019. "Hydrogen as a Chemical Constituent and as an Energy Source." CHM031D, BCC Publishing.

. 2020. "Electric Vehicles and Fuel Cell Vehicles Global Markets." FCB040D, Business Research Company.

The Business Research Company, and Gerry Runte. 2016. "SEAWATER AND BRACKISH WATER DESALINATION." MSTO52D, Business Research Company.

The White House. 2021. "Paris Climate Agreement." Statements and Releases. Last modified January 20, 2021. https://www.whitehouse.gov/briefing-room/statementsreleases/2021/01/20/paris-climate-agreement/.

U.S. Department of Energy. 2020. "Hydrogen Program Plan." Accessed April 22, 2021 https://www.hydrogen.energy.gov/roadmaps_vision.html.

U.S. Department of Energy, Advanced Manufacturing Office. 2018a. "Cement Manufacturing Energy and Carbon Footprint (2014 Data)."Accessed April 22, 2021. https://www.energy.gov/eere/amo/manufacturing-energy-and-carbon-footprints-2014mecs.

. 2018b. "Chemicals Manufacturing Energy and Carbon Footprint (2014 Data)."

Advanced Manufacturing Office. Accessed April 22, 2021.

https://www.energy.gov/sites/prod/files/2018/10/f56/2014_mecs_chemicals_energy_ footprint_0.pdf.

. 2018c. "Iron and Steel Manufacturing Energy and Carbon Footprint (2014 Data)."

Advanced Manufacturing Office. Accessed April 22, 2021. https://www.energy.gov/sites/prod/files/2018/10/f56/2014_mecs_iron_steel_energy footprint.pdf.

. 2018 d. "Petroleum Refining Manufacturing Energy and Carbon Footprint (2014 Data)."

Advanced Manufacturing

Office.https://energy.gov/sites/prod/files/2014/02/f7/2014_petroleum_refining_ener gy_carbon_footprint.pdf.

U.S. Department of Energy Office of Energy Efficiency and Renewable Energy. 2015. "Bandwidth Study on Energy Use and Potential Energy Saving Opportunities in U.S. Petroleum Refining." Last modified June 2015. https://www.energy.gov/sites/prod/files/2015/08/f26/petroleum_refining_bandwidth _report.pdf. 
U.S. Department of Energy Office of Nuclear Energy. 2021. "Advanced Reactor Technology Development Fact Sheet." Energy.Gov. Accessed January 22, 2021. https://www.energy.gov/ne/downloads/advanced-reactor-technology-developmentfact-sheet.

U.S. Energy Information Administration. 2019. "The Future of Hydrogen." Last modified June 2019. https://www.iea.org/reports/the-future-of-hydrogen.

U.S. Energy Information Administration. Annual Energy Outlook 2021. https://www.eia.gov/outlooks/aeo.

U.S. Environmental Protection Agency. 2018. "Sources of Greenhouse Gas Emissions." Overviews and Factsheets. US EPA. Accessed April 22, 2021. https://www.epa.gov/ghgemissions/sources-greenhouse-gas-emissions. . 2019. "Facility Level Information on GreenHouse Gases Tool (FLIGHT)." Accessed April 22, 2021. https://ghgdata.epa.gov/ghgp/main.do.

Ward, David M. 2013. "The Effect of Weather on Grid Systems and the Reliability of Electricity Supply." Climatic Change 121 : 103-13. https://doi.org/10.1007/s10584-013-0916-z.

World Nuclear Association. 2020. "Nuclear Desalination." Last modifed March 2020. https://www.world-nuclear.org/information-library/non-power-nuclearapplications/industry/nuclear-desalination.aspx.

—. 2021. "Hydrogen Production and Uses." Last modified February 2021. https://www.world-nuclear.org/information-library/energy-and-theenvironment/hydrogen-production-and-uses.aspx.

Worsham, Elizabeth, Cristian Rabiti, and Samuel Kerber. 2021 (forthcoming). "Case Study: Hybrid Carbon Conversion Using Low-Carbon Energy Sources in Coal-Producing States." INL/EXT-21-61758, Idaho National Laboratory.

Worsham, Elizabeth K., and Stephen D. Terry. 2020. "Pulp and Paper Mill Steady State Analysis for Carbon Neutral Integration of a Small Modular Reactor." Presented at ASME 2020 Power Conference, Virtual, August 2020. https://doi.org/10.1115/POWER2020-16247.

Wutich, Amber. 2020. "Water Insecurity: An Agenda for Research and Call to Action for Human Biology." American Journal of Human Biology 32 (1).

https://doi.org/10.1002/ajhb.23345 


\section{Appendix A: Cost Competitiveness of Advanced Reactors}

There is large uncertainty in advanced reactor (AR) cost forecasts (across all the non-LWR reactor types and specific plant concepts) in the absence of actual plant deployments to date. Likewise, the current and future operating costs of natural-gas-fired plants and processes that nuclear IES may replace are heterogeneous among energy customers (particularly due to geographic location). Therefore, a discussion of cost drivers is important for identifying promising applications for nuclear IES.

\section{A.1 Uncertainties in Advanced Reactor Costs}

This subsection describes several key cost drivers for all types of non-LWR reactors. The specific characteristics of each AR type, such as reactor equipment, power density, and fuel cycle, will also affect plant costs, and in-depth examination of such variation across AR types could be performed in follow-on analysis.

\section{A.1.1 First to $n^{\text {th }}$ Unit}

AR costs will likely decline from the first unit to later deployments for several reasons (Energy Technologies Institute (ETI) 2018; Nuclear Energy Agency (NEA) 2020). The initial unit, which may be a non-commercial demonstration project, will likely have high costs because design changes may be necessary as the project proceeds, regulators may discover issues as they assesses the new technology of the as-built plant, and the project team may lack experience in nuclear construction. Over time, costs should decline as fewer changes to the design become necessary and the regulators and project team gain experience. The gradual efficiencies from experience and collaboration, which are often referred to as "learning effects," could be especially significant if the same organizations and individuals work on successive units. Other possible sources of cost reductions include scaling up production facilities, maturing supply chains, and price competition as more suppliers enter the market. Contrary to these considerations, U.S. nuclear plant costs rose from the 1970s through the 1980s and more-recent projects, but developers of future AR plants seek to avoid high costs through various plant design and project execution strategies (MIT 2018; Energy Innovation Reform Project (EIRP) 2017).

\section{A.1.2 Unit and Plant Capacity}

AR costs could depend significantly on unit and plant capacity because of economies of scale and economies of multiples. For plant projects with fixed costs, such as plant design and site permitting, the fixed costs can be spread over more units of energy production if the projects are large. These economies of scale, which reflect classic economic theory for many industries and applications, are the main reason that most nuclear reactor units in the U.S. and world are large. Building multiple units at a plant site can also lead to cost efficiencies, as demonstrated by many examples of nuclear plants with four or more units built either simultaneously or sequentially. In addition to these economies of scale, the unit capacity and number of units per plant can lead to cost reductions across successive units through economies of multiples. Small nuclear units can be built and deployed faster than large units, and this accelerates the cost reductions from first to nth through the "learning effects" and scale-up described above. Thus, two factors work in opposite directions for small units: adverse economies of scale and advantageous economies of multiples. Their net effect is difficult to analyze, but some researchers expect that costs per $\mathrm{kW}$ for small units could be lower than costs per $\mathrm{kW}$ for large units after many small units have been produced over time (Locatelli, Bingham, and Mancini 2014; Lyons 2019). 


\section{A.1.3 Construction vs. Manufacturing}

Although reactor equipment, power density, fuel cycles, and other characteristics of AR concepts are certainly important factors for cost analysis and other planning, broader issues of plant delivery also play a large role in project costs. Traditionally, large nuclear plants have been constructed entirely on-site by thousands of workers who install equipment, piping, wiring, instrumentation, controls, and all other plant components. Many activities are also necessary to prepare the site, provide meals and other support to workers during construction, and clean up the site afterward. With these conventional methods, nuclear plant construction has taken more than ten years in several prominent cases. Some nuclear vendors have recently incorporated modularity into their plant designs to reduce on-site construction, avoid potential missteps requiring rework, and compress the project schedule. In this approach, large plant components such as reactor building segments arrive at the plant site as pre-assembled modules from a factory or other production facility. For microreactors, this strategy could be extended to manufacturing the entire plant at a factory and transporting it to the site in a standard shipping container for quick installation. Standardization of nuclear plant designs for numerous deployments would greatly facilitate modularity and manufacturing. These ideas effectively convert nuclear plants from complex, customized, and high-cost projects to simplified, high-volume, and potentially low-cost products. All these considerations regarding alternate methods of plant delivery could significantly affect AR costs.

\section{A.1.4 Nuclear Fuel Prices}

In contrast with the low-enriched uranium for LWRs (approximately 5\% U-235 by weight), most types of AR plants would use high-assay, low-enriched uranium (HALEU, with approximately $15-20 \%$ by weight). The market for HALEU does not yet exist, so fuel prices for AR plants could differ significantly from fuel costs for LWRs based on existing markets for lower enrichment. The need for higher enrichment and a new supply chain suggests that the fuel prices for AR plants would be higher than for LWRs, but the U.S. government has indicated that it may provide some HALEU at a subsidized cost for initial units of innovative nuclear concepts by utilizing existing government stockpiles of enriched uranium. While HALEU fuel is likely to have higher costs, it enables reactors that are smaller per unit of power generated and that have longer operating cycles between refueling outages. These two factors are expected to decrease costs in construction and operation.

\section{A.1.5 Other Operating and Maintenance Costs}

AR plants will also likely differ from LWRs in their operating and maintenance (O\&M) profiles with associated costs. LWRs require approximately 1,000 on-site workers to operate the reactor and other plant equipment, monitor safety conditions, respond to any irregularities, and perform other management or administrative functions. The two broad reasons for O\&M differences with AR plants are that they will differ in their equipment, fuel, risks, and processes from LWRs, and that they will incorporate advances in technology since the construction of LWRs in the U.S. many decades ago. For example, AR plants will leverage automation and robotics to mitigate risks and avoid high staff headcounts to the extent permitted by the Nuclear Regulatory Commission. These innovations from the current labor-intensive operation of nuclear plants could lead to large reductions in O\&M costs for $A R$ plants.

In summary, the costs of AR plants remain highly speculative at present, whether for particular types of reactor systems (e.g., HTGRs, MSRs, metal-cooled fast reactors) or for the overall category in a generic sense. Follow-on analysis could examine the drivers behind AR cost uncertainty in more detail. 


\section{A.2 Uncertainties in Natural Gas Plant Costs}

As a mature and largely standardized technology, the construction costs for natural gas plants are well established. A natural gas combined-cycle plant exclusively for electricity production costs around $\$ 1000 / \mathrm{kW}_{\mathrm{e}}$ for typical sizes (roughly 75-300 $\mathrm{MW}_{\mathrm{e}}$ ), and the costs for other sizes will reflect economies of scale as described above in the context of AR plants. The construction costs for natural gas plants to produce heat, or both electricity and heat, account for the differences in equipment relative to natural gas combined-cycle plants, along with economies of scale. The major source of uncertainty lies in the operating costs for natural gas plants, particularly regarding future natural gas fuel prices and $\mathrm{CO}_{2}$ constraints.

\section{A.2.1 Natural Gas Fuel Price}

Natural gas fuel prices have fluctuated markedly over the last two decades, from spikes above $\$ 12 / M M B$ tu down to $\$ 2 / M M B$ tu in recent years. The U.S. Energy Information Administration (EIA) has developed the following scenarios for natural gas fuel prices over the next three decades, ranging from $\$ 2.50 / \mathrm{MMBtu}$ to $4.60 / \mathrm{MMBtu}$ in 2030 and from $\$ 2.50 / \mathrm{MMBtu}$ to 6.50/MMBtu in 2050. These scenarios are shown in Figure 32. Prices shown reflect wholesale trading at Henry Hub in Lovisiana, near large onshore and offshore fields.

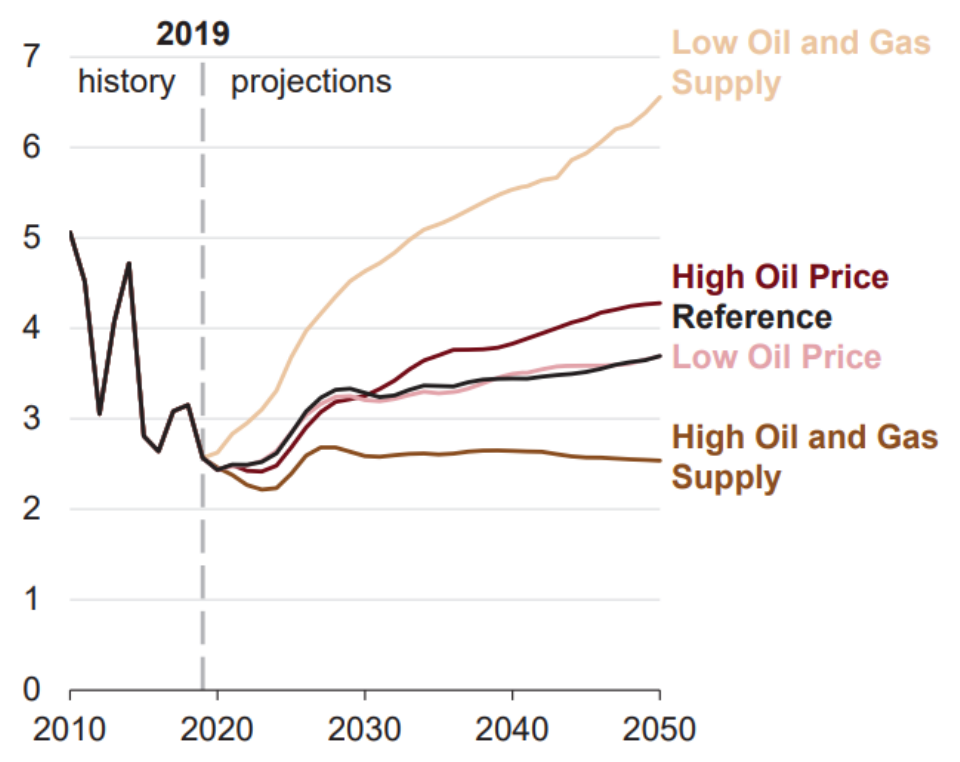

Figure 32. EIA scenarios for natural gas price at Henry Hub (\$/MMBtu). Source: (U.S. Energy Information Administration 2020a).

In addition to the inherent uncertainty in long-term price trajectories, individual industrial customers pay for transportation of natural gas from the wholesale hub to their facility. These retail prices, which include transportation adders, are often called "citygate" prices. The size of transportation adders on top of wholesale prices varies by location and access to pipelines or other fuel-transportation modes. Figure 33 shows how regional hubs usually have higher wholesale prices than Henry Hub, with occasional large spikes. Note that local transportation costs for natural gas customers must be added to these region-level costs, as well. Some remote industrial facilities must, therefore, pay much higher fuel prices than Henry Hub wholesale levels, and AR plants could appear more attractive to them as a result. 


\section{A.2.2 $\mathrm{CO}_{2}$ Constraints}

Many national $\mathrm{CO}_{2}$ programs have been proposed over the years with various levels of stringency and price. The lack of a national program at present may suggest that any eventual program will be relatively loose, at least initially, with low $\mathrm{CO}_{2}$ prices and low adders on fossilfuel costs for companies and households. On the other hand, the mounting evidence for ongoing intensification of climate change, along with growing attention to this issue from society and the government (including recent U.S. re-entry into the Paris Agreement of 2016 under the UN Framework Convention on Climate Change), may ultimately lead to a stringent national program in the decades ahead. In the absence of a national program, several regions, states, and cities have adopted mandatory $\mathrm{CO}_{2}$ programs to meet emission-reduction goals. Industrial facilities in jurisdictions imposing these high $\mathrm{CO}_{2}$ prices or other tight constraints may be most interested in $\mathrm{AR}$ plants as an alternative to natural gas plants because of these extra costs.

In summary, natural gas operating costs for fuel and $\mathrm{CO}_{2}$ emissions over the next several decades are highly uncertain, and the geographic location of industrial facilities may cause sufficient heterogeneity for certain energy customers to consider AR plants as an economically attractive alternative to natural gas plants.

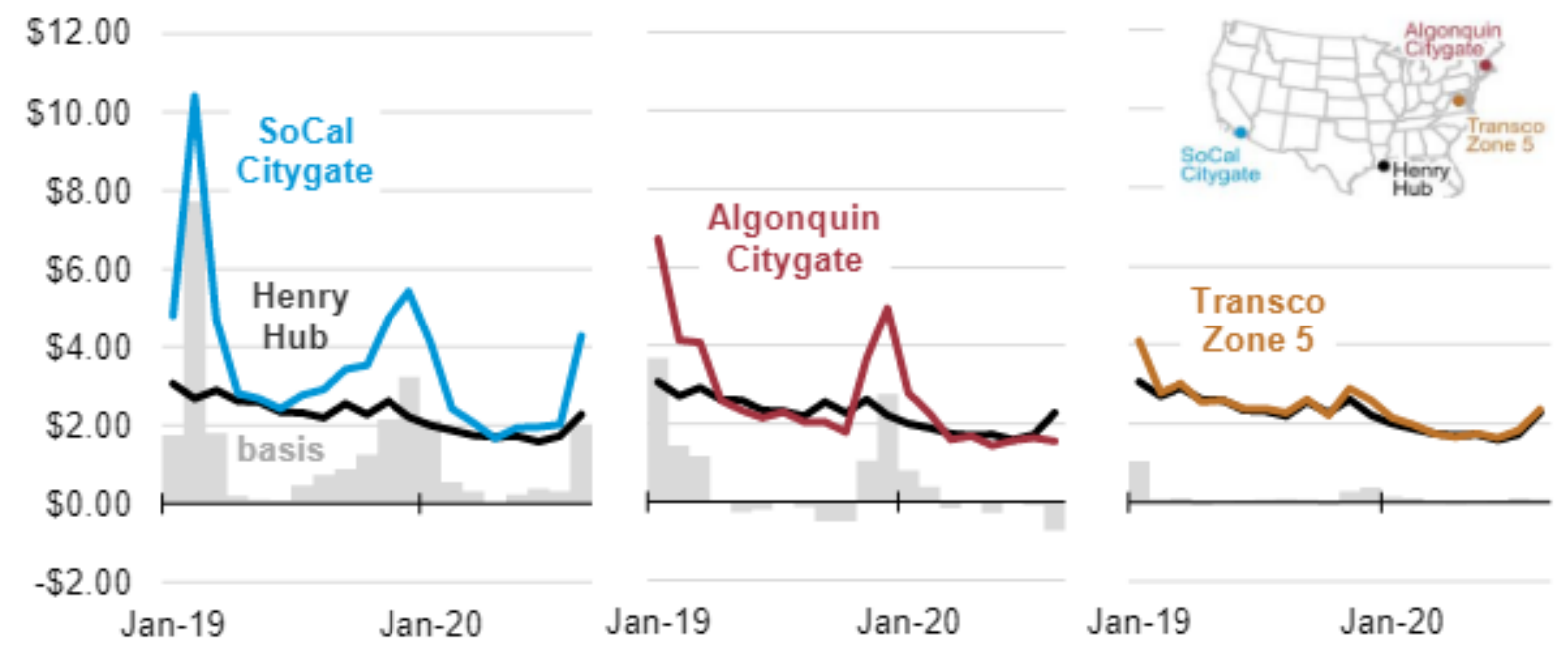

Figure 33. Natural gas spot-price differentials (\$/MMBtu) at major regional hubs relative to Henry Hub. Source: (U.S. Energy Information Administration 2020b).

\section{A.3 Implications for NRIC IES Planning and Partnerships}

Given the breadth and depth of these uncertainties, complex economic scenario planning and sensitivity analysis is required to effectively identify economically favorable applications for nuclear IES. While work is still in progress, preliminary analysis found that the economics of ARs are more likely to be favorable for electricity and heat production, relative to incumbent natural gas technology, in applications with the following conditions:

- Energy generation capacity requirements are consistent with small AR, small modular reactor, or microreactor designs are suitable. These reactors have lower capital cost due to factory production, decreased construction complexity, and economies of multiples.

- Coproduction of energy products (e.g., hydrogen, ammonia) is possible, which generates secondary revenue through sale of coproducts on commodity markets or avoids cost by internally consuming coproducts. 
- Systems sited in locations with exceptionally high, natural gas. retail prices due to distance from natural gas distribution hubs and other, local market factors will be more cost competitive.

- Systems sited in regions, states, and/or local jurisdictions with restrictive emissions control regulation or high carbon penalties will be more cost competitive.

Applications where small or small modular ARs and microreactors are suitable are also appealing because they require smaller capital outlays, lowering investment risk and simplifying the process of raising required capital. Small ARs and microreactors also have smaller exclusion zones and emergency planning zones, making co-location with industrial facilities more practical and less expensive.

In remote areas without access to natural gas distribution and the electric grid, the primary energy source typically is petroleum, which is delivered over the road or via tanker ship at significant expense. Siting nuclear IES employing microreactors to serve end users in these areas may be highly attractive. Microreactors are expected to be easily transportable, making installation at remote locations practical and inexpensive.

Even in areas with nominally inexpensive energy, nuclear IESs may be beneficial in applications and use cases requiring high reliability and resilience. These may include critical infrastructure, defense installations, and transportation fueling hubs.

Finally, the distribution of hydrogen or other energy coproducts to the marketplace requires infrastructure that, if not presently available, may create a barrier to adoption of nuclear IES. Preference should be given to applications and use cases where local consumption of coproducts is feasible and beneficial.

\section{A.3 Appendix References}

Energy Innovation Reform Project (EIRP). 2017. "What Will Advanced Nuclear Plants Cost? A Standardized Cost Analysis of Advanced Nuclear Technologies in Commercial Development." https://www.innovationreform.org/2017/07/01/will-advanced-nuclearpower-plants-cost/.

Energy Technologies Institute (ETI). 2018. "Nuclear Cost Drivers (ETI NCD) Full Technical Report." https://es.catapult.org.uk/reports/nuclear-cost-drivers/.

Locatelli, Giorgio, Chris Bingham, and Mauro Mancini. 2014. "Small Modular Reactors: A Comprehensive Overview of Their Economics and Strategic Aspects." Progress in Nuclear Energy 73 (May): 75-85. https://doi.org/10.1016/i.pnucene.2014.01.010.

Lyons, Robbie Eric. 2019. "The Effect of Supply Chain Configuration on Small Modular Reactor Economics." University of Cambridge Ph.D. thesis. https://www.repository.cam.ac.uk/bitstream/handle/1810/302392/RL\%20Final\%20The sis\%20\%5BOnline\%20Repository\%20v2\%5D.pdf.

MIT. 2018. The Future of Nuclear Energy in a Carbon-Constrained World: An Interdisciplinary MIT Study. MIT Energy Initiative. https://books.google.com/books?id=UJj-xAEACAAJ.

Nuclear Energy Agency (NEA). 2020. "Unlocking Reductions in the Construction Cost of Nuclear: A Practical Guide for Stakeholders." https://www.oecdnea.org/upload/docs/application/pdf/2020-07/7530-reducing-cost-nuclearconstruction.pdf.

U.S. Energy Information Administration. 2020a. "AEO 2020 Full Report." https://www.eia.gov/outlooks/aeo/pdf/AEO2020\%20Full\%20Report.pdf. . 2020b. "Natural Gas Price Differentials to Henry Hub Narrowed at Most Hubs in First Half of 2020." https://www.eia.gov/todayinenergy/detail.php?id=45037. 